\title{
The role of immune checkpoint inhibitors in triple- negative breast cancer: recent developments and future perspectives
}

\author{
Marios Papadimitriou', Zoi Liakouli ${ }^{2}$, Christos A. Papadimitriou ${ }^{1}$ \\ 'Oncology Unit, Second Department of Surgery, Aretaieion University Hospital, National and Kapodistrian University of Athens, \\ Medical School, Athens 11528, Greece. \\ ${ }^{2}$ Radiotherapy Unit, First Department of Radiology, Aretaieion University Hospital, National and Kapodistrian University of \\ Athens, Medical School, Athens 11528, Greece.
}

Correspondence to: Prof. Christos A. Papadimitriou, Oncology Unit, Second Department of Surgery, Aretaieion University Hospital, National and Kapodistrian University of Athens, Medical School, Vassilisis Sofias 76, Athens 11528, Greece. E-mail:chr_papadim@yahoo.gr

How to cite this article: Papadimitriou M, Liakouli Z, Papadimitriou CA. The role of immune checkpoint inhibitors in triplenegative breast cancer: recent developments and future perspectives. J Cancer Metastasis Treat 2021;7:63.

https://dx.doi.org/10.20517/2394-4722.2021.138

Received: 22 Jun 2021 Accepted: 15 Jul 2021 Published: 5 Nov 2021

Academic Editor: Lucio Miele Copy Editor: Yue-Yue Zhang Production Editor: Yue-Yue Zhang

\begin{abstract}
Triple-negative breast cancer (TNBC) represents the subtype of breast cancer with the most aggressive biological behavior and the worst prognosis compared to other breast cancers. Metastatic TNBC is characterized by a high proliferative index, rapid progression with metastases to the viscera and central nervous system, and generally an unfavorable prognosis with a survival of about one year. It is, therefore, necessary to identify specific targets and more effective treatments for patients with TNBC. Evidence of the effect of the tumor immune microenvironment on clinical outcomes is considered a significant issue in breast cancer therapeutics. Compared to other subtypes of breast cancer, TNBC is characterized by a higher mutational burden and is recognized as the most immunogenic among them. Based on these findings, immune checkpoint inhibition was evaluated in TNBC with encouraging results. Indeed, enhancing antitumor immunity in TNBC by blocking the cytotoxic T-lymphocyte-associated antigen 4 (CTLA-4) axis or the programmed cell death-1 (PD-1) receptor/programmed death-ligand 1 (PD-L1) pathway is a promising treatment option. In this review, we examine the role of monoclonal antibodies targeting CTLA-4 and PD-1/PD-L1 in this breast cancer subtype and discuss combination approaches for early and advanced disease.
\end{abstract}

The Author(s) 2021. Open Access This article is licensed under a Creative Commons Attribution 4.0 International License (https://creativecommons.org/licenses/by/4.0/), which permits unrestricted use, sharing, adaptation, distribution and reproduction in any medium or format, for any purpose, even commercially, as long as you give appropriate credit to the original author(s) and the source, provide a link to the Creative Commons license, and indicate if changes were made. 
Keywords: Triple-negative breast cancer, immune checkpoint inhibition, CTLA-4, PD-1, PD-L1

\section{INTRODUCTION}

Triple negative breast cancer (TNBC) is a specific subtype of breast cancer which is immunohistochemically characterized by the lack of expression of estrogen receptors, progesterone receptors (PR), and HER2 ${ }^{[1-5]}$. It represents about $15 \%-20 \%$ of all breast cancers and is a group of miscellaneous tumors with different molecular and clinicopathological characteristics that lead to different clinical behaviors. Although the majority of TNBCs are of basal-like phenotype and the majority of basal-like tumors (characterized by the frequent expression of cytokeratins 5/6 and the prominent membranous expression of EGFR) are TNBCs, clinical, microarray, and immunohistochemical data show these two terms are not synonymous. More specifically, the basal-like cancers are associated with a microarray gene-expression profile similar to that of basal or myoepithelial cells of the breast and represent the most homogeneous of all subtypes in the transcriptional term. TNBC, on the other hand, is routinely defined by immunohistochemistry and refers to a heterogeneous entity comprising several subtypes with distinct molecular characteristics. There is a discordance of up to $30 \%$ in the overlap between molecular and immunohistochemical definitions when comparing TNBC and basal-like cancers ${ }^{[1,3,4]}$.

Distant metastases are more likely to develop in TNBC than in other subtypes of breast cancer with the risk peaking early at three years after initial diagnosis, while most deaths occur within the first five years, i.e., TNBCs have a shorter median time to relapse and death. A large single-institution cohort study showed that patients with TNBC were significantly more likely to have died compared to those with other breast cancer subtypes $(42.2 \% \text { vs. } 28 \%)^{[6]}$. The median time to death was 4.2 years for TNBC patients vs. 6 years for patients with other breast cancers, and all deaths due to breast cancer in TNBC patients occurred within the first decade of diagnosis. On the other hand, disease cause-specific deaths in patients with luminal breast cancers continued to increase for up to 18 years after diagnosis. In addition, the rate of metastases was higher in patients with TNBC compared to other breast cancer subtypes (33.9\% vs. 20.4\%). Li et al. ${ }^{[7]}$, reviewing SEER data for patients diagnosed with breast cancer between 2010 and 2012, found that patients with TNBC had worse overall survival and disease cause-specific survival than patients with other breast cancer subtypes at every stage.

Conventional chemotherapy still plays a central role in the treatment of metastatic TNBC (mTNBC) but with suboptimal results. The median overall survival (OS) in advanced/metastatic TNBC is approximately 12 months, an interval significantly shorter than the corresponding seen in other breast cancer subtypes ${ }^{[5-7]}$. Therefore, identifying specific molecular targets and consequently more effective/personalized therapies for TNBC patients remains a significant clinical challenge. Among the most promising treatments is immunotherapy for reasons related to the characteristics of the disease that may make it more responsive to this type of therapy. One of these features is a higher tumor mutational burden (TMB), since TNBC has been shown to have more median mutations compared with other breast cancer subtypes. High TMB could increase T-cell responses against a wide-spectrum of tumor-specific neoantigens. In TNBC, a positive correlation was found between TMB and tumor immune cell infiltration, while tumor infiltrating lymphocytes (TILs) have prognostic value and are associated with improved clinical outcomes in this tumor entity $^{[8,9]}$.

In this article, we look at the role of immune checkpoint inhibitors in the treatment of TNBC and review the most important completed clinical trials, as well as those in progress. 


\section{MOLECULAR AND IMMUNOPHENOTYPIC CHARACTERIZATION OF TNBC}

Due to its aggressive biological behavior and the heterogeneity which characterizes tumors within the TNBC group, the molecular classification of these neoplasms is an important research priority for the better identification of molecular-targeted therapies. Thus far, several groups have investigated the biology of TNBC using a variety of tools, such as immunohistochemistry, gene expression analysis, and sequencing. Lehmann et al. ${ }^{[10]}$, analyzed TNBC gene expression profiles obtained from 21 breast cancer datasets and identified 6 different TNBC subtypes. The two basal-like subtypes (BL1 and BL2) were heavily enriched in cell cycle pathways and DNA damage response genes; the immunomodulatory subtype (IM) was enriched for genes whose expression regulates immune cell processes; the mesenchymal and mesenchymal stem-like subtypes had a high expression of genes involved in epithelial-mesenchymal transition and growth factor pathways; and, finally, the luminal androgen receptor (LAR) subtype was characterized by a prominent androgen receptor signaling. In a more recent study from the Baylor University ${ }^{[1]}$, the RNA and DNA profiles of 198 TNBCs were analyzed, which led to the identification of four subtypes: LAR, mesenchymal, basal-like immune-suppressed (BLIS), and basal-like immune-activated (BLIA). BLIS and BLIA cancers had the best and worst prognosis, respectively, in terms of disease-free survival (DFS). The researchers also identified many highly expressed molecules that could possibly represent targets for more effective treatment of TNBC. Finally, researchers from France ${ }^{[12]}$ separated TNBCs by a fuzzy clustering method into three clusters. Twenty-two percent of patients had not basal-like tumors, enriched in luminal subtypes and positive androgen receptor (C1), 45\% were pure basal-like (C2), and 33\% of them had high immune responses (C3). In contrast to the studies from Vanderbilt and Baylor, the French study did not recognize a mesenchymal subtype. However, despite the various methodologies used in the aforementioned studies and the different number of identified subtypes, it is consistently suggested that TNBC is comprising of four subtypes: basal-like, mesenchymal, luminal androgen receptor, and immune-enriched ${ }^{[13]}$.

A special genetic feature of TNBC is its association with germline $B R C A$ mutations. Indeed, TNBC patients have a higher incidence of germline BRCA1/2 mutations, with a rate of approximately $15 \%-20 \%$ according to various studies ${ }^{[14-17]}$. BRCA1 and BRCA2 proteins are key components of the homologous recombination (HR) pathway and cells lacking these proteins are unable to repair double-strand breaks (DSBs) by HR. Because functional $B R C A 1$ and $B R C A 2$ genes are involved in maintaining genome stability, their inactivation may lead to oncogenic transformation and further progression to breast cancer. Furthermore, this genomic instability gives rise to breast cancers with increased likelihood of immunogenic somatic mutations (and consequently of neoantigens), that is cancers with an immunogenic phenotype ${ }^{[18,19]}$. In a whole-genome sequences analysis of 560 breast cancers, 90 had germline or somatic inactivating mutations in $B R C A 1$ or $B R C A 2$ or showed $B R C A 1$ promoter methylation. These cancers carried many genomic rearrangements ${ }^{[20]}$. Wen and Leong ${ }^{[19]}$ evaluated data from two breast cancer datasets (The Cancer Genome Atlas and the Wellcome Sanger Institute) and found that BRCA1- and BRCA2-deficient breast cancers had significantly higher numbers of mutations when compared to $B R C A 1 / 2$-proficient tumors. Furthermore, BRCA 1-deficient breast cancers were associated with increased expression of PD-L1 and PD-1, a significantly greater number of immune cells infiltrating the tumor microenvironment, and an enriched $\mathrm{T}$ cell-inflamed gene expression profile when compared to BRCA1/2-proficient tumors. However, these findings were not observed in BRCA2-deficient tumors. In addition to the aforementioned study, other studies have also shown that TNBC is characterized by a higher TMB compared to luminal breast cancers that may lead to a higher incidence of immunogenic mutations ${ }^{[21,22]}$. Of note, TMB has been associated with both response to immunotherapy and improved clinical outcomes in patients with various malignancies ${ }^{[23,24]}$. 
In early-stage breast cancer, TIL count is associated with improved survival, decreased risk of distant recurrences, and an increased likelihood of responding to neoadjuvant chemotherapy (NACT) ${ }^{[25-27]}$. A systematic review of fifteen studies ${ }^{[28]}$ showed that TNBC had the highest incidence of TILs, and their count may represent a potential biomarker for response to immunotherapy. TNBC has also a higher rate of PD-L1 expression when compared to the luminal subtypes ${ }^{[2,3,30]}$, and this underlines the therapeutic role of monoclonal antibodies (moAbs) targeting the PD-1/PD-L1 axis. Recently, the FDA approved atezolizumab (anti-PD-L1 moAb) in combination with nab-paclitaxel for the treatment of PD-L1-positive advanced/metastatic $\mathrm{TNBC}^{[31]}$.

\section{IMMUNOTHERAPEUTIC APPROACHES IN TRIPLE-NEGATIVE BREAST CANCER}

The immune system consists of two different parts, the innate (non-specific) and the adaptive (specific or acquired) immunity, which have overlapping functions. Innate immune cells, such as natural killer (NK) cells and cells of myeloid origin, act as an organized network against foreign (non-self) antigens without having been previously stimulated by them. These cells then activate the adaptive immunity through antigen presentation - which is one of their major functions - while enhancing their own activities, such as phagocytosis for macrophages and granulocytes and natural cytotoxicity for NK cells ${ }^{[32,33]}$. Functional responses of the adaptive immune system are achieved by its stimulation by professional antigen-presenting cells, such as dendritic cells (DCs). Adaptive immunity includes components of humoral immunity (B lymphocytes) and components of cell-mediated immunity (T lymphocytes). The main functions of the adaptive immune system include recognition of specific foreign antigens during the process of antigen presentation, generation of responses that are adapted to efficiently eliminate potential pathogens or pathogen-infected cells that escape innate host defenses, and development of immunologic memory ${ }^{[3,334]}$.

The immune system plays a composite role in breast cancer pathogenesis and progression ${ }^{[35,36]}$. In the context of cancer biology, the various immune reactions that protect against cancer development are referred to as immunosurveillance.

However, despite the existence of functional immunosurveillance, individuals still develop cancers, which indicate the role of immunity not only in the elimination but also in the progression of breast cancer. This complex network of evolving interactions between breast cancer and host immunity is characterized by the term "immunoediting", a process consisting of three phases: in the elimination phase, the immune system effectively targets and eliminates breast cancer; in the equilibrium phase, a balance is obtained between cancer progression and its elimination by the immune system; and, finally, in the escape phase, cancer persists and overcomes the host's immunity, progressing and metastasizing to other organs ${ }^{[37]}$. Early in breast cancer oncogenesis, acute inflammation activates innate immunity, leading to tumor cell death and maturation of DCs that trigger a tumor-specific T-cell response. It is at this stage that either rejection of the tumor or selection of breast cancer cell populations capable of escaping the immune response will occur ${ }^{[36]}$. The transition from an acute to a chronic inflammation phase establishes a composite tumor microenvironment (TME) comprising suppressive immune cells and stromal cells, such as fibroblasts and endothelial cells, which allow immune escape to occur and breast cancer to progres ${ }^{[3,3,39]}$. During this transition, the $\mathrm{CD} 4^{+} \mathrm{T}$-cell response deviates from $\mathrm{T}$ helper (Th) type 1 to Th type $2^{[40]}$, immune checkpoint molecules are upregulated on both tumor and immune cells ${ }^{[41]}$, and more importantly immune-suppressive metabolic pathways are activated in various immune cell types ${ }^{[42,43]}$. All these mechanisms together create a powerful network of immunosuppression within the breast tumor microenvironment.

Today, most immunotherapy strategies used in breast cancer are designed to bypass diminished immune stimulation. In their majority, these immunomodulatory approaches aim to enhance T-cell responses, either 
by targeting inhibitory pathways with immune checkpoint inhibitors or by targeting activating pathways. As in all malignancies, TNBC immunotherapy can be divided into passive and active. Passive immunotherapy includes the administration of immunomodulating agents and adoptive cell transfer, which enhance the existing antitumor immune response. Further, immunomodulating agents include co-stimulatory agonists, such as stimulatory moAbs to $4-1 \mathrm{BB}, \mathrm{OX} 40$, and GITR and co-inhibitory antagonists, such as stimulation through checkpoint blockade [cytotoxic T-lymphocyte-associated antigen 4 (CTLA-4), PD-1, and PD-L1]. Adoptive cell transfer refers to the transfer into a patient of autologous TILs, genetically engineered T-cell receptor (TCR) cells, or chimeric antigen receptor T cells. Active immunotherapy, on the other hand, aims to stimulate the immune system and is divided into specific (cancer vaccines) and non-specific (cytokines and immune adjuvants) ${ }^{[4-51]}$.

There are currently more than 300 ongoing clinical trials evaluating the role of immunotherapy in breast cancer. Most of these trials focus on assessing immune checkpoint inhibitors alone or in various combinations in TNBC, with approximately $80 \%$ of studies being performed in the metastatic setting ${ }^{[52,53]}$. One of the first trials with immune checkpoint inhibitor monotherapy in mTNBC was the phase Ib trial KEYNOTE-012 that assessed pembrolizumab in heavily pretreated patients ${ }^{[54]}$. In this trial, monotherapy with pembrolizumab achieved an overall response rate (ORR) of $18.5 \%$. However, these results of singleagent pembrolizumab were considered discouraging when compared to those obtained in other solid tumors, such as melanoma and lung cancer ${ }^{[53]}$. Other early clinical trials of monotherapy with immune checkpoint inhibitors (atezolizumab or avelumab) in mTNBC demonstrated ORR of around 10\% or less ${ }^{[55-57]}$. ORR with monotherapy also appears to be lower in PD-L1-negative baseline patients, in patients with $\geq 2$ prior chemotherapy lines for their metastatic disease, and in patients with prior exposure to taxanes $^{[52]}$. In most studies, immune checkpoint inhibitors were combined with chemotherapy, other inhibitors, or biologic agents. The suggestion to combine immune checkpoint inhibitors with chemotherapy was based on the observation that chemotherapeutic agents and other types of treatment (including irradiation, photodynamic therapy, or cryoablation) could promote the so-called immunogenic cell death (ICD). This particular type of cell death is the result of the activation of adaptive immune responses in dying cancer cells due to the exposure or secretion of immunostimulatory molecules ${ }^{[2,58,55]}$.

\section{CTLA-4 (CD152) INHIBITION}

The binding of TCR to the cell surface proteins of the major histocompatibility complex (MHC) does provide specificity to T-cell activation, but other co-stimulatory signals are also needed. More specifically, the B7-1/B7-2:CD28/CTLA-4 co-stimulatory pathway plays a crucial role in regulating T-cell activation and tolerance. Binding of B7-1 (CD80) or B7-2 (CD86) molecules, which are expressed on professional APCs, with $\mathrm{CD} 28$ molecules on the $\mathrm{T}$ cells initiates and regulates $\mathrm{T}$-cell response, a process involving $\mathrm{T}$-cell proliferation, differentiation, and survival and characterized by increased energy metabolism and upregulation of various genes, such as cell survival genes ${ }^{[49,60,61]}$.

CTLA-4 shows high affinity for B7-1/2 (CD80/86). The molecule is not constitutively expressed on T lymphocytes, but is induced following T-cell activation ${ }^{[4,50,60]}$. While the CD28:B7-1/2 binding acts as a costimulatory signal for T-cell proliferation and activation, CTLA-4:B7-1/2 interaction serves as a coinhibitory signal aimed at preventing early activation of Tcells ${ }^{[62]}$.

CTLA-4 is recognized as the "leader" among the inhibitory immune checkpoint molecules, as it stops potentially autoreactive $\mathrm{T}$ cells at the initial stage of naïve T-cell activation. Binding of B7-1/2 molecules to CTLA-4 on $\mathrm{CD}^{+} \mathrm{T}$ lymphocytes results in the dephosphorylation of TCR signaling proteins, among which CD3 leads to T-cell inhibition. Inhibitory signals produced by CTLA- 4 binding to the B7-1/2 molecules 
counterbalance the stimulatory signals derived from CD28:B7-1/7 and TCR:MHC binding. Mechanisms of this opposing effect on T-cell response include capturing and removing B7-1/2 from the membrane of APCs, modulation of T-cell motility that leads to decreased interaction with APCs, and inhibition of TCR signal transduction by binding to TCR $\zeta$ chain and consequently inhibiting tyrosine phosphorylation after Tcell activation ${ }^{[63-66]}$.

In resting naïve T cells, CTLA-4 molecules are located mainly intracellularly. Stimulatory signals resulting from both TCR:MHC and CD28:B7-1/7 binding lead to increased expression of CTLA-4 molecules on the cell surface due to exocytosis of CTLA-4-containing vesicles. It is, therefore, a graded feedback loop where stronger TCR signaling causes more translocation of CTL- 4 molecules to the cell surface ${ }^{[6,67]}$. Figure 1 illustrates CD80/86:CTLA-4 interactions and CTL-4 blockade with moAbs, while main molecular aspects of this pathway are shown in Figure 2. Inhibition of CTLA-4 with moAbs leads to increased activation of the immune system and represents a novel strategy in cancer therapeutics. Table 1 summarizes CTLA-4 inhibition strategies with moAbs in TNBC, in both neoadjuvant and metastatic setting.

\section{Monoclonal antibodies targeting CTLA-4}

Ipilimumab

In 1995, Krummel and Allison ${ }^{[68]}$ described the antagonist effect between CD28 and CTLA-4 on the response to T-cell stimulation. They generated an antibody to CTLA-4 (9H10) to investigate the effects of engagement of this molecule in a carefully defined system using highly purified $\mathrm{T}$ cells and concluded that the outcome of T-cell stimulation is regulated by $\mathrm{CD} 28$ costimulatory signals, as well as inhibitory signals derived from CTLA-4. One year later, Leach et al. ${ }^{[69]}$ described that administration of anti-CTLA-4 antibodies resulted in the rejection of tumors in mouse models. Furthermore, tumor rejection induced by CTLA-4 blockade generated immunity that protected experimental animals at second exposure to cancer cells. The authors concluded that blocking the inhibitory effects of CTLA-4 could enable and enhance effective immune responses against cancer cells. Following these pioneering studies, several subsequent studies in animal experimental models have demonstrated that CTLA-4 blockade leads to regression of established tumors by increasing anticancer activity due to reversal of $\mathrm{CD} 8^{+} \mathrm{T}$-cell tolerance.

Ipilimumab, a fully human IgG1 moAB that blocks CTLA-4, improved overall survival when administered with or without a gp100 peptide vaccine in patients with metastatic melanoma ${ }^{[70]}$. The therapeutic indications of ipilimumab include metastatic melanoma (as monotherapy or in combination with nivolumab) and intermediate/poor-risk advanced renal cell carcinoma in combination with nivolumab as first-line treatment ${ }^{[7] 1}$. To date, no completed clinical trials with single-agent ipilimumab in TNBC have been published. There is an interesting clinical report for a patient with metastatic TNBC who was treated with low-dose immune checkpoint blockade (concurrent nivolumab and ipilimumab) with IL-2 and locoregional hyperthermia and whole-body hyperthermia. The treatment resulted in complete clinical remission ${ }^{[72]}$. Selected current clinical trials with the CTLA-4 inhibitor are presented in Table 2.

\section{Ipilimumab in the neoadjuvant setting}

Because it has been demonstrated in murine models that intracellular cryopreservation with immune modulation generates a strong systemic anti-tumor immune response, it was thought that this approach could be applied to improve outcomes in early breast cancer. A pilot study investigated the safety and tolerability of preoperative, single-dose ipilimumab and/or cryoablation. T-cell activation was observed in the blood of patients receiving a single-dose of ipilimumab, while a moderate increase in the ratio of tumor $\mathrm{CD}^{+} \mathrm{Ki}^{+} 7^{+} \mathrm{T}$ cells to $\mathrm{T}$ regulatory (Treg) cells after combination therapy only was documented ${ }^{[73]}$. Based on 


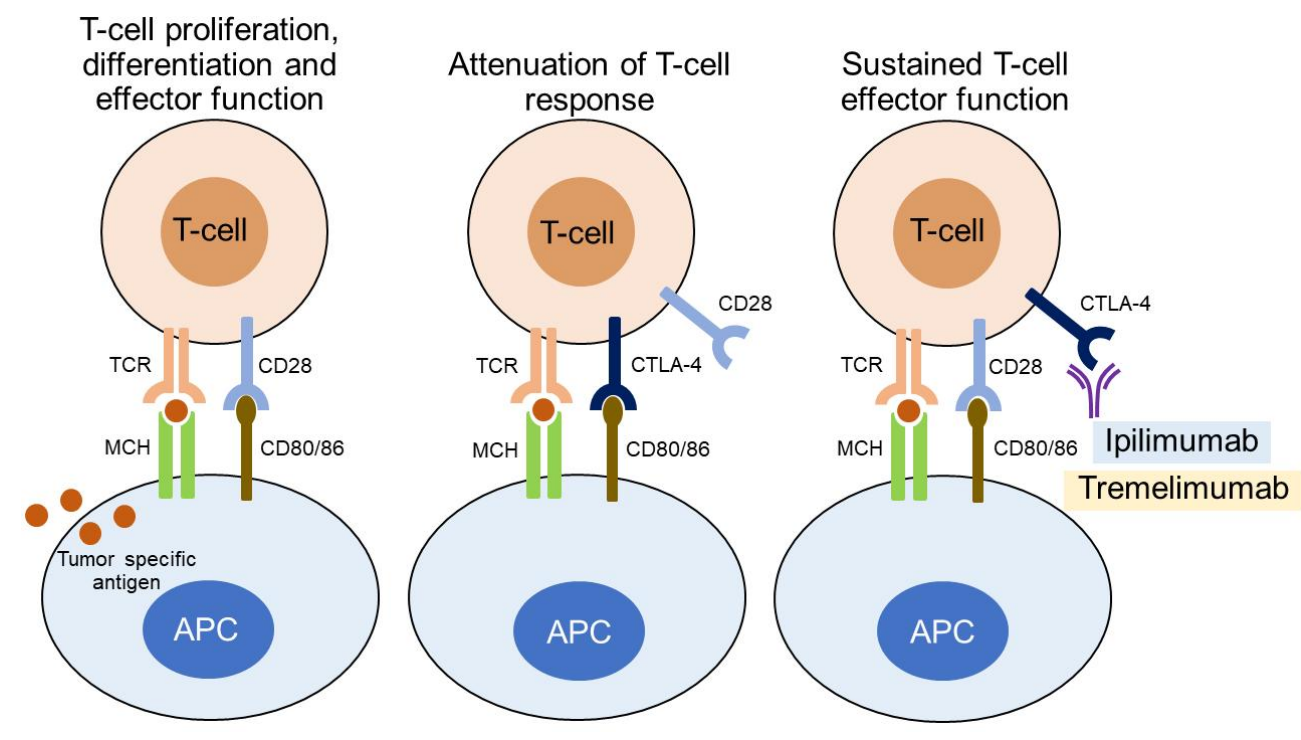

Figure 1. CD80/86:CTLA-4 interactions and CTL-4 blockade with monoclonal antibodies.

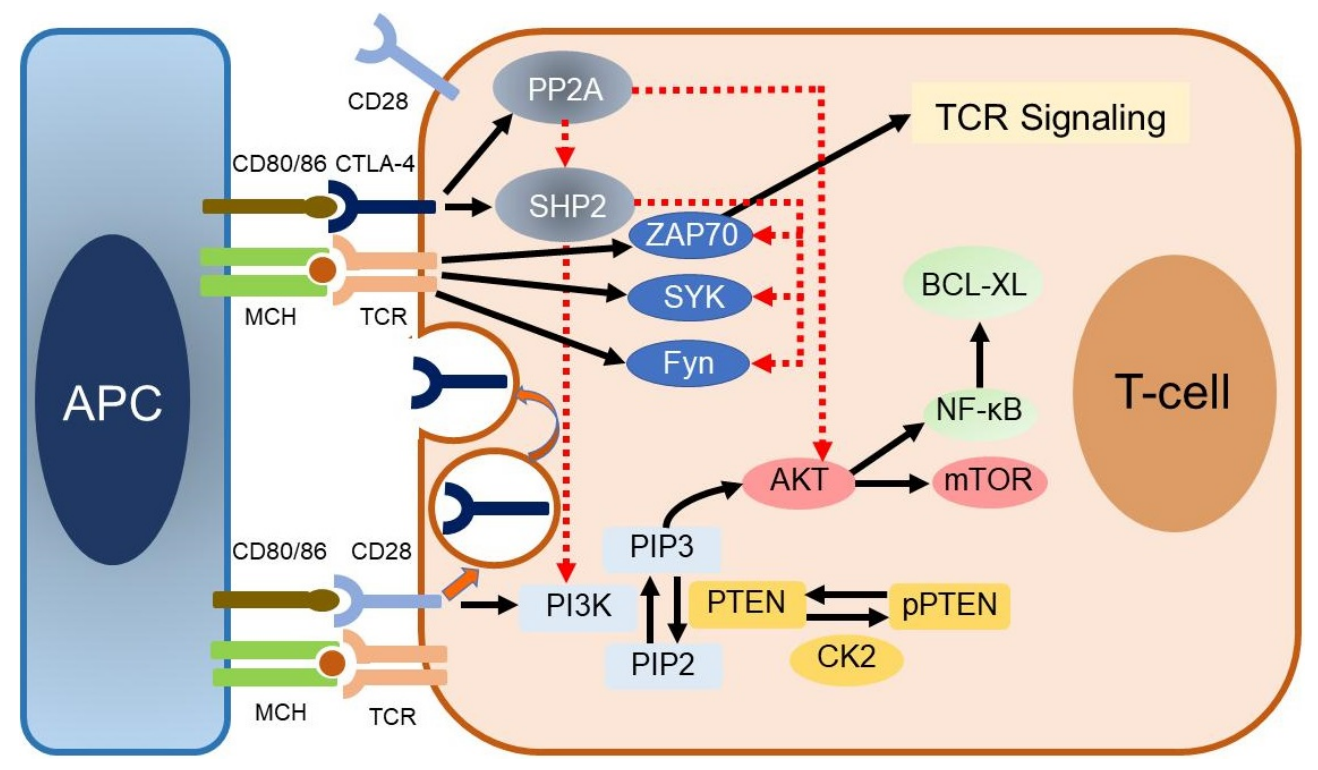

Figure 2. Main molecular aspects of the CD80/86:CTLA-4 pathway.

these findings, a phase II trial has been designed in which 160 patients with operable TNBC and residual disease $\geq 1.0 \mathrm{~cm}$ after taxane-based NACT will be randomized to either breast surgery only (control arm) or ipilimumab/nivolumab/cryoablation followed by breast surgery and adjuvant nivolumab (intervention arm). Adjuvant capecitabine is recommended for all patients ${ }^{[74]}$.

The phase II BCT 1702-CHARIOT trial has been designed for patients who have residual TNBC of at least $15 \mathrm{~mm}$ and less than $50 \%$ reduction in its longest diameter after four cycles of standard anthracycline-based NACT. The trial combines weekly paclitaxel for 12 doses with ipilimumab and nivolumab. Postoperatively, nivolumab is administered every four weeks for nine doses ${ }^{[75]}$. The aim of the CHARIOT trial is to test whether these patients with unfavorable prognosis could benefit from combined immune checkpoint 
Table 1. Summary of CTLA-4 inhibition strategies with monoclonal antibodies in TNBC

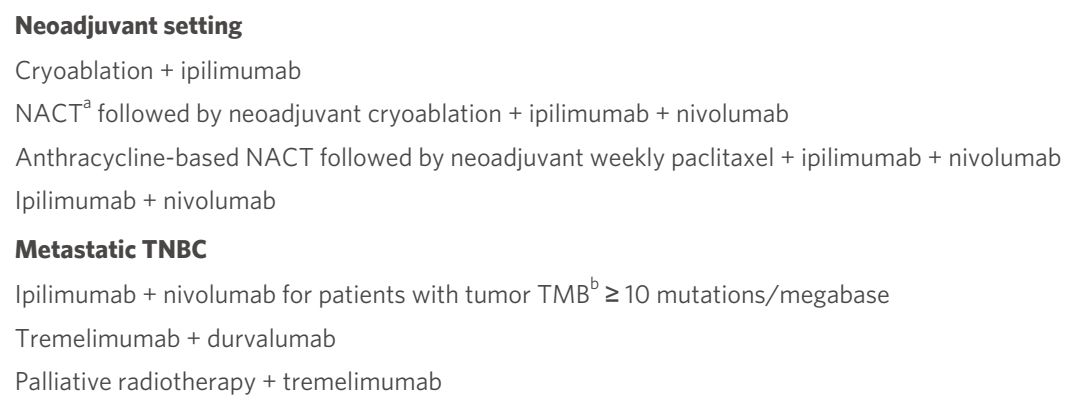

Metastatic TNBC

Ipilimumab + nivolumab for patients with tumor $\mathrm{TMB}^{\mathrm{b}} \geq 10$ mutations/megabase

Tremelimumab + durvalumab

Palliative radiotherapy + tremelimumab

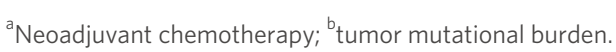

Table 2. Selected current clinical trials investigating ipilimumab in TNBC

\begin{tabular}{|c|c|c|c|c|}
\hline Study identifier & $\begin{array}{l}\text { Type of } \\
\text { study }\end{array}$ & Study population & Regimen/treatment arms & Status \\
\hline NCT04185311 & Phase I & $\begin{array}{l}\text { Localized, palpable, biopsy } \\
\text { proven TNBC or ER }+/ \mathrm{HER} 2- \\
\text { negative breast cancer }>1.5 \mathrm{~cm} \\
\text { by palpation }\end{array}$ & $\begin{array}{l}\text { Neoadjuvant talimogene laherparepvec intratumorally } \\
\text { on Days 1, 22, and 36; nivolumab on Days 1, 15, 29, and } \\
43 \text {; and ipilimumab on Days } 1 \text { and } 43\end{array}$ & Recruiting \\
\hline $\begin{array}{l}\text { ACTRN12617000651381 } \\
\text { BCT } 1702 \text { (CHARIOT) }\end{array}$ & Phase II & High-risk primary TNBC & $\begin{array}{l}\text { Anthracycline-based } \mathrm{NACT}^{\mathrm{a}} \text { followed by ipilimumab } \\
\text { and nivolumab with weekly paclitaxel then by definitive } \\
\text { surgery and further adjuvant treatment with } \\
\text { mivolumab }\end{array}$ & Recruiting \\
\hline NCT03818685 & $\begin{array}{l}\text { Randomized } \\
\text { Phase II }\end{array}$ & $\begin{array}{l}\text { TNBC patients who have } \\
\text { residual cancer burden of class } \\
\text { III after NACT }\end{array}$ & $\begin{array}{l}\text { Arm A: Nivolumab, every } 3 \text { weeks for } 8 \text { doses and } \\
\text { Ipilimumab every other dose of Nivolumab for } 4 \text { doses } \\
\text { Arm B: Capecitabine } 14 \text { days on } / 7 \text { days off for } 8 \text { cycles } \\
\text { In both arms, radiotherapy has to be initiated one week } \\
\text { before starting systemic treatment }\end{array}$ & $\begin{array}{l}\text { Active, not } \\
\text { recruiting }\end{array}$ \\
\hline NCT03546686 & $\begin{array}{l}\text { Randomized } \\
\text { Phase II }\end{array}$ & $\begin{array}{l}\text { Residual TNBC after taxane- } \\
\text { based NACT }\end{array}$ & $\begin{array}{l}\text { Arm A: Ipilimumab and nivolumab 1-5 days prior to } \\
\text { core biopsy and cryoablation followed by breast } \\
\text { surgery and adjuvant nivolumab for } 3 \text { doses } \\
\text { Arm B: Standard-of-care definitive breast surgery }\end{array}$ & Recruiting \\
\hline
\end{tabular}

${ }^{a}$ Neoadjuvant chemotherapy.

blockade plus chemotherapy.

2. Ipilimumab in $\mathrm{mTNBC}$

The phase II study NIMBUS will assess the efficacy of nivolumab plus ipilimumab in patients with hypermutated (TMB $\geq 10$ mutations/megabase) HER2-negative metastatic breast cancer and $\leq 3$ prior lines of chemotherapy for advanced disease ${ }^{[7]}$.

\section{Tremelimumab}

Tremelimumab is a fully human IgG2 moAb targeting CTLA-4 ${ }^{[77-79]}$ that binds to the same epitope with ipilimumab on the CTLA-4 molecule ${ }^{[80]}$. Although initial phase I and II trials of tremelimumab were promising ${ }^{[81-83]}$, a phase III trial in patients with metastatic melanoma was discontinued after reviewing early interim data, which indicated that treatment with tremelimumab would not be superior to standard chemotherapy ${ }^{[8]}$. Following the presentation of the findings of this trial, interest in the development of tremelimumab in the therapeutics of various malignancies, including breast cancer, was significantly reduced. Recently, however, it is being tested again, mainly in combination with other immune checkpoint inhibitors. 


\section{Tremelimumab in mTNBC}

A pilot study was designed to determine ORR and evaluate immunogenomic characteristics in 7 patients with metastatic TNBC and 11 patients with metastatic luminal breast cancer who received the combination of tremelimumab and durvalumab. All responses (3/7) were observed among patients with mTNBC. Responders showed an overexpression of $C D 8$, granzyme A, and perforin 1 genes and a higher mutational and neoantigen load when compared to non-responders. Furthermore, patients with TNBC demonstrated an oligoclonal shift of the most abundant TCR $\beta$ clonotypes compared to those with luminal disease ${ }^{[85]}$.

Based on the results of preclinical studies suggesting that ionizing radiation induces ICD, thus enhancing, through multiple mechanisms, the systemic antitumor immune respons $\mathrm{e}^{[86-90]}$, a phase I study assessed the safety of tremelimumab on the third day of palliative radiotherapy in patients with metastatic breast cancer. Among the six patients enrolled, five had luminal disease and one had mTNBC. Tremelimumab in combination with radiotherapy appeared to be a tolerable treatment, while an increase of proliferating Tregs in peripheral blood was observed one week after treatment in five patients ${ }^{[91]}$.

Selected current clinical trials with tremelimumab in combination with moAbs targeting the PD-1/PD-L1 pathway are presented in Table 3.

\section{PD-1/PD-L1 INHIBITION}

The PDCD1 gene and the corresponding surface receptor PD-1 (CD279) were first discovered in a murine $\mathrm{T}$-cell hybridoma and a murine hematopoietic progenitor cell line and was thought to induce cell death ${ }^{[2]}$. However, it has since been clarified that PD-1 is primarily involved in inhibitory immune signaling and is an essential regulator of adaptive immune responses ${ }^{[4,66,93,94]}$. Although PD-1 is not expressed on most circulating $\mathrm{T}$ cells, its expression can be induced upon stimulation, through the TCR complex or exposure to cytokines ${ }^{[95,96]}$. Other cell types, such as B cells, mast cells, and myeloid dendritic cells, can also express PD-1 protein, which can regulate their own and bystander cell functions under pathophysiological conditions $^{[97,98]}$.

PD-1 binds to counter-receptors PD-L1 (B7-H1; CD274) and PD-L2 (B7-DC; CD273). PD-L1 is expressed on miscellaneous cell types, including tumor cells, APCs, infiltrating immune cells ${ }^{[99]}$, and endothelial and epithelial cells $s^{[4,94]}$. PD-L1 expression on tumor cells is induced by inflammatory cytokines but may also be constitutively upregulated by autonomous cancer cell mutations or gene alterations. In T cells, binding of PD-1 to its ligand causes phosphorylation of tyrosine residues, initiating an intracellular downstream signaling event that transmits the dephosphorylation of TCR proximal signaling components. Among these, CD28 is the primary target, as the PD-1-associated SHP-2 preferentially dephosphorylates CD28 over the $\mathrm{TCR} \zeta$ chain and other substrates ${ }^{[100-106]}$. By intervening in the early stages of TCR/CD28 signaling and relative IL-2-dependent positive feedback, PD-1 signaling leads to decreased cytokine production, cell cycle progression, and BCL2L1 gene expression, as well as decreased expression of transcription factors involved in $\mathrm{T}$ cell effector functions ${ }^{[105,106]}$. PD-1 activity is, therefore, only relevant when T cells are activated by TCRdependent signaling ${ }^{[107]}$. Overall, PD-1 pathway is vital for maintaining effective immunity and peripheral self-tolerance, so as to avoid autoimmunity and immunopathology ${ }^{[49,66,94]}$. Figure 3 illustrates PD-1/PD-L1 interactions and their blockade with moAbs, while main molecular aspects of the PD-1/PD-L1 signaling are shown in Figure 4. Neutralizing moAbs targeting the PD-1/PD-L1 pathway have resulted in dramatic improvements in the outcome of various advanced neoplasms. Table 4 summarizes PD-1/PD-L1 inhibition strategies with moAbs in TNBC. 
Table 3. Selected current clinical trials investigating tremelimumab in TNBC

\begin{tabular}{|c|c|c|c|c|}
\hline $\begin{array}{l}\text { Study } \\
\text { identifier }\end{array}$ & $\begin{array}{l}\text { Type of } \\
\text { study }\end{array}$ & Study population & Regimen/treatment arms & Status \\
\hline NCT03674827 & Phase I & Advanced NSCLC and metastatic TNBC & PF-06801591 + tremelimumab & Recruiting \\
\hline NCT02527434 & Phase II & $\begin{array}{l}\text { First-line treatment of patients with selected advanced solid } \\
\text { tumors, including TNBC }\end{array}$ & $\begin{array}{l}\text { Tremelimumab monotherapy. After disease progression, patients will have the option of being } \\
\text { sequenced to durvalumab monotherapy or durvalumab + tremelimumab combination therapy, for up } \\
\text { to } 12 \text { months or until disease progression }\end{array}$ & $\begin{array}{l}\text { Active, not } \\
\text { recruiting }\end{array}$ \\
\hline $\begin{array}{l}\text { NCT03982173 } \\
\text { MATILDA trial }\end{array}$ & Phase II & $\begin{array}{l}\text { Advanced solid tumors, including TNBC, which are resistant or } \\
\text { refractory to standard therapy and have } \geq 5 \text { somatic } \\
\text { mutations/megabase }\end{array}$ & Durvalumab + tremelimumab & $\begin{array}{l}\text { Active, not } \\
\text { recruiting }\end{array}$ \\
\hline
\end{tabular}

${ }^{a}$ Non-small cell lung cancer; ${ }^{b}$ PF-6801591 (sasanlimab) is a monoclonal antibody that targets PD-1.

\section{Monoclonal antibodies targeting PD-1}

Nivolumab

Nivolumab is a fully human IgG4 moAb targeting PD- $1^{[108,109]}$. Nivolumab is indicated for the treatment of a wide spectrum of malignancies, including nonsmall cell lung cancer (NSCLC), small cell lung cancer (SCLC), renal cell carcinoma, Hodgkin's lymphoma, squamous cell carcinoma of the head and neck, urothelial carcinoma, mismatch repair deficient (dMMR) metastatic colorectal cancer, and hepatocellular carcinoma ${ }^{[110]}$. Selected current clinical trials with nivolumab in combination with other agents in early and metastatic TNBC are presented in Table 5.

1. Nivolumab in early breast cancer: neoadjuvant and adjuvant setting

As mentioned in the "Ipilimumab" Section, in a phase II trial, nivolumab plus ipilimumab is combined with intratumoral cryoablation before definitive breast surgery in patients with residual tumors $\geq 1.0 \mathrm{~cm}$ after taxane-based NACT. Postoperatively, nivolumab is administered with standard adjuvant chemotherapy. The rationale for this study is based on observations in murine models that cryoablation could potentially enhance the activity of immune checkpoint inhibitors by inducing immunogenic cell death ${ }^{[74]}$.

The design of the pilot open-label three-arm randomized OXEL trial ${ }^{[111]}$ was based on the results of the CREATE-X trial ${ }^{[112]}$. The latter showed that adding capecitabine adjuvantly to patients with HER2-negative breast cancer who had after standard NACT pathological residuum at surgery effectively prolonged DFS and OS, with a particularly remarkable effect in TNBC patients. The OXEL trial enrolls patients with early TNBC who have residual disease $\geq 1.0 \mathrm{~cm}$ in the breast and/or lymph node positive disease at surgery after NACT containing an anthracycline, a taxane, or both, or carboplatin-containing NACT. Patients are randomized to nivolumab alone, capecitabine alone, or nivolumab plus capecitabine. The primary endpoint of OXEL is to investigate the immunologic effects of the treatment by peripheral immunoscore (PIS). Other endpoints include toxicity evaluation, distant recurrence free survival and overall survival rates at three years, correlation between changes in PIS and circulating tumor DNA (ctDNA) at different time points with clinical outcomes, and 

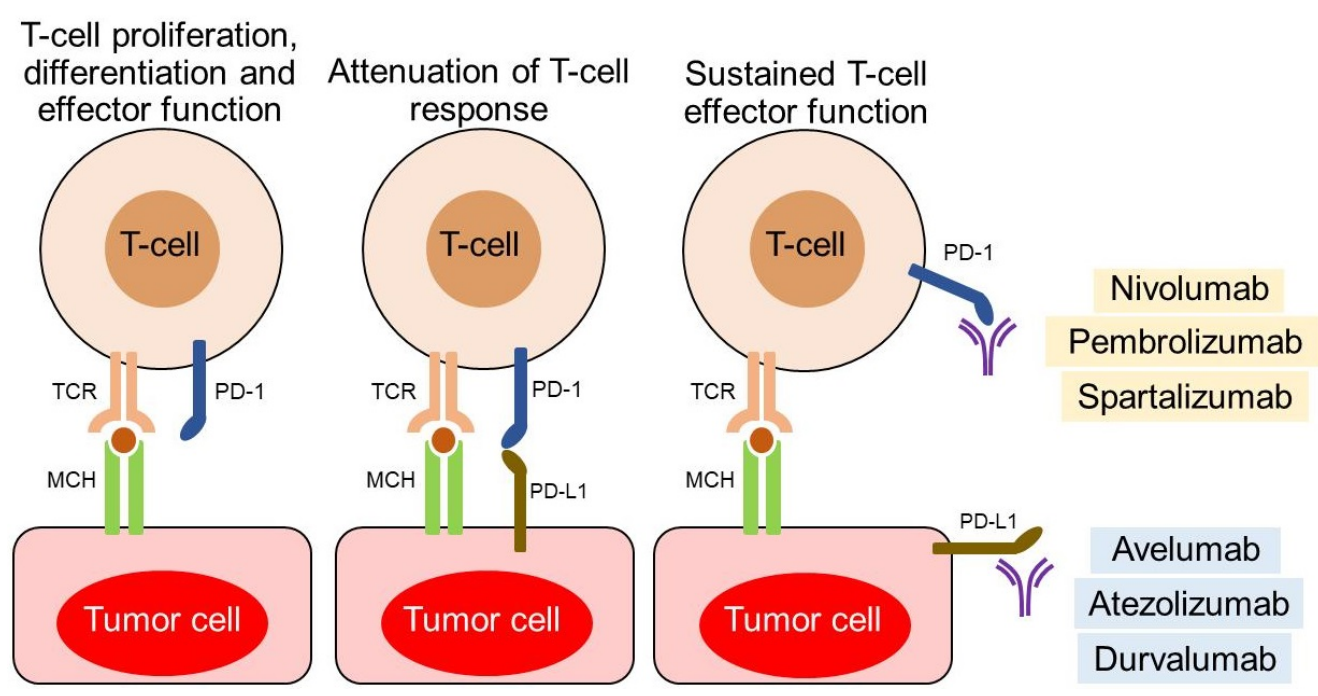

Figure 3. PD-1/PD-L1 interactions and their blockade with monoclonal antibodies.

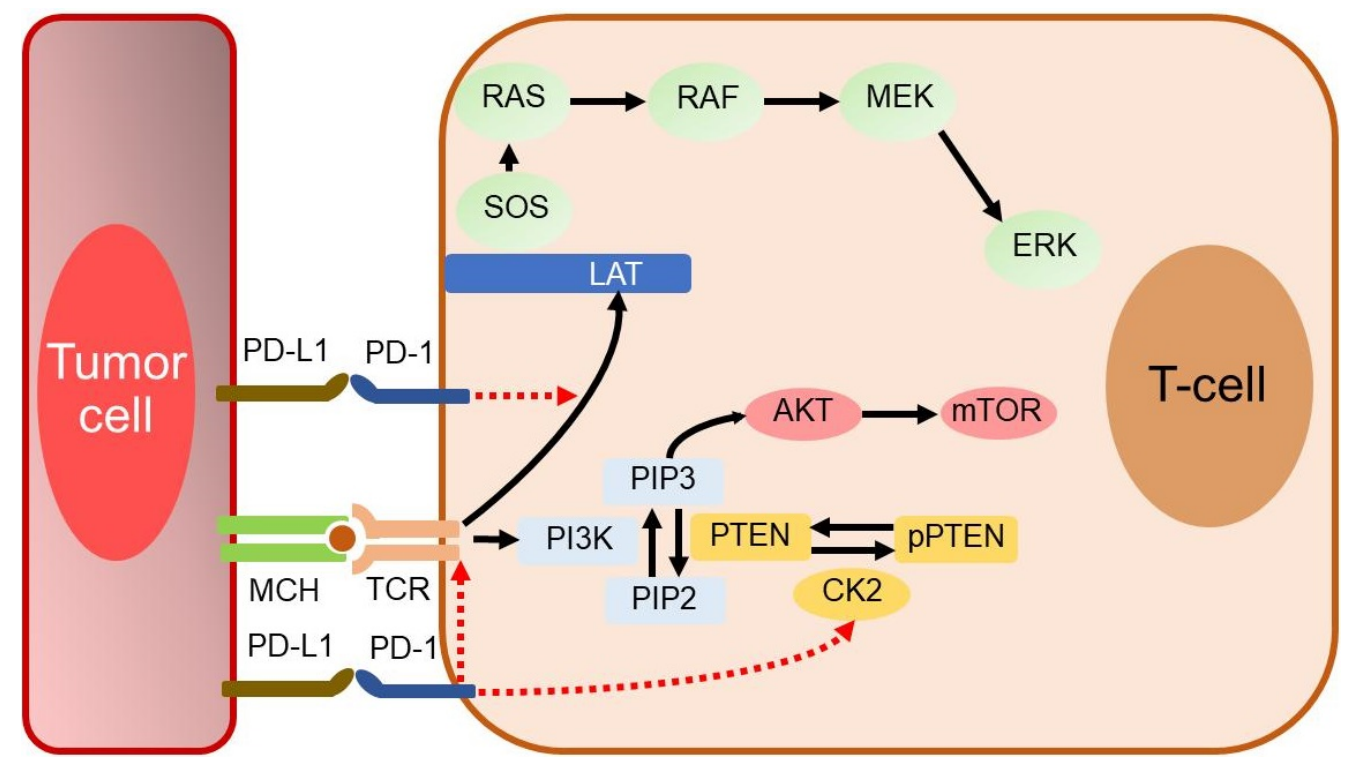

Figure 4. Main molecular aspects of the PD-1/PD-L1 pathway.

characterization of the immune profile of residual tumors.

In the context of the neoadjuvant setting, the ongoing phase II BELLINI trial evaluates the efficacy of nivolumab in combination with ipilimumab ${ }^{[113]}$.

2. Nivolumab in mTNBC

A. Nivolumab with chemotherapy and/or irradiation 
Table 4. PD-1/PD-L1 inhibition strategies with monoclonal antibodies in the various settings of TNBC: single-agent treatment and combinations

\author{
Combinations in the neoadjuvant setting \\ $\mathrm{NACT}^{\mathrm{a}}$ followed by neoadjuvant cryoablation/chemotherapy + nivolumab + ipilimumab \\ Nivolumab + ipilimumab \\ Pembrolizumab, atezolizumab, or durvalumab + NACT \\ Avelumab + aspirin + lansoprazole \\ Combinations in the adjuvant setting \\ Nivolumab \pm capecitabine for patients with residual disease after standard NACT \\ Chemotherapy followed by avelumab \\ Adjuvant chemotherapy + atezolizumab followed by single-agent atezolizumab

\section{Metastatic TNBC} \\ Monotherapy with anti-PD(L)-1 monoclonal antibodies \\ Pembrolizumab, spartalizumab, avelumab, atezolizumab, or durvalumab maintenance \\ Combinations with chemotherapy and/or local therapy \\ Nivolumab, atezolizumab, or durvalumab + chemotherapy \\ Induction treatment ${ }^{\text {f }}$ followed by nivolumab \\ Combinations with molecular-targeted agents \\ Combinations with TKIs \\ Nivolumab + cabozantinib $^{c}$, pembrolizumab + BGB324 (bemcentinib) ${ }^{d}$, or durvalumab + cediranib ${ }^{e}$ \\ Combinations with PARP inhibitors \\ Pembrolizumab + niraparib ${ }^{\dagger}$, avelumab + talazoparib ${ }^{\dagger}$, or durvalumab + Olaparib ${ }^{\dagger}$
}

Combinations of monoclonal antibodies targeting immune checkpoint molecules

Anti-PD(L)-1+anti-CTLA-4 monoclonal antibodies

Nivolumab + ipilimumab

Anti-PD-1 + anti-LAG3 monoclonal antibodies

Spartalizumab + ieramilimab $\left(\right.$ LAG525) ${ }^{g}$

Combinations with immunomodulating agents or vaccines

JTX-2011 ${ }^{\text {h }}+$ ipilimumab, nivolumab, or pembrolizumab

Nivolumab + bempegaldesleukin ${ }^{i}$

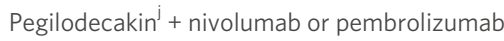

Pembrolizumab + PGG ${ }^{k}$

Chemokine modulating pre-treatment 'followed by pembrolizumab

Pembrolizumab + ladiratuzumab vedotin (LV, SGN-LIV1A) ${ }^{m}$

Spartalizumab + lacnotuzumab ${ }^{n}$

Spartalizumab + ADU-S100 (MIW815)

Pembrolizumab + SV-BR-1-GM vaccine ${ }^{\mathrm{p}}$

${ }^{a}$ Neoadjuvant chemotherapy; ${ }^{b}$ irradiation, doxorubicin, oral cyclophosphamide, cisplatin, or cryoablation; ' $a$ an oral multi-targeted tyrosine kinase

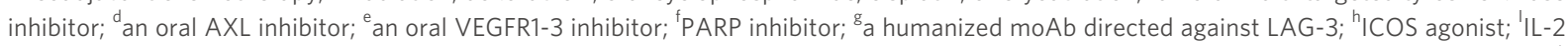
protein bound by multiple releasable polyethylene glycol chains; ${ }^{j}$ EGylated IL-10; ${ }^{j}$ novel $\beta-1,3 / 1,6$ glucan biologic derived from Saccharomyces; ${ }^{k}$ consisting of rintatolimod, IFNa, and celecoxib; ' an antibody-drug conjugate targeting LIV-1 protein; ${ }^{\mathrm{m}}$ a humanized moAb directed against LAG-3; ${ }^{\mathrm{n}}$ a humanized moAb targeting CSF-1; ${ }^{\circ}$ a synthetic cyclic dinucleotide agonist (activator) of stimulator of interferon genes (STINGs); ${ }^{{ }^{\text {irradiated }}}$ allogeneic breast cancer cells derived from the breast cancer cell line SV-BR-1 that are transfected with the immunostimulant GM-CSF gene.

In metastatic TNBC, nivolumab has been assessed in combination with other agents. A phase I trial evaluates the safety of nivolumab with nab-paclitaxel in three cancer types: HER2-negative metastatic breast cancer, advanced NSCLC with carboplatin, and advanced pancreatic cancer with or without gemcitabine. Breast cancer patients are treated with two different dosing regimens of the combination of nivolumab with nab-paclitaxel. Eligibility criteria include $0-1$ prior lines of chemotherapy in the metastatic setting and 
Table 5. Selected current clinical trials investigating nivolumab in TNBC

\begin{tabular}{|c|c|c|c|c|}
\hline $\begin{array}{l}\text { Study } \\
\text { identifier }\end{array}$ & Type of study & Study population & Regimen/treatment arms & Status \\
\hline NCT04331067 & Phase $\mathrm{lb} / \mathrm{II}$ & $\begin{array}{l}\text { Neoadjuvant treatment for patients with clinical stage II or } \\
\text { III (at least T2, any N, MO or if N+ then any T) TNBC }\end{array}$ & $\begin{array}{l}\text { Arm A: Paclitaxel }\left(80 \mathrm{mg} / \mathrm{m}^{2} \text { weekly } \times 12\right) \text { and carboplatin (AUC } \times 5 \text { every } 3 \text { weeks for } 12 \text { weeks) + } \\
\text { nivolumab } 240 \mathrm{mg} \text { every } 2 \text { weeks for } 12 \text { weeks } \\
\text { Arm B: Paclitaxel }\left(80 \mathrm{mg} / \mathrm{m}^{2} \text { weekly } \times 12 \text { and carboplatin (AUC } \times 5 \text { every } 3 \text { weeks for } 12 \text { weeks) + }\right. \\
\text { nivolumab } 240 \mathrm{mg} \text { every } 2 \text { weeks for } 12 \text { weeks }+ \text { cabiralizumab } 4 \mathrm{mg} / \mathrm{kg} \text { every } 2 \text { weeks for } 12 \text { weeks }\end{array}$ & Not recruiting \\
\hline NCT03098550 & Phase I/II & $\begin{array}{l}\text { Patients with metastatic TNBC, pancreatic } \\
\text { adenocarcinoma or NSCLC }\end{array}$ & $\begin{array}{l}\text { Cohort A (TNBC and pancreatic adenocarcinoma): Nivolumab + daratumumab } \\
\text { Cohort B (NSCLC): Nivolumab }\end{array}$ & $\begin{array}{l}\text { Active, not } \\
\text { recruiting }\end{array}$ \\
\hline NCT03952325 & $\begin{array}{l}\text { Randomized } \\
\text { Phase II }\end{array}$ & $\begin{array}{l}\text { Patients with metastatic TNBC who have not received } \\
\text { prior chemotherapy for advanced disease }\end{array}$ & $\begin{array}{l}\text { Cohort 1, Arm A: Tesetaxel }\left.\right|^{b}+\text { nivolumab } \\
\text { Cohort 1, Arm B: Tesetaxel }\left.\right|^{b}+\text { pembrolizumab } \\
\text { Cohort 1, Arm C: Tesetaxel }+ \text { atezolizumab } \\
\text { Cohort 2: Tesetaxel }\end{array}$ & Recruiting \\
\hline
\end{tabular}

${ }^{a}$ A humanized monoclonal antibody directed against the tyrosine kinase receptor colony stimulating factor 1 receptor; ${ }^{b}$ a semi-synthetic, orally bioavailable taxane derivative.

relapse $\geq 12$ months after taxane-based adjuvant therapy ${ }^{[114]}$.

In another phase II trial, patients with metastatic TNBC and 0-1 prior lines of chemotherapy in the metastatic setting are randomly allocated to receive carboplatin with or without nivolumab. Treatment with platinum-based chemotherapy in the neoadjuvant or adjuvant setting does not exclude patients from enrollment in the study if metastatic disease has been diagnosed at least one year after completion of previous platinum-containing chemotherapy. Pharmacodynamic changes in TILs and other biomarkers of response and resistance to treatment are also studied. Furthermore, additional relevant studies will be performed, including analyses of ctDNA, peripheral blood mononuclear cells, and intestinal microbiome ${ }^{[15]}$.

The recently presented Japanese, phase II NEWBEAT trial assessed the efficacy and safety of the combination of nivolumab with paclitaxel and bevacizumab as first-line therapy in HER2-negative metastatic breast cancer. Thirty-nine (68\%) patients were with luminal disease and 18 (32\%) patients were with TNBC. ORR based on investigator assessment was $75.4 \%$ and disease-control rate (DCR) was $96.4 \%$. ORR was $71.7 \%$ in patients with luminal breast cancer and $83.3 \%$ in patients with TNBC. At 12 months, the PFS and OS rates were $75.8 \%$ and $87.1 \%$, respectively. Immune-related Grade 3 or 4 adverse events (AEs) occurred in $58 \%$ of patients ${ }^{[116]}$. Patients from the NEWBEAT trial were also enrolled in a biomarker analysis ${ }^{[117]}$.

Immunohistochemistry assays were performed to monitor in the TME the expression of PD-L1, CD4, and CD8. In addition, the number of circulating immunosuppressive cells [Tregs, myeloid-derived suppressor cells, and tumor-associated macrophages (TAMs)] was measured in peripheral blood samples collected prior to treatment and at four time points during treatment. 
The Dutch TONIC trial is of particular interest ${ }^{[118,119]}$. Because treatment with anti-PD(L)-1 moAbs benefits a small percentage of unselected patients with $\mathrm{mTNBC}^{[3,52,53]}$, strategies have been proposed to make the TME more susceptible to PD-1/PD-L1 pathway inhibition. As existing preclinical data suggest immunomodulatory properties for both chemotherapy and irradiation ${ }^{[120-122]}$, induction treatment with either low-dose chemotherapy or irradiation aimed at stimulating antitumor immune responses could represent such a strategy. In the first stage of the TONIC trial, 67 patients with mTNBC who had received $\leq$ 3 prior lines of chemotherapy were randomly allocated to nivolumab or to a two-week induction treatment followed by nivolumab. This induction treatment consisted of irradiation of one metastatic lesion; two weekly infusions of doxorubicin; oral cyclophosphamide; or two weekly infusions of cisplatin. After the induction period, all patients received nivolumab until disease progression by iRECIST criteria ${ }^{[123]}$. ORR was $20 \%$ in the entire population. Most responses were observed in the doxorubicin cohort (ORR 35\%) followed by those in the cisplatin cohort (ORR 23\%). After induction with doxorubicin or cisplatin, an upregulation of immune-related genes involved in PD-1/PD-L1 and T-cell cytotoxicity pathways was detected. This was further supported, after induction with doxorubicin, by enrichment among upregulated genes associated to inflammation, JAK-STAT and TNF- $\alpha$ signaling. All these clinical and translational data suggest that priming with short-term doxorubicin and cisplatin may create a more favorable TME, thus increasing the likelihood of response to immune checkpoint inhibitors in $\mathrm{mTNBC}^{[119]}$.

\section{B. Nivolumab in combination with other immune checkpoint inhibitors}

Inducible T-cell costimulator (ICOS) or CD278, the third member of the CD28/CTLA4 family, is an immune checkpoint costimulatory molecule that is expressed on activated $\mathrm{T}$ cells playing a crucial role in cell signaling, immune responses, and regulation of cell proliferation. ICOS activity is considered important, especially for Th2 cells, to direct appropriate antibody responses to foreign antigen $s^{[124-128]}$. The ICOS axis has a dual effect by playing two opposite roles, and this depends on its expression on the various T-cell subtypes and the pathophysiological circumstance ${ }^{[128]}$. More specifically, it is an activator of antitumor T-cell responses, but also can participate in pro-tumor responses and immune invasion due to its close connection with the suppressive activity of Tregs. In preclinical models, ICOS agonist moAbs have been shown to potentiate the effect of immune checkpoint inhibition, whereas antagonist moAbs reduce immunosuppressive Tregs, while inhibiting ICOS-expressing lymphoid cells. Therefore, the therapeutic modification of the ICOS pathway should theoretically be based on the administration of either an antagonist or an agonist moAb, depending on the characteristics of the tumor and its microenvironment ${ }^{[129-131]}$.

JTX-2011 is an agonist moAb that binds to and activates ICOS. The phase I/II ICONIC trial ${ }^{[132]}$ assessed the safety, tolerability, and preliminary efficacy of JTX-2011 alone and in combination with ipilimumab, nivolumab, or pembrolizumab in patients with various advanced and/or refractory types of cancer, including TNBC. JTX-2011 monotherapy and combined treatment with nivolumab were well tolerated and showed antitumor activity in heavily pre-treated patients with $\mathrm{mTNBC}^{[133]}$.

\section{Nivolumab in combination with molecular-targeted agents}

A phase II study is assessing the efficacy of the combination of nivolumab plus cabozantinib in patients with mTNBC who have received $\leq 3$ previous lines of chemotherapy for their metastatic disease ${ }^{[134]}$. Cabozantinib is a tyrosine kinase inhibitor (TKI) that strongly binds to and inhibits several tyrosine kinases, such as cMET (hepatocyte growth factor receptor, HGFR), vascular endothelial growth factor receptor types 1-3 (VEGFR-1/2/3), c-KIT, FLT-3, TIE-2, tropomyosin-related kinase B (TRKB), and AXL ${ }^{[135-139]}$. The design of 
this study was based on the assumption that cabozantinib may enhance the activity of nivolumab by reducing myeloid-derived suppressor cells, while increasing the number of T cells. Peripheral blood samples and tumor biopsies will be taken before the start of treatment, during it, and at disease progression for immune profiling and for examining biomarkers of the response to treatment.

\section{Nivolumab with immunomodulating cytokines}

Interleukin-2 (IL-2) is a pleiotropic cytokine with a broad spectrum of activities including functions leading to proliferation and survival of T cells. IL-2 also enhances the cytolytic activity of $\mathrm{CD} 8^{+} \mathrm{T}$ cells and NK cells, induces the differentiation of Tregs, and mediates activation-induced cell death ${ }^{[140,141]}$. Treatment of metastatic melanoma and renal cell carcinoma with IL-2 at high doses was approved by FDA in the 1990s, providing up to $25 \%$ objective responses ${ }^{[142-145]}$. However, high-dose IL-2 has not been widely used due to severe toxicity associated with the overactivation of the immune system ${ }^{[145]}$.

Bempegaldesleukin (BEMPEG or NKTR-214) is a prodrug in clinical development comprising IL-2 protein bound by multiple releasable polyethylene glycol (PEG) chains. This agent was developed to harness the immunostimulatory benefits of the IL-2 pathway, maximize anticancer responses, and minimize AEs. When bempegaldesleukin is administered in vivo, PEG chains are released slowly, creating a cascade of increasingly active IL-2 conjugates bound by fewer PEG chains. The PEG chains on bempegaldesleukin are located in the region of IL- 2 that contacts the $\alpha$ subunit of the heterotrimeric IL-2 receptor complex, IL $2 \mathrm{R} \alpha \beta \gamma$, thus reducing bempegaldesleukin's ability to bind to and activate the heterotrimer. Because the IL2R $\alpha \beta \gamma$ complex is constitutively expressed on Tregs, PEGylation reduces the cytokine for IL2R $\alpha \beta \gamma$ to a greater extent than for IL $2 \mathrm{R} \beta \gamma$, which is the predominant receptor complex on $\mathrm{CD}^{+} \mathrm{T}$ cells. It has been shown in multiple syngeneic models that treatment with bempegaldesleukin favors the activation of $\mathrm{CD} 8^{+}$ cells over Tregs in the TME providing antitumor activity ${ }^{[146,147]}$.

The PIVOT-02 phase I/II trial ${ }^{[148]}$ is investigating the efficacy and safety of bempegaldesleukin in combination with nivolumab in patients with metastatic melanoma, renal cell carcinoma, NSCLC, urothelial carcinoma, or TNBC. The dose escalation stage enrolled 38 patients and established the recommended phase II dose. The expansion phase is evaluating the combination in patients who are either immune therapy naïve or have relapsed/refractory disease to prior PD-1/PD-L1 inhibition. Among patients with TNBC, who were included in the trial and evaluated for response, ORR was 13\%, regardless of PD-L1 expression, and DCR 45\%. ORR was $11 \%$ in patients with PD-L1-negative tumors and 17\% in PD-L1positive patients. ORR was $20 \%$ in patients with $\geq 2$ lines of prior therapy, regardless of PD-L1 expression. Adverse events of Grade $\geq 3$ were observed in $23 \%$ of patients and included dehydration, hypotension, and myalgia. The predictive and prognostic factors assessed in PIVOT-02 trial included PD-L1 status, age, DFS, $\mathrm{LDH}$, number and type of metastatic sites, and prior taxane-based chemotherapy.

Interleukin-10 (IL-10) is considered a prototypical anti-inflammatory cytokine, which contributes significantly to the maintenance and restoration of immune homeostasis ${ }^{[149-151]}$. Recent evidence, however, suggests that the cytokine has pleiotropic roles, such as supporting $\mathrm{B}$-cell and $\mathrm{CD} 8^{+} \mathrm{T}$-cell activation ${ }^{[151]}$. Experimental data in mouse models show that IL-10 can inhibit the development of metastases ${ }^{[152]}$, while additional data support the immunostimulatory capacity of IL-10 in an immune-oncology context ${ }^{[153-155]}$. However, the short biological half-life of IL-10 in vivo restricts its therapeutic application because it requires large and frequent dosage administration ${ }^{[156,157]}$. PEGylation of IL-10 leads to the product pegilodecakin, providing increased serum half-life and prolonged systemic exposure, also allowing one subcutaneous injection of pegilodecakin daily ${ }^{[157,158]}$. Pegilodecakin monotherapy has shown activity in patients with 
advanced cancers, and PEGylated cytokine alone or in combination with anti-PD-1 treatment leads to proliferation and expansion of $\mathrm{PD}-1+\mathrm{Lag}-3^{+} \mathrm{CD}^{+} \mathrm{T}$ cells and expansion of novel CD8 $8^{+} \mathrm{T}$-cell clones ${ }^{[159]}$. In a phase $\mathrm{Ib}$ trial, patients with various malignancies refractory to previous therapies (among them one woman with TNBC) were treated with pegilodecakin combined with nivolumab or pembrolizumab ${ }^{[160]}$.

\section{Pembrolizumab}

Pembrolizumab is a humanized IgG4 kappa moAB directed against human cell surface PD-1 $1^{[108,109,161,162]}$. Pembrolizumab is indicated for the treatment of a wide spectrum of malignancies, including melanoma, metastatic NSCLC (alone or in combination with chemotherapy), squamous cell carcinoma of the head and neck, urothelial carcinoma, gastric cancer, cervical cancer, Merkel cell carcinoma, dMMR metastatic solid tumors, hepatocellular carcinoma, and Hodgkin's disease ${ }^{[163,164]}$.

As previously mentioned, the phase Ib KEYNOTE-012 study was one of the first immune checkpoint inhibitor monotherapy trials ${ }^{[54]}$. Although its results have been considered discouraging, regarding mTNBC, more recent trials that evaluated the combination of pembrolizumab with other agents have yielded promising results. Selected current clinical trials with pembrolizumab alone or in combination with other agents in TNBC are presented in Table 6.

1. Pembrolizumab in the neoadjuvant setting: combinations with chemotherapy

In the context of neoadjuvant therapy, the results of three very interesting trials were published in the first half of 2020. The phase Ib KEYNOTE-173 study assessed the efficacy and safety of NACT plus pembrolizumab in high-risk, early-stage $\mathrm{TNBC}^{[165]}$. Six different pembrolizumab plus chemotherapy regimens were evaluated. All patients were given pembrolizumab, every three weeks, for a total of nine cycles. In Cycle 1, patients received pembrolizumab monotherapy, while, in Cycles 2-5, they also received one of the following chemotherapeutic regimens: weekly nab-paclitaxel alone (Cohort A); weekly nabpaclitaxel plus carboplatin every three weeks (Cohort B); weekly nab-paclitaxel plus carboplatin every three weeks (Cohort C); nab-paclitaxel plus carboplatin, both weekly (Cohort D); weekly paclitaxel plus carboplatin every three weeks (Cohort E); and paclitaxel plus carboplatin, both weekly (Cohort F). All patients were also given, in Cycles 6-9, doxorubicin plus cyclophosphamide, every three weeks. The incorporation of carboplatin into the nab-paclitaxel/paclitaxel regimen (Cohorts $\mathrm{E}$ and $\mathrm{F}$ ) was performed, because previous studies have shown that the adding carboplatin and/or bevacizumab to NACT with taxane and anthracycline significantly increases the rate of pathological complete responses (pCR), in stage II/III $\mathrm{TNBC}^{[166,167]}$. Response to NACT, in the sense of $\mathrm{pCR}$, predicts an improved OS in $\mathrm{TNBC}^{[168]}$.

In KEYNOTE-173, the pCR rate (ypTo/Tis ypNo) was 60\% across all cohorts. This rate was the same with and without carboplatin, but it was higher for patients who received carboplatin every three weeks compared with those who were treated with weekly carboplatin (63\%vs. 55\%). Overall, the highest pCR rates were obtained with regimens that combined weekly nab-paclitaxel and carboplatin (Cohorts B-D), but they were associated with higher toxicity and, therefore, did not meet the predefined recommended phase II dose threshold. Event-free survival (EFS) rates at 12 months were $100 \%$ for patients who achieved ypTo/Tis ypNo response $v$ s. $88 \%$ for those who did not, while OS rates at 12 months were $98 \%$ for patients who received carboplatin $v s .80 \%$ for patients who did not. Higher pre-treatment PD-L1 combined positive score (CPS) and pre- and on-treatment stromal TILs were significantly associated with higher pCR rates. Immune-related AEs and infusion reactions occurred in $30 \%$ of patients and were of Grade $\geq 3$ in $10 \%$ of them. 
Table 6. Selected current clinical trials investigating pembrolizumab in TNBC

\begin{tabular}{|c|c|c|c|c|}
\hline $\begin{array}{l}\text { Study } \\
\text { identifier }\end{array}$ & Type of study & Study population & Regimen/treatment arms & Status \\
\hline NCT04468061 & $\begin{array}{l}\text { Randomized } \\
\text { Phase II }\end{array}$ & $\begin{array}{l}\text { First-line treatment of patients with metastatic TNBC and PD-L1 expression }<1 \% \\
\text { on tumor-infiltrating immune cells }\end{array}$ & $\begin{array}{l}\text { Arm A: Sacituzumab dovitecan }{ }^{\text {a }}+\text { pembrolizumab } \\
\text { Arm B: Sacituzumab dovitecan } \\
\text { Retreatment: Patients randomized to the combination arm who stop with CR after } \\
\text { at least } 24 \text { weeks of treatment may be eligible for additional pembrolizumab } \pm \\
\text { sacituzumab govitecan if they progress after stopping treatment }\end{array}$ & Recruiting \\
\hline NCT02755272 & $\begin{array}{l}\text { Randomized } \\
\text { Phase II }\end{array}$ & $\begin{array}{l}\text { Patients with metastatic TNBC who have received } \leq 2 \text { prior regimens in the } \\
\text { metastatic setting }\end{array}$ & $\begin{array}{l}\text { Arm A: Pembrolizumab + standard chemotherapy using carboplatin and } \\
\text { gemcitabine } \\
\text { Arm B: Standard chemotherapy alone using carboplatin and gemcitabine }\end{array}$ & Recruiting \\
\hline NCT03310957 & Phase I/II & $\begin{array}{l}\text { First-line treatment of patients with unresectable locally advanced or metastatic } \\
\text { TNBC }\end{array}$ & SGN-LIV1A + pembrolizumab & Recruiting \\
\hline NCT03004183 & Phase II & $\begin{array}{l}\text { Metastatic TNBC that is refractory to standard of care therapy or metastatic } \\
\text { NSCLC that is immunotherapy and chemotherapy naive or previously treated with } \\
1 \text { cycle of platinum-containing chemotherapy }\end{array}$ & $\begin{array}{l}\text { Stereotactic body radiation therapy and in situ ADV/HSV-tk }{ }^{\mathrm{c}} \text { therapy + } \\
\text { valacyclovir followed by pembrolizumab }\end{array}$ & Recruiting \\
\hline NCT03012230 & Phase I & $\begin{array}{l}\text { Patients with metastatic TNBC that has progressed after at least one prior } \\
\text { chemotherapy regimen in the metastatic setting }\end{array}$ & Pembrolizumab and ruxolitinib phosphate $^{d}$ & Recruiting \\
\hline NCT04265872 & Early Phase I & $\begin{array}{l}\text { Patients with metastatic TNBC previously treated with standard anthracycline, } \\
\text { cyclophosphamide, and taxane chemotherapy }\end{array}$ & Bortezomib $^{e}$ followed by pembrolizumab and cisplatin & Recruiting \\
\hline NCT02954874 & Phase III & $\begin{array}{l}\text { Patients with early TNBC or low ER-positive and/or HER2 borderline breast } \\
\text { cancer who have } \geq 1 \mathrm{~cm} \text { residual invasive breast cancer and/or positive lymph } \\
\text { nodes after NACT }\end{array}$ & $\begin{array}{l}\text { Arm I: Observation } \\
\text { Arm II: Pembrolizumab intravenously over } 30 \text { min on Days } 1 \text { and } 22 \text { with cycles } \\
\text { repeated every } 42 \text { days for } 52 \text { weeks }\end{array}$ & Recruiting \\
\hline NCT02957968 & Phase II & Patients with locally advanced HER2-negative breast cancer & $\begin{array}{l}\text { Cohort A (TNBC): Decitabine }{ }^{\dagger} \text { and pembrolizumab on Days } 8 \text { and } 22 \text { followed by } 4 \\
\text { cycles of dose-dense doxorubicin and cyclophosphamide and } 12 \text { doses of weekly } \\
\text { paclitaxel and carboplatin } \\
\text { Cohort B (hormone receptor-positive tumors): Identical doses and treatment } \\
\text { schedules as described for TNBC }\end{array}$ & Recruiting \\
\hline NCT04024800 & $\begin{array}{l}\text { Phase II (NSABP } \\
\text { FB-14) }\end{array}$ & $\begin{array}{l}\text { Patients with metastatic } \text { TNBC who have received } \leq 1 \text { prior regimens in the } \\
\text { metastatic setting }\end{array}$ & AE37 peptide vaccine ${ }^{g}$ every 21 days for 5 doses + pembrolizumab & Recruiting \\
\hline NCT03362060 & Phase I & $\begin{array}{l}\text { At least one line of prior systemic therapy for metastatic or recurrent TNBC } \\
\text { (there is no limit to the number of prior therapies) }\end{array}$ & $\begin{array}{l}\text { PVX- } 410 \text { vaccine at Weeks } 0,1,2,3,4 \text {, and } 5 \text { followed by booster PVX- } 410 \\
\text { vaccine doses at Weeks } 10 \text { and } 28+\text { pembrolizumab every } 3 \text { weeks intravenously } \\
\text { starting in Week } 1\end{array}$ & Recruiting \\
\hline NCT04427293 & Phase I & Neoadjuvant treatment for patients with cT1b-T2/NO-N1/MO TNBC & $\begin{array}{l}\text { Lenvatinib' } 12 \text { mg daily on Days 1-14 and pembrolizumab } 200 \text { mg intravenously } \\
\text { on Day } 1\end{array}$ & Recruiting \\
\hline NCT04191135 & $\begin{array}{l}\text { Phase II/III } \\
\text { (KEYLYNK-009) }\end{array}$ & $\begin{array}{l}\text { Patients with locally recurrent inoperable TNBC who have not previously been } \\
\text { treated with chemotherapy and who cannot be treated with curative intent or } \\
\text { with metastatic TNBC that has not been previously treated with chemotherapy }\end{array}$ & $\begin{array}{l}\text { Arm A: Carboplatin AUC X× with gemcitabine } 1000 \mathrm{mg} / \mathrm{m}^{2} \text { on Days } 1 \text { and } 8+ \\
\text { pembrolizumab } 200 \mathrm{mg} \text { intravenously on Day } 1, \text { every } 3 \text { weeks, for } 4-6 \text { cycles } \\
\text { Patients who achieve CR, PR, or SD will continue with the same regimen } \\
\text { Arm B: Carboplatin AUC } \times 2 \text { with gemcitabine } 1000 \mathrm{mg} / \mathrm{m}^{2} \text { on Days } 1 \text { and } 8+ \\
\text { pembrolizumab } 200 \mathrm{mg} \text { intravenously on Day } 1 \text {, every } 3 \text { weeks, for } 4-6 \text { cycles } \\
\text { Patients who achieve CR, PR, or SD will continue with pembrolizumab + olaparib }\end{array}$ & Recruiting \\
\hline
\end{tabular}

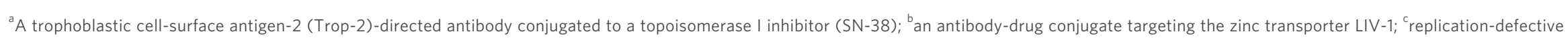


recombinant adenovirus vector; ${ }^{\mathrm{d}}$ a janus kinase (JAK) inhibitor with selectivity for subtypes JAK1 and JAK2; ${ }^{e}$ a $26 \mathrm{~S}$ proteasome inhibitor; ${ }^{\mathrm{f}}$ a prodrug analog of the natural nucleotide 2 '-deoxycytidine that acts as hypomethylating agent; ${ }^{g}$ a vaccine containing HER2-derived epitope (amino acids 776-790) linked to li-Key peptide (li-Key/HER2 hybrid peptide or AE37); ${ }^{\text {ha }}$ tetra-peptide vaccine with three of the four antigens [XBP1 (two splice variants) and CD138] commonly overexpressed in TNBC; 'a multireceptor tyrosine kinase inhibitor.

In the ongoing phase II open-label, multicenter I-SPY2 trial ${ }^{[169]}$, patients with high-risk (by MammaPrint), stage II/III, HER2-negative breast cancer and primary tumors $>2.5 \mathrm{~cm}$ by clinical examination or $>2.0 \mathrm{~cm}$ by imaging were randomly allocated to taxane- and anthracycline-containing NACT with or without pembrolizumab. In the control arm, patients received weekly paclitaxel, for 12 weeks, followed by four cycles of doxorubicin plus cyclophosphamide, every 2-3 weeks. In the intervention arm, patients received standard NACT plus pembrolizumab, every three weeks for four cycles, concurrently with paclitaxel. In the intervention arm, the pCR rates for HER2-negative, HR-positive/HER2-negative, and triple-negative breast cancer signatures were 44\%, 30\%, and $60 \%$, compared with $17 \%, 13 \%$, and $22 \%$ in the control populations, respectively, i.e., adding pembrolizumab to NACT more than doubled pCR rates. In addition, patients in the pembrolizumab plus NACT arm, who achieved pCR, had EFS rates of $93 \%$ at three years. AEs included immune-related endocrinopathies, notably thyroid abnormalities and adrenal insufficiency.

Finally, the phase III KEYNOTE-522 trial ${ }^{[170]}$ is of particular importance. Patients with stage II and III TNBC were randomized in a 2:1 ratio to neoadjuvant therapy with four cycles of pembrolizumab plus weekly paclitaxel and carboplatin (administered either weekly or every three weeks) or placebo plus paclitaxel and carboplatin in the same dosage regimen as in the experimental arm. This first stage was followed by four additional cycles of pembrolizumab or placebo plus cyclophosphamide and doxorubicin or epirubicin, every three weeks (second neoadjuvant treatment). After surgery, the patients received adjuvant pembrolizumab or placebo, every three weeks, for up to nine cycles. Overall, pCR rates were $64.8 \%$ in the intervention arm $v s .51 .2 \%$ in the control arm (estimated treatment difference, 13.6\%; 95\%CI: 5.4-21.8; $P<0.001$ ). Furthermore, in the PD-L1-positive population, the pCR rates were 68.9\% among patients who received pembrolizumab plus chemotherapy vs. 54.9\% for those who received placebo plus chemotherapy, while, in the PD-L1-negative population, the corresponding rates were $45.3 \%$ vs. 30.3\%. The hazard ratio for disease progression, recurrence or a second primary tumor, or death from any cause favored the experimental arm ( $\mathrm{HR}=0.63$; 95\%CI: 0.43-0.93). The incidence of AEs of Grade $\geq 3$ was $78.0 \%$ in the experimental arm and $73.0 \%$ in the control arm, including death in $0.4 \%$ and $0.3 \%$ of patients, respectively.

In the context of the neoadjuvant setting, the NeoPACT phase II trial ${ }^{[171]}$ is assessing the efficacy of the combination of pembrolizumab with docetaxel plus carboplatin.

2. Pembrolizumab in mTNBC

A. Pembrolizumab monotherapy 
In the aforementioned KEYNOTE-012 trial ${ }^{[54]}$, pembrolizumab was administered to patients with advanced/metastatic TNBC, gastric cancer, urothelial cancer, and head and neck cancer that expressed PDL1 in the stroma or in $\geq 1 \%$ of tumor cells by immunohistochemistry (PD-L1-positive tumors). Among TNBC patients, ORR was $18.5 \%$ with a median time to response of 17.9 weeks. The median duration of response was not yet reached at the time of analysis. Adverse events of Grade $\geq 3$ were observed in $15.6 \%$ of patients including one treatment-related death.

The phase II study KEYNOTE-086 had two cohorts. Cohort A included 170 pre-treated women with mTNBC, regardless of PD-L1 expression ${ }^{[172]}$, while Cohort B included 84 women with PD-L1-positive disease who had not previously received systemic treatment in the metastatic setting ${ }^{[173]}$. All patients in both cohorts were given pembrolizumab, every three weeks, for up to two years. In Cohort A, the ORR was 5.3\% for the total population and 5.7\% for the PD-L1-positive subpopulation. Median PFS and OS were 2.0 and 9.0 months, respectively. AEs of Grade $\geq 3$ were observed in $12.9 \%$ of patients. In Cohort B, ORR amounted to $21.4 \%$ and DCR to $23.8 \%$. Median PFS and median OS were 2.1 and 18.0 months, respectively. Eight patients (9.5\%) experienced AEs of Grade 3, whereas AEs of Grade 4 or death were not observed.

Cortés et al. ${ }^{[174]}$ presented at the 2019 ESMO Meeting the results of the KEYNOTE-119 study that randomized 622 patients with $\mathrm{mTNBC}$ in a 1:1 ratio to receive, as second- or third-line systemic treatment, pembrolizumab monotherapy or chemotherapy by investigator's choice (including capecitabine, eribulin, vinorelbine, and gemcitabine). All patients had been previously exposed to anthracyclines and taxanes. Median OS (primary endpoint) did not differ statistically significantly between subpopulations with tumors with CPS $\geq 10$ or CPS $\geq 1$ compared with the overall population, although the therapeutic effect of pembrolizumab increased as CPS increased.

\section{B. Pembrolizumab and irradiation}

Radiotherapy is thought to enhance the immune response by promoting pro-immunogenic cell death and apoptosis, as well as priming and activating cytotoxic $\mathrm{T}$ cells ${ }^{[120,175,176]}$. Based on this rationale, which was the same as in the TONIC trial ${ }^{[119]}$, a phase II study assessed the efficacy and safety of pembrolizumab plus radiotherapy in $\mathrm{mTNBC}$, regardless of PD-L1 expression ${ }^{[177]}$. Patients received 3000 cGy of radiotherapy delivered in five daily fractions. The total dose of radiotherapy administered and its fractionation were based on the clinical feasibility and efficacy, in the context of palliative care, and preclinical data suggesting immunostimulatory benefits of hypofractionated doses in breast cancer ${ }^{[178]}$. Indications for radiotherapy included palliation of pain or control of metastases that developed while the patient was on systemic antitumor treatment. Pembrolizumab was given 1-3 days after the first fraction of radiotherapy and then every three weeks until disease progression was diagnosed or unacceptable toxicity occurred. The ORR for the entire population (17 patients) was $17.6 \%$. All three patients who achieved CR also had complete disappearance of all lesions outside the irradiated field. The most common toxicity of Grade 1 or 2 was dermatitis (29\%).

\section{Pembrolizumab with chemotherapy}

A phase Ib trial of pembrolizumab plus chemotherapy (PembroPlus) was performed to evaluate their safety and efficacy in 49 patients with various advanced/metastatic solid tumors, including 12 breast cancer patients. Pembrolizumab was administered with one of the following chemotherapy regimens: gemcitabine, gemcitabine plus docetaxel, gemcitabine plus nab-paclitaxel, gemcitabine plus vinorelbine or irinotecan, and liposomal doxorubicin. There were eight PRs across multiple tumor types ${ }^{[179]}$. 
An ongoing phase II trial is evaluating the combination of pembrolizumab with nab-paclitaxel in patients with metastatic HER2-negative breast cancer who have received $\leq 2$ previous treatment lines for advanced/metastatic disease. In addition to clinical efficacy and safety, various parameters related to the effect of treatment on TME will be examined, as well as predictive factors of response to the therapeutic combination. These include mutational and neoantigen load, TILs, TCR by immunosequencing, and immune gene profiles in tumor samples. The predictive role of PD-L1 expression in tumor tissue will also be assessed, but the expression is not among the inclusion criteria. Finally, the possible role of the intestinal microbiome in modifying the immune response will be examined ${ }^{[180]}$.

Another ongoing multicenter phase II study is evaluating pembrolizumab following a single priming dose of cyclophosphamide, in patients with advanced/metastatic TNBC. The primary endpoint is to estimate PFS, whereas the reduction of circulating Tregs represents the co-primary endpoint. Secondary endpoints include ORR, duration of response, DCR, and $\mathrm{OS}^{[181]}$. The rationale for this study was based on the wellestablished knowledge that low-dose cyclophosphamide has the capacity to deplete intratumoral Tregs in various tumors, including breast cancer ${ }^{[182-184]}$. Tregs can suppress antitumor immunity, thereby inhibiting effective immune responses in the host and hindering immunosurveillance of neoplasia, thus promoting tumor growth and progression ${ }^{[185]}$. Therefore, early infiltration of the TME with Tregs indicates a possible mechanism for the failure of immune checkpoint inhibition in certain tumor types which are heavily infiltrated by adaptive immune cells. Of note, infiltration with Tregs is significantly increased in TNBC and claudin-low breast cancer compared to other breast cancer subtypes ${ }^{[186,187]}$. Claudin-low tumors have been recognized to preferentially display a triple-negative phenotype and Treg depletion potentiates immune checkpoint inhibition in this subtype $\mathrm{e}^{[187]}$.

As previously mentioned in the context of ICD, the combination of chemotherapy with immune checkpoint inhibitors may enhance the activity of the latter ${ }^{[121,122]}$ and this has been clearly demonstrated in lung cancer by combining platinum-based chemotherapy with immunotherapy ${ }^{[188-192]}$. An ongoing randomized phase II trial is enrolling patients with refractory breast cancer with chest wall disease. Patients are randomly allocated in a 2:1 ratio to either pembrolizumab plus carboplatin, every three weeks for at least six cycles, followed by single-agent pembrolizumab (Arm A), or carboplatin, every three weeks (Arm B), until disease progression. Cross over to pembrolizumab on disease progression is allowed for patients in the control arm (Arm B). The primary endpoint is to estimate DCR at 18 weeks of treatment. The secondary endpoints include toxicity, PFS, and ORR based on iRECIST criteria and PD-L1 expression ${ }^{[193]}$.

The following two studies were conducted with the same rationale. A pilot phase II study assessed the efficacy and safety of concurrent pembrolizumab plus investigator-selected first- or second-line paclitaxel or oral capecitabine in mTNBC. Toxicities were generally consistent with monotherapy experience and improved with dose-reduction. ORRs were $43 \%$ and $25 \%$ for capecitabine plus pembrolizumab and paclitaxel plus pembrolizumab, respectively. Interestingly, patients enrolled $<12$ months after treatment with curative intent had numerically lower responses than patients who did not progress rapidly. No significant differences in immunomodulation were observed between the two types of chemotherapy, however, both capecitabine and paclitaxel were associated with a decrease in T-cell count ${ }^{[194]}$. A phase II study conducted by Shah et al ${ }^{[195]}$ assessed the combination of pembrolizumab plus capecitabine administered in three-week cycles in mTNBC or endocrine-refractory metastatic luminal breast cancer. For the entire population, median OS was 15.4 months and median PFS 4.0 months, which was not significantly longer than that of three months in historical controls. The ORR and clinical benefit rate (CBR) were not significantly different between disease subtypes (ORR 13\% and 14\%, CBR 25\%, and 29\% for TNBC and endocrine-refractory luminal breast cancer, respectively). Of note, some patients experienced a prolonged 
disease control.

D. Pembrolizumab with molecular-targeted agents

Poly (ADP-ribose) polymerase (PARP) inhibitors target the DNA base excision repair (BER) pathway and the repair of DNA single strand breaks (SSBs). If PARP activity is inhibited and BER is impaired, unrepaired SSBs accumulate, and they degenerate in replication forks to become DSBs. DSBs are repaired by various repair pathways, with HR representing the most important of them. In the process of HR repair, BRCA1 and BRCA2 proteins play a central role. The concept of synthetic lethality by inhibiting PARP in HR defective tumors is thought to be due to failure to repair SSBs. Indeed, in the absence of HR, accumulating SSBs that degenerate to DSBs prove lethal as they persist, while they can only be repaired by alternative pathways, such as non-homologous end joining, that are prone to errors ${ }^{[5,196]}$. FDA has approved the PARP inhibitors olaparib and talazoparib for germline BRCA1/2 mutated metastatic breast cancer ${ }^{[197,198]}$.

In the phase II study TOPACIO, 55 women with advanced or metastatic TNBC, regardless of $B R C A 1 / 2$ mutation status or PD-L1 expression, were administered oral niraparib plus pembrolizumab. ORR was $21 \%$ and DCR $49 \%$, respectively. In patients carrying BRCA1/2 mutations, ORR was $47 \%$ and DCR $80 \%$, respectively, with a median PFS of 8.3 months. Treatment was safe and warrants further investigation, especially in patients with $B R C A 1 / 2$-mutated $\mathrm{mTNBC}^{[199]}$.

BGB324 (bemcentinib) is an oral inhibitor of AXL, a cell surface receptor tyrosine kinase (RTK), part of the TAM family of kinases. All three TAM family RTKs are pleiotropic inhibitors of the innate immune response. AXL is expressed throughout all normal tissue and cell types and overexpressed in various malignancies including chronic and acute myelogenous leukemia, NSCLC, melanoma, gastric and colorectal cancer, breast cancer, and prostate cancer. Binding of AXL to its ligand GAS6, a vitamin K-dependent protein, leads to the activation of various signaling pathways, such as PI3K-AKT-mTOR, MAPK/ERK, NF- $\kappa$ $\mathrm{B}$, and JAK/STAT. In tumors, AXL activation regulates cellular pathways involved in cell survival, proliferation, apoptosis, epithelial-mesenchymal transition, cell adhesion, invasion, migration, and immune suppression ${ }^{[200-205]}$. Blocking AXL signaling with BGB324 has been shown to enhance the effect of immune checkpoint blockade in lung and mammary adenocarcinoma models ${ }^{[206]}$. A phase II study (BGBC007) is evaluating the efficacy of pembrolizumab plus BGB324 in patients with previously treated, advanced or metastatic $\mathrm{TNBC}^{[207]}$.

E. Pembrolizumab with immunomodulating agents/cytokines

PGG (Imprime) is a novel $\beta-1,3 / 1,6$ glucan biologic derived from Saccharomyces, which utilizes innate immune effector cells to enhance killing of antibody-targeted, complement-opsonized tumor cells. More specifically, when administered intravenously, endogenous anti-b glucan antibodies bind to PGG. Through the classical pathway of complement activation, PGG becomes opsonized and then binds to complement receptor 3 (CR3) on circulating neutrophils and monocytes. Thus, PGG modulates innate immune functions, leading to "priming" of these cells. In the TME, when a complement-activating anti-tumor moAb binds to tumor cell antigens, it induces complement deposition on the tumor cells. Subsequently, chemoattractant components produced in the complement cascade attract innate immune cells to the TME. Primed neutrophils and macrophages can exert anti-tumor activity against opsonized tumor cells through a CR3-dependent mechanism, while they can also modulate responses of other cells ${ }^{[208-210]}$. In a phase II study (IMPRIME 1), 44 previously treated patients with mTNBC received PGG plus pembrolizumab until PD or intolerable toxicity. Tumor biopsies and blood samples were also assessed for PGG-mediated immune 
activation. ORR was $15.9 \%$, while an additional $38.6 \%$ of patients had SD as best response (DCR at any time 54.5\%). Median OS was 13.7 months. Furthermore, confirmed responses were evident in patient subpopulations with poor prognosis, such as patients with high LDH levels, visceral metastases, and liver metastases. O'day et al. ${ }^{[211]}$ concluded that these clinical data suggest that PGG provides added clinical benefit to pembrolizumab.

Finally, a phase IIa trial is evaluating a chemokine modulating (CKM) pre-treatment followed by pembrolizumab in patients with $\mathrm{mTNBC}$ previously treated with at least one line of systemic therapy ${ }^{[212]}$. Pre-clinical ex-vivo data show that a CKM regimen consisting of rintatolimod, IFN $\alpha$, and celecoxib selectively attracts cytotoxic $\mathrm{T}$ cells into tumors and increases intratumoral expression of PD-1/PD-L1/PDL2, without enhancing soluble suppressive mechanisms ${ }^{[213]}$. Furthermore, experimental data from murine models demonstrate the safety of the combined CKM and PD-1 blockade, as well as efficiency in inducing long-term survival of mice with resistant tumors ${ }^{[212]}$. Rintatolimod, a mismatched double stranded polymer of RNA, is a restricted toll-like receptor 3 and represents a medication intended for treatment of chronic fatigue syndrome/myalgic encephalomyelitis ${ }^{[214]}$.

\section{F. Pembrolizumab in combination with antibody-drug conjugates}

Ladiratuzumab vedotin (LV, SGN-LIV1A) is an antibody-drug conjugate targeting LIV-1 protein. LV consists of an IgG1 antibody conjugated through a proteolytically cleavable linker to monomethyl auristatin $\mathrm{E}$, a potent microtubule-disrupting agent. LIV-1 is a transmembrane protein with zinc transporter and metalloproteinase activity, which is expressed in $>60 \%$ of mTNBCs. Its expression has been found to be associated with lymph node metastasis and metastatic progression. LV antitumor activity is thought to primarily be the result of intracellular payload release, leading to mitotic arrest and apoptotic cell death $^{[215-219]}$. LV induced apoptosis is consistent with immunogenic cell death ${ }^{[218]}$. SGNLVA-002, a phase $\mathrm{Ib} / \mathrm{II}$ trial of LV plus pembrolizumab as first-line treatment for patients with locally advanced/metastatic $\mathrm{TNBC}$, is currently enrolling in the USA and $\mathrm{EU}^{[220]}$.

\section{G. Pembrolizumab with vaccines}

SV-BR-1-GM is a vaccine consisting of irradiated allogeneic breast cancer cells, derived from the cell line SV-BR-1. These cells are transfected with the GM-CSF gene and secrete GM-CSF when administered intradermally, thus potentiating a tumor-specific cytotoxic T-lymphocyte immune response ${ }^{[221,222]}$.

A phase I/IIa trial assessed SV-BR1-GM in combination with immune checkpoint inhibitors in patients with advanced/metastatic breast cancer refractory to standard therapy ${ }^{[223]}$. Patients received intravenous cyclophosphamide prior to intradermal injection of SV-BR-1-GM and IFNa into the inoculation sites approximately two and four days later. Cycles were administered every two weeks $\times 3$, and then monthly $\times$ 3. Immunologic responses were measured by delayed type hypersensitivity (DTH) after each inoculation. A similar regimen was used with SV-BR-1-GM in combination with pembrolizumab with cycles administered every three weeks. In the phase I/IIa trial, among 23 patients who underwent 1-8 cycles of treatment, tumor response was observed in three (13\%) of them, all of whom matched SV-BR-1-GM at least at one HLA allele. There were no related serious AEs. A measurable DTH response was present in 21 patients. Of patients who developed a DTH response and had at least one HLA match, the tumor regression rate was $33 \%$, and it was $67 \%$ for those with two HLA matches. In responders after treatment, blood lymphocytes showed increased cytokine secretion following stimulation with antigens expressed in SV-BR-1-GM. Twenty-one patients had expression of PD-L1 in identified circulating cancer-associated cells, and 
expression levels increased with treatment. Therefore, a combination study with pembrolizumab was initiated. Data on the first six patients show that the regimen is clinically active and safe. One patient with a robust DTH response had evidence of tumor regression in liver metastases. The study is ongoing and has been modified to evaluate the combination of PD-1 inhibitor INCMGA00012 with the IDO inhibitor epacadostat.

Spartalizumab

Spartalizumab (PDR001) is a humanized IgG4א moAb that binds PD-1 with subnanomolar activity in vitro ${ }^{[224,225]}$.

\section{Spartalizumab in mTNBC}

\section{A. Spartalizumab monotherapy}

In a phase I study, Japanese patients with advanced malignancies who progressed on standard therapy received spartalizumab in three dose groups. The most common cancer types were ovarian cancer (17\%), head and neck cancer (11\%), cervical cancer (11\%), and TNBC (11\%). Overall, ORR was $11 \%$ with partial responses seen in patients with hepatocellular carcinoma and transitional cell carcinoma ${ }^{[226]}$.

B. Spartalizumab in combination with monoclonal antibodies targeting other immune checkpoint molecules

In a phase I/II trial, ieramilimab (LAG525) plus spartalizumab was dosed at 15 dose levels/schedules in patients with various advanced malignancies, including TNBC. The combination produced durable responses in two out of five women with mTNBC. Furthermore, treatment with LAG525 plus spartalizumab resulted in immune profile modulation, i.e., a trend to convert the biomarker profiles from immune-cold to immune-activated in TNBC tumor biopsies ${ }^{[227]}$. Ieramilimab is a humanized moAb directed against the inhibitory lymphocyte activation gene-3 (LAG-3) receptor. LAG-3 is expressed on activated $\mathrm{CD}_{4}^{+}$and $\mathrm{CD}^{+}$ T cells, a subset of Tregs, NK cells, B cells, and plasmacytoid dendritic cells. This inhibitory receptor suppresses T-cell activation, proliferation, and homeostasis and has been reported to play a role in the suppressive function of Tregs ${ }^{[228-232]}$. Upon administration, ieramilimab binds to LAG-3 expressed on TILs and blocks its binding to MHC class II molecules that are expressed on tumor cells. Targeting LAG-3 with antagonistic moAbs may invigorate the immune response to cancer, while preclinical evidence supports promising synergy especially with simultaneous inhibition of the PD-1/PD-L1 pathway ${ }^{[229,230]}$.

C. Spartalizumab in combination with immunomodulating agents

A phase Ib/II study assessed lacnotuzumab with spartalizumab in patients with advanced/metastatic melanoma, endometrial cancer, pancreatic cancer, or $\mathrm{TNBC}^{[233]}$. Lacnotuzumab (MCS110) is a high affinity humanized moAb targeting CSF-1 and inhibiting CSF-1/CSF-1R interactions. Inappropriate overexpression of CSF-1/CSF-1R has been documented in breast, prostate, and ovarian cancer, as well as in Hodgkin's lymphoma. CSF-1R signaling was found to enhance the invasion and metastasis of solid tumors ${ }^{[234-237]}$. In malignant neoplasms, the increased activity of the CSF-1/CSF-1R axis leads to increased infiltration of the TME by TAMs which are important tumor-promoting cells, especially in breast cancer, stimulating tumor progression and mediating resistance to PD-1 inhibitors ${ }^{[231,235,238]}$. In the trial conducted by Calvo et al. ${ }^{[233]}$, lacnotuzumab was combined with spartalizumab at six dose levels. By RECIST 1.1 criteria, there was one PR, while the SD rate was $19 \%$. By iRECIST criteria, disease control rate was $27 \%$. The combination of 
lacnotuzumab with spartalizumab was well tolerated overall.

ADU-S100 (MIW815) is a synthetic cyclic dinucleotide agonist (activator) of stimulator of interferon genes (STINGs), a receptor crucial to activate the innate immune system. ADU-S100 (MIW815) activates all known human and mouse STINGs and effectively induces the expression of cytokines and chemokines, leading to a robust and durable antigen-specific T-cell-mediated immune response against cancer cells $^{[239-241]}$. In a phase Ib study, patients with metastatic cancers or lymphomas received intratumoral injections of ADU-S100 with intravenous spartalizumab at various doses/schedules ${ }^{[242]}$. No DLTs were reported during the first cycle at any dose level. The most common ( $\geq 5$ patients) treatment-related AEs were pain at the injection site, pyrexia, and diarrhea. PRs were observed in TNBC patients without prior exposure to anti-PD-1 treatment and in melanoma patients with recurrent/refractory disease to prior antiPD-1 treatment.

Selected current clinical trials with spartalizumab in combination with other agents in metastatic TNBC are presented in Table 7.

\section{Monoclonal antibodies targeting PD-L1}

\section{Avelumab}

Avelumab is a human IgG1 moAb that binds to PD-L1 and prevents its interaction with PD-1 ${ }^{[24-245]}$. It has been shown in vitro that avelumab may also trigger ADCC against a panel of TNBC cells independently of the blockade of the PD-1/PD-L1 axis, and its combination with immunomodulators such as IL-2 or IL-15 could increase the therapeutic efficacy of this immune checkpoint inhibitor ${ }^{[246]}$. The indications of avelumab include metastatic Merkel-cell carcinoma, locally advanced or metastatic urothelial carcinoma, and advanced renal cell carcinoma in combination with axitinib as first-line treatment ${ }^{[247-251]}$.

\section{Avelumab in early breast cancer: neoadjuvant and adjuvant setting}

In a pre-therapy proof of concept window study (IMpALA), patients with newly diagnosed TNBC will be treated with one cycle of avelumab either alone or in combination with aspirin ${ }^{[252]}$. Patients in both arms will also receive lansoprazole (a proton pump inhibitor). It is expected that the combination of avelumab and aspirin will shift the local tumor inflammatory microenvironment towards higher expression of markers associated with effector cytotoxic immunity and clinical benefit. This rationale is based on the knowledge that the production of the inflammatory lipid prostaglandin E2, via cyclooxygenase-2 activity of tumor cells, enables tumor growth through immune escape in pre-clinical models, including TNBC ${ }^{[253-255]}$.

In the adjuvant setting, the very interesting, investigator-driven, phase III A-BRAVE trial ${ }^{[256]}$ randomizes patients who completed treatment with radical intent for primary TNBC, including surgery and chemotherapy, to one year of treatment with avelumab vs. observation. The study enrolls patients in two strata. Patients are stratified to Stratum A if they have completed surgery followed by adjuvant chemotherapy and belong to the following stage categories: $\mathrm{pT}>5 \mathrm{~cm}$ and $\mathrm{pNo}, \mathrm{pT}>2 \mathrm{~cm}$ and $\mathrm{pN} 1$, and any $\mathrm{pT}$ with pN2. Patients are stratified to Stratum B if they have completed NACT followed by surgery and did not achieve pCR. Patients who also received additional adjuvant chemotherapy for no more than six months are eligible in Stratum B, after the completion of the adjuvant chemotherapy.

2. Avelumab in mTNBC: monotherapy and combinations with PARP inhibitors 
Table 7. Selected current clinical with spartalizumab in combination with other agents in metastatic TNBC

\begin{tabular}{|c|c|c|c|c|}
\hline $\begin{array}{l}\text { Study } \\
\text { identifier }\end{array}$ & $\begin{array}{l}\text { Type of } \\
\text { study }\end{array}$ & Study population & Regimen/treatment arms & Status \\
\hline NCT03499899 & $\begin{array}{l}\text { Randomized } \\
\text { Phase II }\end{array}$ & $\begin{array}{l}\text { Patients with advanced (loco-regionally recurrent not } \\
\text { amenable to curative therapy or metastatic) TNBC that } \\
\text { progressed after adjuvant or } 1 \text { prior systemic treatment } \\
\text { in the metastatic setting }\end{array}$ & $\begin{array}{l}\text { Arm 1: leramilimab (LAG525) } 400 \text { mg } \\
\text { + spartalizumab } 300 \text { mg, every } 3 \\
\text { weeks } \\
\text { Arm 2: leramilimab (LAG525) } 400 \text { mg } \\
\text { + spartalizumab } 300 \text { mg + carboplatin } \\
\text { AUCX6, every } 3 \text { weeks } \\
\text { Arm 3: leramilimab (LAG525) } 400 \text { mg } \\
\text { + carboplatin AUC } \times 6 \text {, every } 3 \text { weeks }\end{array}$ & $\begin{array}{l}\text { Active, not } \\
\text { recruiting }\end{array}$ \\
\hline NCT03742349 & Phase lb & $\begin{array}{l}\text { Patients with advanced/metastatic TNBC who have } \\
\text { received } \leq 2 \text { prior lines of standard taxane-based } \\
\text { chemotherapy }\end{array}$ & $\begin{array}{l}\text { Arm 1: Spartalizumab + ieramilimab } \\
\text { (LAG525) + NIR178 } \\
\text { Arm 2: Spartalizumab + ieramilimab } \\
\text { (LAG525) + capmatinib } \\
\text { Arm 3: Spartalizumab + ieramilimab } \\
\text { (LAG525) + lacnotuzumab (MCS110) } \\
\text { Arm 4: Spartalizumab + ieramilimab } \\
\text { (LAG525) + canakinumab }\end{array}$ & Recruiting \\
\hline
\end{tabular}

${ }^{a}$ The sponsor and the study steering committee decided to prematurely stop enrollment of subjects to Arm 1 after data review showed an increased treatment discontinuation rate due to progressive disease in Arm 1 as compared to Arms 2 and 3; ban orally bioavailable immune checkpoint inhibitor and antagonist of the adenosine A2A receptor (A2AR; ADORA2A) expressed on T lymphocytes; ${ }^{c}$ an orally bioavailable MET inhibitor; ${ }^{d}$ canakinumab (ACZ885) is a human anti-IL-1 $\beta$ monoclonal antibody.

In a phase Ib trial (JAVELIN) ${ }^{[55]}$, patients with metastatic breast cancer, including TNBC, refractory to or progressing after standard-of-care therapy were treated with single-agent avelumab. ORR was 3.0\% in the entire population and $5.2 \%$ in patients with mTNBC. A trend toward a higher ORR was seen in patients with PD-L1-positive vs. PD-L1-negative tumor-associated immune cells (16.7\% vs. $1.6 \%$ in the overall population and $22.2 \%$ vs. $2.6 \%$ in the TNBC subgroup). Treatment-related AEs of Grade $\geq 3$ were observed in $13.7 \%$ of patients, including two treatment-related deaths.

In another multicohort phase Ib/II trial (JAVELIN PARP Medley) ${ }^{[257]}$, avelumab was combined with the PARPi talazoparib. In the phase Ib study (Cohort 1), patients with advanced solid tumors who had received $\geq 1$ prior standard-of-care chemotherapy regimens were treated with avelumab in combination with oral talazoparib. The phase II study enrolled patients with either advanced/metastatic TNBC (Cohort 2A) or advanced/metastatic HR+, HER2-, DNA damage repair defect-positive BC (Cohort 2B). Patients in Cohort $2 \mathrm{~A}$ had received 0-2 prior chemotherapy regimens without progression on prior platinum-based treatment and patients in Cohort $2 \mathrm{~B}$ had received prior standard of care hormone therapy in either the adjuvant and/or metastatic setting followed by 0-2 prior chemotherapy regimens without progression on previous platinum-based treatment. Twelve patients with advanced cancers were treated in Cohort 1, including two patients with TNBC. Both patients with TNBC had a best overall response (BOR) of SD and remained on treatment for $\geq 9$ months. In Cohort $2 \mathrm{~A}, 12$ patients were evaluable for disease assessment; BOR was PR in one, SD in six, and PD in five. Adverse events of any grade occurred in 11 patients (91.7\%) in Cohort 1 and 18 (94.7\%) patients in Cohort 2A. In Cohort 2A, the most common AEs were anemia (57.9\%), nausea (26.3\%), fatigue $(21.1 \%)$, and thrombocytopenia $(21.1 \%)$.

Selected current clinical trials with avelumab in combination with other agents are presented in Table 8.

\section{Atezolizumab}

Atezolizumab (MPDL3280A) is a humanized IgG1 moAb that specifically binds to PD-L1 ${ }^{[258,259]}$ but does not affect the interaction of PD-1 with its alternative ligand PD-L2, which plays a key role in maintaining immune tolerance ${ }^{[260]}$. 
Table 8. Selected current clinical trials with avelumab in combination with other agents in metastatic TNBC

\begin{tabular}{|c|c|c|c|c|}
\hline $\begin{array}{l}\text { Study } \\
\text { identifier }\end{array}$ & Type of study & Study population & Regimen/treatment arms & Status \\
\hline NCT04360941 & $\begin{array}{l}\text { Phase lb } \\
\text { (PAveMenT) }\end{array}$ & $\begin{array}{l}\text { In Part A, patients with recurrent inoperable locally advanced or metastatic breast } \\
\text { cancer previously treated with one or two prior lines of chemotherapy for advanced } \\
\text { disease } \\
\text { In Part B, patients with AR-positive } \text { mTNBC }^{\text {a }} \text {. }\end{array}$ & Palbociclib + avelumab & Recruiting \\
\hline NCT03971409 & $\begin{array}{l}\text { Randomized Phase II } \\
\text { (InCITe) }\end{array}$ & $\begin{array}{l}\text { Patients with advanced/metastatic TNBC who have received } \leq 3 \text { prior lines of } \\
\text { chemotherapy and } \leq 1 \text { prior line of checkpoint inhibitor therapy in the metastatic setting }\end{array}$ & $\begin{array}{l}\text { Arm I: } 15 \text {-day lead-in of binimetinib }{ }^{b} \text { followed by binimetinib and } \\
\text { avelumab } \\
\text { Arm II: } 15 \text {-day lead-in of anti-OX } 40^{c} \text { antibody PF- } 04518600^{d} \text {, } \\
\text { followed by anti-OX } 40 \text { antibody PF- } 04518600 \text { and avelumab } \\
\text { Arm 3: } 15 \text {-day lead-in of utomilumab }{ }^{\mathrm{e}} \text {, followed by utomilumab and } \\
\text { avelumab }\end{array}$ & Recruiting \\
\hline NCT03861403 & Phase lb/Ila & $\begin{array}{l}\text { In Phase Ib, patients with advanced solid malignancies with at least one prior line of } \\
\text { systemic therapy for metastatic or locally advanced disease } \\
\text { In Phase lla, patients with mTNBC, } \mathrm{HR}^{f}+\text { breast cancer, } \mathrm{mCRPC}^{\mathrm{g}} \text {, and platinum } \\
\text { resistant ovarian cancer }\end{array}$ & TRX518 + cyclophosphamide intravenously + avelumab & $\begin{array}{l}\text { Active, not } \\
\text { recruiting }\end{array}$ \\
\hline NCT02630368 & $\begin{array}{l}\text { Phase I/II } \\
\text { (METROmaJX) }\end{array}$ & $\begin{array}{l}\text { Patients with advanced } \mathrm{HR}+\text { and triple negative breast cancer and advanced soft tissue } \\
\text { sarcoma }\end{array}$ & $\begin{array}{l}\text { Phase I: Intratumoral JX-594' + metronomic oral } \\
\text { cyclophosphamide } \\
\text { Phase II-First strategy } \\
\text { Sarcoma (randomized) } \\
\text { Arm 1: Metronomic oral cyclophosphamide } \\
\text { Arm 2: Intratumoral JX-594 + metronomic oral cyclophosphamide } \\
\text { Breast cancer } \\
\text { Intratumoral JX-594 + metronomic oral cyclophosphamide } \\
\text { Phase II-Second strategy } \\
\text { Intratumoral JX-594 + metronomic oral cyclophosphamide + } \\
\text { avelumab }\end{array}$ & Recruiting \\
\hline
\end{tabular}

${ }^{a}$ Androgen receptor; ${ }^{b}$ an orally bioavailable inhibitor of MEK1/2; ${ }^{c} \mathrm{OX} 40$ (CD134) is tumor necrosis factor receptor superfamily member 4 (TNFRSF4); ${ }^{\mathrm{d} a}$ humanized agonist IgG2 monoclonal antibody to OX40; utomilumab (PF-05082566) is a fully-human IgG2 agonist moAb that selectively binds 4-1BB/CD137 (tumor necrosis factor receptor superfamily member 9 , TNFRSF9), resulting in NF-KB activation and downstream cytokine production; hormone receptor; ${ }^{8}$ metastatic castration-resistant prostate cancer; ${ }^{\text {hTX }}$ T18A is a moAB that selectively binds glucocorticoid-induced TNF receptor (GITR) blocking the interaction of GITR with its ligand, thereby both inducing the activation of tumor-antigen-specific T effector cells and abrogating the suppression induced by inappropriately activated T regulatory cells: 'JX-594 (pexastimogene devacirepvec) is an oncolytic virus derived from a vaccinia vaccine strain that has been engineered to target cancer cells and expresses the therapeutic transgene GM-CSF in order to stimulate antitumor immunity.

1. Atezolizumab in the neoadjuvant and adjuvant setting: combinations with chemotherapy

In the ongoing phase III trial GeparDouze (NCT03281954/NSABP B-59/GBG96) ${ }^{[261,262]}$, TNBC patients are randomly allocated in 1:1 ratio to either atezolizumab or placebo concurrently with sequential regimens of weekly paclitaxel with carboplatin every three weeks for four cycles, followed by AC/EC every 2-3 weeks (per investigator's choice) for four cycles. After surgery, patients receive adjuvant atezolizumab or placebo for 6 months. Co-primary 
endpoints are EFS and pCR (ypTo/Tis ypNo).

In the neoadjuvant setting, the phase III NeoTRIPaPDL1/Michelangelo trial ${ }^{[263]}$ randomized 280 patients with TNBC to neoadjuvant carboplatin and nab-paclitaxel with or without atezolizumab. Neoadjuvant treatment was followed by surgery and then four cycles of an anthracycline-based adjuvant regimen. In contrast to KEYNOTE-522, the NeoTRIPaPDL1/Michelangelo trial did not report a favorable outcome with a neoadjuvant immune checkpoint inhibitor with respect to pCR. More specifically, the addition of atezolizumab to NACT for approximately six months resulted in slightly higher rates of pCR when compared to NACT alone in the intent-to-treat population ( $43.5 \% v s .40 .8 \%)$; however, the increase was not statistically significant. Among patients with PD-L1-positive tumors, pCR rates were $51.9 \%$ in the atezolizumab plus chemotherapy arm $v$ s. $48.0 \%$ in the NACT only arm, but this difference was also not significant.

The findings of the very recently published IMpassion031 trial ${ }^{[264]}$ are of particular interest because they deviate from those of the previously mentioned NeoTRIPaPDL1/Michelangelo trial. The double-blind, phase III, IMpassion031 trial randomized 455 patients with stage II/III TNBC to receive chemotherapy plus atezolizumab or placebo. More specifically, chemotherapy comprised 12 weekly doses of nab-paclitaxel followed by four cycles of doxorubicin plus cyclophosphamide. After the completion of neoadjuvant treatment, surgery followed. Among 333 eligible patients, pCR was documented in 95 (58\%) patients in the atezolizumab plus chemotherapy group and $69(41 \%)$ patients in the placebo plus chemotherapy group (difference rate $17 \%, 95 \% \mathrm{CI}$ : 6 -27; one-sided $P=0.0044$ ). In the PD-L1-positive population, pCR was observed in $53(69 \%)$ patients in the atezolizumab plus chemotherapy group vs. 37 (49\%) patients in the placebo plus chemotherapy group (difference rate $20 \%, 95 \% \mathrm{CI}$ : 4-35; one-sided $P=0.021$ ). AEs of Grade 3 or 4 were balanced between the two groups.

Finally, a large phase III trial randomizes patients with TNBC to NACT in combination with either atezolizumab or placebo. They will receive 12 doses of weekly paclitaxel plus carboplatin every three weeks, followed by four cycles of AC/EC every two or three weeks. Atezolizumab or placebo will be administered every three weeks during both phases of $\mathrm{NACT}^{[265]}$.

In the adjuvant setting, the phase III ALEXANDRA/IMpassiono30 trial ${ }^{[266]}$ randomizes patients with stage II or III TNBC to chemotherapy plus atezolizumab or chemotherapy alone. Adjuvant chemotherapy will consist of 12 doses of weekly paclitaxel followed by four cycles of a biweekly anthracycline plus cyclophosphamide regimen. Atezolizumab at $840 \mathrm{mg}$, every two weeks, will be given concomitantly with chemotherapy, and then at $1200 \mathrm{mg}$, every three weeks, until completion of one year of atezolizumab.

\section{Atezolizumab in mTNBC}

\section{A. Atezolizumab monotherapy}

A phase I trial (NCT01375842) evaluated atezolizumab in advanced treatment-refractory cancers ${ }^{[267]}$. Among 116 evaluable patients with TNBC, ORR was 24\% in first line and 6\% in second line or greater. Median duration of response was 21 months, while median PFS was 1.4 months by RECIST criteria and 1.9 months by iRECIST criteria. In first-line patients, median OS was 17.6 months. Patients with PD-L1 expression in $\geq 1 \%$ of tumor-infiltrating immune cells had higher ORR and longer OS than those with $<1 \%$ expression of PD-L1 (12\% and 10.1 months $v s .0 \%$ and 6.0 months, respectively). Adverse events occurred in $63 \%$ of patients and were of Grade 1 or 2 in the majority of them. 


\section{B. Atezolizumab with chemotherapy}

In a phase Ib trial, women with advanced/metastatic TNBC, who had received $\leq 2$ prior lines of chemotherapy in the metastatic setting, were treated with atezolizumab plus weekly nab-paclitaxel. ORR was $39.4 \%$ and DCR was 51.5\%. Median duration of response was 9.1 months. Median PFS and OS were 5.5 and 14.7 months, respectively. Concurrent nab-paclitaxel neither significantly changed biomarkers of the TME nor impaired atezolizumab systemic immune activation $^{[268]}$.

The phase III IMpassion 130 trial $^{[269]}$ evaluated the combination of nab-paclitaxel with atezolizumab as firstline treatment in patients with mTNBC. In total, 902 patients were randomly allocated in a 1:1 ratio to either nab-paclitaxel $100 \mathrm{mg} / \mathrm{m}^{2}$, on Days 1, 8, and 15, plus atezolizumab $840 \mathrm{mg}$, on Days 1, and 15, every four weeks, or corresponding placebo until disease progression or unacceptable treatment-related toxicities. Primary objectives were PFS and OS, for both the total patient population and PD-L1-positive patients (cutoff $\geq 1 \%$ ). In the ITT population, the investigator-assessed ORR was $56.0 \%$ in the intervention arm, as compared with $45.9 \%$ in the control arm $(P=0.002)$. Furthermore, $7.1 \%$ of the patients in the intervention arm had a CR, as compared with $1.6 \%$ in the control arm, respectively. In the PD-L1-positive subpopulation, ORR was $58.9 \%$ with atezolizumab plus nab-paclitaxel $v s .42 .6 \%$ with placebo plus nabpaclitaxel $(P=0.002)$, while the CR rate was $10.3 \%$ and only $1.1 \%$ in the intervention arm and control arm, respectively $(P=0.002)$.

At the first interim analysis ${ }^{[269]}$, in the ITT population, median PFS was 7.2 months with atezolizumab plus nab-paclitaxel, as compared with 5.5 months with placebo plus nab-paclitaxel (HR $=0.80$; 95\%CI: 0.69-0.92; $P=0.002)$. In the PD-L1-positive subpopulation, median PFS was 7.5 and 5.0 months for patients randomized to atezolizumab and placebo, respectively $(\mathrm{HR}=0.62 ; 95 \% \mathrm{CI}: 0.49-0.78 ; P<0.001)$. At the second interim analysis ${ }^{[270]}$, in the ITT population, median OS was 21.0 months with atezolizumab plus nabpaclitaxel, as compared with 18.7 months with placebo plus nab-paclitaxel $(\mathrm{HR}=0.86$; 95\%CI: 0.72-1.02; $P=$ 0.078). In the PD-L1-positive subpopulation, median OS was 25.0 and 18.0 months for patients randomized to atezolizumab and placebo, respectively $(\mathrm{HR}=0.62 ; 95 \% \mathrm{CI}: 0.49-0.78 ; P<0.001)$.

The most common AEs of Grade 3 or 4 included neutropenia in $8 \%$ of 453 patients in the atezolizumab arm vs. $8 \%$ of 437 patients in the placebo arm; peripheral neuropathy ( $6 \% v s .13 \%)$; decreased neutrophil count ( $5 \%$ vs. $4 \%)$; and fatigue ( $4 \%$ vs. $3 \%)$. Treatment-related deaths occurred in two $(<1 \%)$ patients in the atezolizumab arm (autoimmune hepatitis related to atezolizumab and septic shock related to nab-paclitaxel) and one $(<1 \%)$ patient in the placebo arm (hepatic failure). The data of IMpassion 130 confirm the results of the previously mentioned phase Ib trial conducted by Emens et al. ${ }^{[5]}$. Essentially, the results of IMpassion 130 provide evidence of the efficacy of atezolizumab in combination with nab-paclitaxel in patients with PD-L1-positive mTNBC. Therefore, patients' PD-L1 expression status on tumor-infiltrating immune cells must be taken into consideration when examining treatment options in this subtype of breast cancer characterized by particular therapeutic difficulties in the metastatic stage.

The subgroup analysis of Japanese patients who participated in the IMpassion130 study showed that the efficacy of atezolizumab plus nab-paclitaxel was consistent with that observed in the entire study population. In addition, safety results in the subgroup were consistent with those in the overall population, while Japanese patients had a lower incidence of AEs leading to treatment withdrawal than the overall population $^{[271]}$. In the context of IMpassion130, Adams et al. ${ }^{[272]}$ published data on patient-reported outcomes. The combination did not compromise patients' daily functioning or health-related quality of life or worsening treatment symptoms. Finally, a cost-effectiveness analysis of the first-line treatment with 
atezolizumab plus nab-paclitaxel for advanced/metastatic TNBC showed that the combination is not a costeffective choice in the United States and China ${ }^{[273]}$.

In contrast to IMpassion130, the phase III IMpassion131 trial ${ }^{[274]}$, which compared the efficacy and safety of first-line atezolizumab plus paclitaxel $v s$. placebo plus paclitaxel in patients with advanced/metastatic TNBC, did not meet statistical significance on its primary endpoint of $\mathrm{PFS}^{[275]}$.

Finally, the phase III IMpassion 132 trial $^{[276]}$ is of interest, which compares atezolizumab plus chemotherapy $v s$. placebo plus chemotherapy in patients with progressive disease $\leq 12$ months after completing chemotherapy for early TNBC. Investigators can choose as chemotherapy regimen either gemcitabine plus carboplatin or oral capecitabine. Stratification factors are visceral metastases, tumor PD-L1 status, and selected chemotherapy.

\section{Durvalumab}

Durvalumab (MEDI4736) is a fully human high-affinity $\operatorname{IgG} 1 \kappa$ moAb that binds to PD-L1 $1^{[277,278]}$. Durvalumab was granted accelerated approval by the FDA in May 2017 for the treatment of selected patients with locally advanced or metastatic urothelial carcinoma ${ }^{[279]}$. Durvalumab was approved by EMA for the treatment of patients with locally advanced, unresectable NSCLC, only if PD-L1 is expressed in $\geq 1 \%$ of tumor cells and there was no observable disease progression following platinum-based chemoradiation therapy ${ }^{[280]}$. Durvalumab has recently been approved by the FDA for use in combination with etoposide and a platinum analog as first-line treatment for patients with extensive-stage SCLC ${ }^{[281]}$.

1. Durvalumab in the neoadjuvant setting: combinations with chemotherapy

A phase I/II trial evaluated the safety and efficacy of concurrent durvalumab with weekly nab-paclitaxel followed by four cycles of dose dense doxorubicin plus cyclophosphamide as neoadjuvant therapy for TNBC. The phase I part of the trial assessed two dose levels of durvalumab. No dose limiting toxicities occurred during this phase I part, and the final overall pCR rate was $44 \%$. In the PD-L1-positive and PD-L1negative groups, the $\mathrm{pCR}$ rates were $55 \%$ and $21 \%$, respectively $(P=0.03)^{[282]}$.

In the neoadjuvant setting, the GeparNuevo phase II trial ${ }^{[283]}$ randomized patients with TNBC to durvalumab or placebo, administered every four weeks, with concomitant weekly nab-paclitaxel followed by four cycles of biweekly epirubicin plus cyclophosphamide. In the window phase, one dose of durvalumab or placebo alone was given two weeks before nab-paclitaxel was started. The pCR rates in the durvalumab and placebo arm were $53.4 \%$ and $44.2 \%$, respectively. Of note, durvalumab effect was observed only in the window cohort ( $\mathrm{pCR} 61.0 \%$ vs. $41.4 \%, P=0.03$ ). In both arms, statistically significantly higher $\mathrm{pCR}$ rates were observed in tumors with higher stromal TILs. Furthermore, there was a trend for increased response in PD-L1-positive tumors, which was statistically significant for PD-L1-positive tumor cells in the durvalumab $\operatorname{arm}(P=0.045)$ and for PD-L1-positive immune cells in the placebo arm $(P=0.040)$. The most common immune-related AE of any grade was thyroid dysfunction.

The phase II PANDoRA trial ${ }^{[284]}$ will randomize patients with TNBC into two treatment arms. Patients in both arms will receive two doses of durvalumab followed by a biopsy, and then they will receive durvalumab with weekly paclitaxel and carboplatin. In Arm B, patients will also receive radiation (24 Gy total) starting with the second durvalumab dose every other day (8 Gy per fraction) for one week. After neoadjuvant treatment, patients will undergo breast surgery and continue on to physician's choices standard-of-care treatment during the three-year follow-up period. 
The open-label, multicenter, phase IIa PHOENIX ${ }^{[285]}$ trial randomizes patients to multiple non-comparative treatment cohorts. The trial consists of two parts: a post-NACT, preoperative window of opportunity component (Part 1) and a postoperative component (Part 2). PHOENIX trial aims to assess whether shortterm exposure to a DNA damage response inhibitor and/or anti-PD-L1 immunotherapy in a preoperative window of opportunity in patients with post-NACT high residual disease load generates a signal of antitumor biological activity within residual TNBC tissue. Patients in Cohort A will receive standard-of-care treatment. Patients in Cohort B will receive AZD6738, preoperatively after NACT in Part 1, and AZD6738, as adjuvant treatment for 12 months in Part 2. AZD6738 (ceralasertib) is an orally available ATR kinase inhibitor that blocks the downstream phosphorylation of CHK1. This prevents ATR-mediated signaling and results in the inhibition of DNA damage checkpoint activation, disruption of DNA damage repair, and induction of tumor cell apoptosis. Furthermore, AZD6738 sensitizes tumor cells to chemotherapy and radiotherapy ${ }^{[286]}$. Finally, patients in Cohort $\mathrm{C}$ of this trial will receive in Part 1 preoperatively olaparib and in Part 2 adjuvant olaparib for 12 months, while in Cohort D they will receive in Part 1 preoperatively durvalumab and in Part 2 durvalumab for 12 months.

Another ongoing phase Ib/II trial (B-IMMUNE) ${ }^{[287]}$ is evaluating in its phase $\mathrm{Ib}$ part the safety and tolerability of durvalumab in combination with a dose dense epirubicin plus cyclophosphamide regimen in the neoadjuvant setting (patients with $\mathrm{cT} 1-\mathrm{cT} 4$ any $\mathrm{N}, \mathrm{Mo}$, luminal B or triple negative breast cancer).

\section{Durvalumab in mTNBC}

\section{A. Durvalumab monotherapy as maintenance}

The SAFIR02 trial ${ }^{[288]}$ enrolled patients with HER2-negative $\mathrm{mBC}$ eligible for first- or second-line chemotherapy. After 6-8 cycles of induction chemotherapy, patients who present an actionable genomic alteration were randomized between targeted therapies and continuation of maintenance chemotherapy, and patients without actionable alterations were randomized between durvalumab for two years and maintenance chemotherapy. The substudy SAFIR02-Immuno trial ${ }^{[28]}$ enrolled 199 patients (HR+ disease $53.4 \%$, TNBC $45.5 \%$ ) and was powered to show an increment in median PFS of durvalumab over chemotherapy. Median PFS with durvalumab was 2.7 months vs. 4.6 months with chemotherapy, at the expense of an increase in the incidence of serious AEs. No subgroup seemed to benefit from immunotherapy. However, median OS was 21.7 months with durvalumab vs. 17.9 months with chemotherapy. This numerical superiority should be attributed to the TNBC and PD-L1-positive subpopulations that appeared to benefit more from durvalumab in the exploratory subgroup analyses. Furthermore, in patients with TNBC, the HR for durvalumab efficacy (OS) was 0.18 for those with CD274 gain/amplification.

\section{B. Durvalumab with other agents}

a. Durvalumab with chemotherapy

A phase I/II clinical trial is testing the safety and efficacy of durvalumab in combination with paclitaxel. Thus far, among evaluable patients, the ORR was $42 \%$ with a median duration of 7.1 months and DCR of $67 \%{ }^{[290]}$. 
b. Durvalumab in combination with other immune checkpoint inhibitors

The combination of durvalumab and tremelimumab is described above in the "Tremelimumab" Section ${ }^{[85]}$.

c. Durvalumab with molecular-targeted agents

A phase I study tested in a $3+3$ dose escalation the combination of cediranib with durvalumab and olaparib ${ }^{[291]}$. Cediranib is an oral VEGFR1-3 kinases inhibitor ${ }^{[292]}$. Angiogenesis pathways interact with both DNA repair mechanisms and immune activity. Tumor hypoxia causes downregulation of genes involved in DNA repair, e.g., RAD51 and BRCA1, leading to further DNA damage, genomic instability, and cell death $^{[293,294]}$. Thus, combining inhibition of DNA repair and angiogenesis pathways may modulate the immune response by increasing DNA damage and tumor mutational burden and attenuating immunosuppressive microenvironments. In this above-mentioned phase I study, which enrolled patients with various malignancies, including TNBC, the recommended phase II dose was tolerable and had preliminary antitumor activity. PD-L1 expression on tumor cells correlated with clinical benefit, but cytokines and peripheral immune subsets did not.

In the phase I/II basket trial MEDIOLA ${ }^{[295]}$, which evaluated the combination of durvalumab with olaparib, patients with various metastatic solid tumors were enrolled into four initial cohorts: germline BRCAmutated, metastatic breast cancer; germline $B R C A$-mutated, metastatic ovarian cancer; metastatic gastric cancer; and relapsed SCLC. Patients with HER2-negative $\mathrm{mBC}$ who had received $\leq 2$ previous lines of chemotherapy in the metastatic setting were treated with oral olaparib for four weeks, and thereafter with the combination of olaparib plus durvalumab. Among 34 patients enrolled in the study, 16 (47\%) had HRpositive breast cancer and 18 (53\%) TNBC. Objective responses at Week 12 were observed in 19 (63\%) patients including one (3\%) complete response. DCR at Weeks 12 and 28 was $80 \%$ and 50\%, respectively.

\section{CONCLUSION}

In the present article, we review major issues related to the development and current use of ICIs in TNBC. Furthermore, we summarize the perspectives on the use of these agents by citing data from active/recruiting trials. Although immunotherapy with ICIs has shown promising results in a variety of malignancies, in mTNBC, i.e., the subtype of breast cancer with the worst outcome, the response rates to single-agent immune checkpoint inhibitors are very modest, especially when administered to unselected patients. Recent research in TNBC, which is recognized as the most immunogenic among the other breast cancer subtypes, has focused on discovering predictive biomarkers to optimize the use of ICIs, strategies that will make the tumor microenvironment more susceptible to anti-PD(L)-1 treatment, as well other immunotherapeutic strategies beyond ICIs. Clinical trials have established the role of PD-1/PD-L1 inhibition in the first-line treatment in combination with chemotherapy, and atezolizumab plus nab-paclitaxel is the first FDAapproved immunotherapy regimen for breast cancer. In addition to chemotherapy, the combination of ICIs with molecular-targeted agents, including PARP and MEK inhibitors, or with other immunotherapeutic approaches, such as targeting new immune checkpoint targets (LAG-3, TIGIT, VISTA, etc.), cancer vaccines, or immunomodulating agents, appears to have the potential to increase their clinical benefit in TNBC. In addition, in the context of immunogenic cell death, of particular interest is the combination of ICIs with local therapies (radiotherapy and cryotherapy) in both neoadjuvant and metastatic settings.

\section{DECLARATIONS}

\section{Authors' contributions}

The collection of data for this review, the writing of the manuscript and its final approval: Papadimitriou M, 
Liakouli Z, Papadimitriou CA

\section{Availability of data and materials}

Not applicable.

\section{Financial support and sponsorship}

None.

\section{Conflicts of interest}

Papadimitriou CA has received speaker honoraria and honoraria for consultancy in advisory boards from Novartis, AstraZeneca, Genesis, MSD, Amgen, Merck and Roche and research grants from BMS and Roche. The other authors declared that there are no conflicts of interest.

\section{Ethical approval and consent to participate}

Not applicable.

\section{Consent for publication}

Not applicable.

\section{Copyright}

(c) The Author(s) 2021.

\section{REFERENCES}

1. Foulkes WD, Smith IE, Reis-Filho JS. Triple-negative breast cancer. $N$ Engl J Med 2010;363:1938-48. DOI PubMed

2. Curigliano G, Goldhirsch A. The triple-negative subtype: new ideas for the poorest prognosis breast cancer. J Natl Cancer Inst Monogr 2011;2011:108-10. DOI PubMed

3. Genome Atlas Network. Comprehensive molecular portraits of human breast tumours. Nature 2012;490:61-70. DOI PubMed PMC

4. Penault-Llorca F, Viale G. Pathological and molecular diagnosis of triple-negative breast cancer: a clinical perspective. Ann Oncol 2012;23 Suppl 6:vi19-22. DOI PubMed

5. Papadimitriou M, Mountzios G, Papadimitriou CA. The role of PARP inhibition in triple-negative breast cancer: unraveling the wide spectrum of synthetic lethality. Cancer Treat Rev 2018;67:34-44. DOI PubMed

6. Dent R, Trudeau M, Pritchard KI, et al. Triple-negative breast cancer: clinical features and patterns of recurrence. Clin Cancer Res 2007;13:4429-34. DOI PubMed

7. Li X, Yang J, Peng L, et al. Triple-negative breast cancer has worse overall syrvival and cause-specific survival than non-triplenegative breast cancer. Breast Cancer Res Treat 2017;161:279-87. DOI PubMed

8. Narang P, Chen M, Sharma AA, Anderson KS, Wilson MA. The neoepitope landscape of breast cancer: implications for immunotherapy. BMC Cancer 2019;19:200. DOI PubMed PMC

9. Kim I, Sanchez K, Mcarthur HL, Page D. Immunotherapy in triple-negative breast cancer: present and future. Curr Breast Cancer Rep 2019;11:259-71. DOI

10. Lehmann BD, Bauer JA, Chen X, et al. Identification of human triple-negative breast cancer subtypes and preclinical models for selection of targeted therapies. J Clin Invest 2011;121:2750-67. DOI PubMed PMC

11. Burstein MD, Tsimelzon A, Poage GM, et al. Comprehensive genomic analysis identifies novel subtypes and targets of triplenegative breast cancer. Clin Cancer Res 2015;21:1688-98. DOI PubMed PMC

12. Jézéquel P, Loussouarn D, Guérin-Charbonnel C, et al. Gene-expression molecular subtyping of triple-negative breast cancer tumours: importance of immune response. Breast Cancer Res 2015;17:43. DOI PubMed PMC

13. Ahn SG, Kim SJ, Kim C, Jeong J. Molecular classification of triple-negative breast cancer. J Breast Cancer 2016;19:223-30. DOI PubMed PMC

14. Gonzalez-Angulo AM, Timms KM, Liu S, et al. Incidence and outcome of BRCA mutations in unselected patients with triple receptor-negative breast cancer. Clin Cancer Res 2011;17:1082-9. DOI PubMed PMC

15. Hartman AR, Kaldate RR, Sailer LM, et al. Prevalence of BRCA mutations in an unselected population of triple-negative breast cancer. Cancer 2012;118:2787-95. DOI PubMed

16. Sharma P, Klemp JR, Kimler BF, et al. Germline BRCA mutation evaluation in a prospective triple-negative breast cancer registry: implications for hereditary breast and/or ovarian cancer syndrome testing. Breast Cancer Res Treat 2014;145:707-14. DOI PubMed PMC

17. Couch FJ, Hart SN, Sharma P, et al. Inherited mutations in 17 breast cancer susceptibility genes among a large triple-negative breast cancer cohort unselected for family history of breast cancer. J Clin Oncol 2015;33:304-11. DOI PubMed PMC 
18. Pellegrino B, Musolino A, Llop-Guevara A, et al. Homologous recombination repair deficiency and the immune response in breast cancer: a literature review. Transl Oncol 2020;13:410-22. DOI PubMed PMC

19. Wen WX, Leong CO. Association of BRCA1- and BRCA2-deficiency with mutation burden, expression of PD-L1/PD-1, immune infiltrates, and T cell-inflamed signature in breast cancer. PLoS One 2019;14:e0215381. DOI PubMed PMC

20. Nik-Zainal S, Davies H, Staaf J, et al. Landscape of somatic mutations in 560 breast cancer whole-genome sequences. Nature 2016;534:47-54. DOI PubMed PMC

21. Budczies J, Bockmayr M, Denkert C, et al. Classical pathology and mutational load of breast cancer - integration of two worlds. $J$ Pathol Clin Res 2015;1:225-38. DOI PubMed PMC

22. Luen S, Virassamy B, Savas P, Salgado R, Loi S. The genomic landscape of breast cancer and its interaction with host immunity. Breast 2016;29:241-50. DOI PubMed

23. Samstein RM, Lee CH, Shoushtari AN, et al. Tumor mutational load predicts survival after immunotherapy across multiple cancer types. Nat Genet 2019;51:202-6. DOI PubMed PMC

24. Goodman AM, Kato S, Bazhenova L, et al. Tumor mutational burden as an independent predictor of response to immunotherapy in diverse cancers. Mol Cancer Ther 2017;16:2598-608. DOI PubMed PMC

25. Loi S, Michiels S, Salgado R, et al. Tumor infiltrating lymphocytes are prognostic in triple negative breast cancer and predictive for trastuzumab benefit in early breast cancer: results from the FinHER trial. Ann Oncol 2014;25:1544-50. DOI PubMed

26. Salgado R, Denkert C, Demaria S, et al; International TILs Working Group 2014. The evaluation of tumor-infiltrating lymphocytes (TILs) in breast cancer: recommendations by an International TILs Working Group 2014. Ann Oncol 2015;26:259-71. DOI PubMed PMC

27. Denkert C, von Minckwitz G, Darb-esfahani S, et al. Tumour-infiltrating lymphocytes and prognosis in different subtypes of breast cancer: a pooled analysis of 3771 patients treated with neoadjuvant therapy. Lancet Oncol 2018;19:40-50. DOI PubMed

28. Stanton SE, Adams S, Disis ML. Variation in the incidence and magnitude of tumor-infiltrating lymphocytes in breast cancer subtypes: a systematic review. JAMA Oncol 2016;2:1354-60. DOI PubMed

29. Beckers RK, Selinger CI, Vilain R, et al. Programmed death ligand 1 expression in triple-negative breast cancer is associated with tumour-infiltrating lymphocytes and improved outcome. Histopathology 2016;69:25-34. DOI PubMed

30. Mittendorf EA, Philips AV, Meric-Bernstam F, et al. PD-L1 expression in triple-negative breast cancer. Cancer Immunol Res 2014;2:361-70. DOI PubMed PMC

31. U.S. Food \& Drug. FDA approves atezolizumab for PD-L1 positive unresectable locally advanced or metastatic triple-negative breast cancer. Available from: https://www.fda.gov/drugs/drug-approvals-and-databases/fda-approves-atezolizumab-pd-11-positiveunresectable-locally-advanced-or-metastatic-triple-negative [Last accessed on 6 Aug 2021].

32. Vivier E, Artis D, Colonna M, et al. Innate lymphoid cells: 10 Years On. Cell 2018;174:1054-66. DOI PubMed

33. Demaria O, Cornen S, Daëron M, Morel Y, Medzhitov R, Vivier E. Harnessing innate immunity in cancer therapy. Nature 2019;574:45-56. DOI PubMed

34. Bonilla FA, Oettgen HC. Adaptive immunity. J Allergy Clin Immunol 2010;125:S33-40. DOI PubMed

35. Emens LA. Breast cancer immunobiology driving immunotherapy: vaccines and immune checkpoint blockade. Expert Rev Anticancer Ther 2012;12:1597-611. DOI PubMed PMC

36. Emens LA. Breast cancer immunotherapy: facts and hopes. Clin Cancer Res 2018;24:511-20. DOI PubMed PMC

37. Smyth MJ, Dunn GP, Schreiber RD. Cancer immunosurveillance and immunoediting: the roles of immunity in suppressing tumor development and shaping tumor immunogenicity. Adv Immunol 2006;90:1-50. DOI PubMed

38. DeNardo DG, Coussens LM. Inflammation and breast cancer. Balancing immune response: crosstalk between adaptive and innate immune cells during breast cancer progression. Breast Cancer Res 2007;9:212. DOI PubMed PMC

39. Coussens LM, Pollard JW. Leukocytes in mammary development and cancer. Cold Spring Harb Perspect Biol 2011;3:a003285. DOI PubMed PMC

40. DeNardo DG, Barreto JB, Andreu P, et al. CD4(+) T cells regulate pulmonary metastasis of mammary carcinomas by enhancing protumor properties of macrophages. Cancer Cell 2009;16:91-102. DOI PubMed PMC

41. Ribas A. Adaptive immune resistance: how cancer protects from immune attack. Cancer Discov 2015;5:915-9. DOI PubMed PMC

42. Allard B, Beavis PA, Darcy PK, Stagg J. Immunosuppressive activities of adenosine in cancer. Curr Opin Pharmacol 2016;29:7-16. DOI PubMed

43. Ho PC, Kaech SM. Reenergizing T cell anti-tumor immunity by harnessing immunometabolic checkpoints and machineries. Curr Opin Immunol 2017;46:38-44. DOI PubMed PMC

44. Zhang H, Chen J. Current status and future directions of cancer immunotherapy. J Cancer 2018;9:1773-81. DOI PubMed PMC

45. Munhoz RR, Postow MA. Recent advances in understanding antitumor immunity. F1000Res 2016;5:2545. DOI PubMed PMC

46. Dustin ML. Cancer immunotherapy: killers on sterols. Nature 2016;531:583-4. DOI PubMed

47. Park J, Kwon M, Shin EC. Immune checkpoint inhibitors for cancer treatment. Arch Pharm Res 2016;39:1577-87. DOI PubMed

48. Khalil DN, Smith EL, Brentjens RJ, Wolchok JD. The future of cancer treatment: immunomodulation, CARs and combination immunotherapy. Nat Rev Clin Oncol 2016;13:273-90. DOI PubMed PMC

49. of cancer immunotherapy from the bench to the bedside. Adv Cancer Res 2019;143:1-62. DOI PubMed

50. Mir MA. Chapter 1. Introduction to costimulation and costimulatory molecules. In: Mir MA, Editor. Developing costimulatory molecules for immunotherapy of diseases. Cambridge, Massachusetts: Academic Press; 2015. p. 1-43. DOI

51. Esfahani K, Roudaia L, Buhlaiga N, Del Rincon SV, Papneja N, Miller WH Jr. A review of cancer immunotherapy: from the past, to the present, to the future. Curr Oncol 2020;27:S87-97. DOI PubMed PMC 
52. Adams S, Gatti-Mays ME, Kalinsky K, et al. Current landscape of immunotherapy in breast cancer: a review. JAMA Oncol 2019;5:1205-14. DOI PubMed

53. Mina LA, Lim S, Bahadur SW, Firoz AT. Immunotherapy for the treatment of breast cancer: emerging new data. Breast Cancer (Dove Med Press) 2019;11:321-8. DOI PubMed PMC

54. Nanda R, Chow LQ, Dees EC, et al. Pembrolizumab in patients with advanced triple-negative breast cancer: phase Ib KEYNOTE012 study. J Clin Oncol 2016;34:2460-7. DOI PubMed PMC

55. Dirix LY, Takacs I, Jerusalem G, et al. Avelumab, an anti-PD-L1 antibody, in patients with locally advanced or metastatic breast cancer: a phase 1b JAVELIN solid tumor study. Breast Cancer Res Treat 2018;167:671-86. DOI PubMed PMC

56. Emens LA, Cruz C, Eder JP, et al. Long-term clinical outcomes and biomarker analyses of atezolizumab therapy for patients with metastatic triple-negative breast cancer: a phase 1 study. JAMA Oncol 2019;5:74-82. DOI PubMed PMC

57. Adams S, Loi S, Toppmeyer DL, et al. KEYNOTE-086 cohort B: pembrolizumab monotherapy for PD-L1-positive, previously untreated, metastatic triple-negative breast cancer (mTNBC). Cancer Res 2018;78(4 Suppl):abstract nr PD6-10. DOI

58. Galluzzi L, Buqué A, Kepp O, Zitvogel L, Kroemer G. Immunogenic cell death in cancer and infectious disease. Nat Rev Immunol 2017;17:97-111. DOI PubMed

59. Garg AD, More S, Rufo N, et al. Trial watch: immunogenic cell death induction by anticancer chemotherapeutics. Oncoimmunology 2017;6:e1386829. DOI PubMed PMC

60. Alegre ML, Frauwirth KA, Thompson CB. T-cell regulation by CD28 and CTLA-4. Nat Rev Immunol 2001;1:220-8. DOI PubMed

61. der Merwe PA, Dushek O. Mechanisms for T cell receptor triggering. Nat Rev Immunol 2011;11:47-55. DOI

62. Ribas A, Wolchok JD. Cancer immunotherapy using checkpoint blockade. Science 2018;359:1350-5. DOI PubMed PMC

63. Chambers CA, Kuhns MS, Egen JG, Allison JP. CTLA-4-mediated inhibition in regulation of T cell responses: mechanisms and manipulation in tumor immunotherapy. Аппи Rev Immunol 2001;19:565-94. DOI PubMed

64. Egen JG, Kuhns MS, Allison JP. CTLA-4: new insights into its biological function and use in tumor immunotherapy. Nat Immunol 2002;3:611-8. DOI PubMed

65. Parry RV, Chemnitz JM, Frauwirth KA, et al. CTLA-4 and PD-1 receptors inhibit T-cell activation by distinct mechanisms. Mol Cell Biol 2005;25:9543-53. DOI PubMed PMC

66. Buchbinder EI, Desai A. CTLA-4 and PD-1 pathways: similarities, differences, and implications of their inhibition. Am J Clin Oncol 2016;39:98-106. DOI PubMed PMC

67. Linsley PS, Bradshaw J, Greene J, Peach R, Bennett KL, Mittler RS. Intracellular trafficking of CTLA-4 and focal localization towards sites of TCR engagement. Immunity 1996;4:535-43. DOI PubMed

68. Krummel MF, Allison JP. CD28 and CTLA-4 have opposing effects on the response of T cells to stimulation. J Exp Med 1995;182:459-65. DOI PubMed PMC

69. Leach DR, Krummel MF, Allison JP. Enhancement of antitumor immunity by CTLA-4 blockade. Science 1996;271:1734-6. DOI PubMed

70. Hodi FS, O'Day SJ, McDermott DF, et al. Improved survival with ipilimumab in patients with metastatic melanoma. $N$ Engl J Med 2010;363:711-23. DOI PubMed PMC

71. European Medicines Agency. Yervoy. Available from: https://www.ema.europa.eu/en/medicines/human/EPAR/yervoy [Last accessed on 6 Aug 2021].

72. Kleef R, Moss R, Szasz AM, Bohdjalian A, Bojar H, Bakacs T. Complete clinical remission of stage IV triple-negative breast cancer lung metastasis administering low-dose immune checkpoint blockade in combination with hyperthermia and interleukin-2. Integr Cancer Ther 2018;17:1297-303. DOI PubMed PMC

73. McArthur HL, Diab A, Page DB, et al. A pilot study of preoperative single-dose ipilimumab and/or cryoablation in women with early-stage breast cancer with comprehensive immune profiling. Clin Cancer Res 2016;22:5729-37. DOI PubMed PMC

74. McArthur H, Comen E, Bryce Y, et al. A randomized phase 2 study of peri-operative ipilimumab, nivolumab and cryoablation versus standard care in women with residual, early stage/resectable, triple negative breast cancer after standard-of-care neoadjuvant chemotherapy. Cancer Res 2020;80(4 Suppl):abstract nr OT1-01. DOI

75. Australian New Zealand Clinical Trials Registry. Available from: https://www.anzctr.org.au/Trial/Registration/TrialReview.aspx?id=367255 [Last accessed on 6 Aug 2021].

76. Barroso-sousa R, Trippa L, Lange P, et al. Nimbus: a phase II study of nivolumab plus ipilimumab in metastatic hypermutated HER2negative breast cancer. J Clin Oncol 2019;37:TPS1115. DOI

77. Hanson DC, Canniff PC, Primiano MJ, et al. Preclinical in vitro characterization of anti-CTLA4 therapeutic antibody CP-675,206. Abstract 3802. Cancer Res 2004;64(7 Supplement):877. DOI

78. Canniff PC, Donovan CB, Burkwit JJ, et al. CP-675,206 anti-CTLA4 antibody clinical candidate enhances IL-2 production in cancer patient T cells in vitro regardless of tumor type or stage of disease. Cancer Res 2004;64(7 Supplement):164.

79. Comin-Anduix B, Escuin-Ordinas H, Ibarrondo FJ. Tremelimumab: research and clinical development. Onco Targets Ther 2016;9:1767-76. DOI PubMed PMC

80. He M, Chai Y, Qi J, et al. Remarkably similar CTLA-4 binding properties of therapeutic ipilimumab and tremelimumab antibodies. Oncotarget 2017;8:67129-39. DOI PubMed PMC

81. Ribas A, Camacho LH, Lopez-Berestein G, et al. Antitumor activity in melanoma and anti-self responses in a phase I trial with the anti-cytotoxic T lymphocyte-associated antigen 4 monoclonal antibody CP-675,206. J Clin Oncol 2005;23:8968-77. DOI PubMed

82. Camacho LH, Antonia S, Sosman J, et al. Phase I/II trial of tremelimumab in patients with metastatic melanoma. J Clin Oncol 2009;27:1075-81. DOI PubMed 
83. Kirkwood JM, Lorigan P, Hersey P, et al. Phase II trial of tremelimumab (CP-675,206) in patients with advanced refractory or relapsed melanoma. Clin Cancer Res 2010;16:1042-8. DOI PubMed

84. Ribas A, Kefford R, Marshall MA, et al. Phase III randomized clinical trial comparing tremelimumab with standard-of-care chemotherapy in patients with advanced melanoma. J Clin Oncol 2013;31:616-22. DOI PubMed PMC

85. Santa-Maria CA, Kato T, Park JH, et al. A pilot study of durvalumab and tremelimumab and immunogenomic dynamics in metastatic breast cancer. Oncotarget 2018;9:18985-96. DOI PubMed PMC

86. Reits EA, Hodge JW, Herberts CA, et al. Radiation modulates the peptide repertoire, enhances MHC class I expression, and induces successful antitumor immunotherapy. J Exp Med 2006;203:1259-71. DOI PubMed PMC

87. Sharabi AB, Nirschl CJ, Kochel CM, et al. Stereotactic radiation therapy augments antigen-specific PD-1-mediated antitumor immune responses via cross-presentation of tumor antigen. Cancer Immunol Res 2015;3:345-55. DOI PubMed PMC

88. Lugade AA, Moran JP, Gerber SA, Rose RC, Frelinger JG, Lord EM. Local radiation therapy of B16 melanoma tumors increases the generation of tumor antigen-specific effector cells that traffic to the tumor. J Immunol 2005; 174:7516-23. DOI PubMed

89. Chakraborty M, Abrams SI, Camphausen K, et al. Irradiation of tumor cells up-regulates Fas and enhances CTL lytic activity and CTL adoptive immunotherapy. J Immunol 2003;170:6338-47. DOI PubMed

90. Matsumura S, Wang B, Kawashima N, et al. Radiation-induced CXCL16 release by breast cancer cells attracts effector T cells. $J$ Immunol 2008;181:3099-107. DOI PubMed PMC

91. Jiang DM, Fyles A, Nguyen LT, et al. Phase I study of local radiation and tremelimumab in patients with inoperable locally recurrent or metastatic breast cancer. Oncotarget 2019;10:2947-58. DOI PubMed PMC

92. Ishida Y, Agata Y, Shibahara K, Honjo T. Induced expression of PD-1, a novel member of the immunoglobulin gene superfamily, upon programmed cell death. EMBO J 1992;11:3887-95. PubMed PMC

93. Nishimura H, Nose M, Hiai H, Minato N, Honjo T. Development of lupus-like autoimmune diseases by disruption of the PD-1 gene encoding an ITIM motif-carrying immunoreceptor. Immunity 1999;11:141-51. DOI PubMed

94. Seidel JA, Otsuka A, Kabashima K. Anti-PD-1 and anti-CTLA-4 therapies in cancer: mechanisms of action, efficacy, and limitations. Front Oncol 2018;8:86. DOI PubMed PMC

95. Agata Y, Kawasaki A, Nishimura H, et al. Expression of the PD-1 antigen on the surface of stimulated mouse T and B lymphocytes. Int Immunol 1996;8:765-72. DOI PubMed

96. Kinter AL, Godbout EJ, McNally JP, et al. The common gamma-chain cytokines IL-2, IL-7, IL-15, and IL-21 induce the expression of programmed death-1 and its ligands. J Immunol 2008;181:6738-46. DOI PubMed

97. Thibult ML, Mamessier E, Gertner-Dardenne J, et al. PD-1 is a novel regulator of human B-cell activation. Int Immunol 2013;25:12937. DOI PubMed

98. Lim TS, Chew V, Sieow JL, et al. PD-1 expression on dendritic cells suppresses CD8 ${ }^{+} \mathrm{T}$ cell function and antitumor immunity. Oncoimmunology 2016;5:e1085146. DOI PubMed PMC

99. Dong H, Zhu G, Tamada K, Chen L. B7-H1, a third member of the B7 family, co-stimulates T-cell proliferation and interleukin-10 secretion. Nat Med 1999;5:1365-9. DOI PubMed

100. Sugiura D, Maruhashi T, Okazaki IM, et al. Restriction of PD-1 function by cis-PD-L1/CD80 interactions is required for optimal T cell responses. Science 2019;364:558-66. DOI PubMed

101. Chemnitz JM, Parry RV, Nichols KE, June CH, Riley JL. SHP-1 and SHP-2 associate with immunoreceptor tyrosine-based switch motif of programmed death 1 upon primary human $\mathrm{T}$ cell stimulation, but only receptor ligation prevents $\mathrm{T}$ cell activation. J Immunol 2004;173:945-54. DOI PubMed

102. Sheppard KA, Fitz LJ, Lee JM, et al. PD-1 inhibits T-cell receptor induced phosphorylation of the ZAP70/CD3zeta signalosome and downstream signaling to PKCtheta. FEBS Lett 2004;574:37-41. DOI PubMed

103. Patsoukis N, Brown J, Petkova V, Liu F, Li L, Boussiotis VA. Selective effects of PD-1 on Akt and Ras pathways regulate molecular components of the cell cycle and inhibit T cell proliferation. Sci Signal 2012;5:ra46. DOI PubMed PMC

104. Hui E, Cheung J, Zhu J, et al. T cell costimulatory receptor CD28 is a primary target for PD-1-mediated inhibition. Science 2017;355:1428-33. DOI PubMed PMC

105. Carter L, Fouser LA, Jussif J, et al. PD-1:PD-L inhibitory pathway affects both CD4+ and CD8+ T cells and is overcome by IL-2. Eur J Immunol 2002;32:634-43. DOI PubMed

106. Nurieva R, Thomas S, Nguyen T, et al. T-cell tolerance or function is determined by combinatorial costimulatory signals. $E M B O J$ 2006;25:2623-33. DOI PubMed PMC

107. Freeman GJ, Long AJ, Iwai Y, et al. Engagement of the Pd-1 immunoinhibitory receptor by a novel B7 family member leads to negative regulation of lymphocyte activation. J Exp Med 2000;192:1027-34. DOI PubMed PMC

108. Lee JY, Lee HT, Shin W, et al. Structural basis of checkpoint blockade by monoclonal antibodies in cancer immunotherapy. Nat Commun 2016;7:13354. DOI PubMed PMC

109. Callahan MK, Postow MA, Wolchok JD. Targeting T cell co-receptors for cancer therapy. Immunity 2016;44:1069-78. DOI PubMed

110. Highlights of prescribing information. Available from : https://www.accessdata.fda.gov/drugsatfda_docs/label/2020/125554s078lbl.pdf [Last accessed on 6 Aug 2021].

111. Khoury K, Isaacs C, Gatti-Mays ME, et al. Nivolumab or capecitabine or combination therapy as adjuvant therapy for triple negative breast cancer (TNBC) with residual disease following neoadjuvant chemotherapy: the OXEL study. Cancer Res 2019;79(4 Supplement):abstract OT3-04. DOI

112. Masuda N, Lee SJ, Ohtani S, et al. Adjuvant capecitabine for breast cancer after preoperative chemotherapy. $N$ Engl $J$ Med 


\section{7;376:2147-59. DOI PubMed}

113. Clinical Trial. Pre-operative phase II trial for breast cancer with nivolumab in combination with novel IO (BELLINI Trial). Available from: https://clinicaltrials.gov/ct2/show/NCT03815890 [Last accessed on 6 Aug 2021].

114. Waterhouse D, Gutierrez M, Bekaii-Saab T, et al. Nab-paclitaxel (nab-P) plus nivolumab (Nivo) in human epidermal growth factor receptor 2 (HER2)-negative recurrent metastatic breast cancer (MBC). Cancer Res 2016;76(4 Supplement):abstract OT1-01. DOI

115. Garrido-Castro AC, Barry WT, Traina TA, et al. A randomized phase II trial of carboplatin with or without nivolumab in first- or second-line metastatic TNBC. J Clin Oncol 2018;36:TPS1118. DOI

116. Ozaki Y, Mukohara T, Tsurutani J, et al. A multicenter phase II study evaluating the efficacy of nivolumab plus paclitaxel plus bevacizumab triple-combination therapy as a first-line treatment in patients with HER2-negative metastatic breast cancer: WJOG9917B NEWBEAT trial. Cancer Res 2020;80(4 Suppl):abstract PD1-03. DOI

117. Ozaki Y, Kitano S, Matsumoto K, et al. Biomarker study of patients with HER2-negative metastatic breast cancer receiving combination therapy with nivolumab, bevacizumab and paclitaxel as first-line treatment (WJOG9917BTR). Cancer Res 2019;79(4 Supplement):abstract OT1-12. DOI

118. Kok M, Voorwerk L, Horlings H, et al. Adaptive phase II randomized trial of nivolumab after induction treatment in triple negative breast cancer (TONIC trial): final response data stage I and first translational data. J Clin Oncol 2018;36:1012. DOI

119. Voorwerk L, Slagter M, Horlings HM, et al. Immune induction strategies in metastatic triple-negative breast cancer to enhance the sensitivity to PD-1 blockade: the TONIC trial. Nat Med 2019;25:920-8. DOI PubMed

120. Demaria S, Ng B, Devitt ML, et al. Ionizing radiation inhibition of distant untreated tumors (abscopal effect) is immune mediated. Int J Radiat Oncol Biol Phys 2004;58:862-70. DOI PubMed

121. Biasi AR, Villena-Vargas J, Adusumilli PS. Cisplatin-induced antitumor immunomodulation: a review of preclinical and clinical evidence. Clin Cancer Res 2014;20:5384-91. DOI PubMed PMC

122. Scurr M, Pembroke T, Bloom A, et al. Low-dose cyclophosphamide induces antitumor T-cell responses, which associate with survival in metastatic colorectal cancer. Clin Cancer Res 2017;23:6771-80. DOI PubMed PMC

123. Seymour L, Bogaerts J, Perrone A, et al. iRECIST: guidelines for response criteria for use in trials testing immunotherapeutics. Lancet Oncol 2017;18:e143-52. DOI PubMed PMC

124. Hutloff A, Dittrich AM, Beier KC, et al. ICOS is an inducible T-cell co-stimulator structurally and functionally related to CD28. Nature 1999;397:263-6. DOI PubMed

125. Yoshinaga SK, Whoriskey JS, Khare SD, et al. T-cell co-stimulation through B7RP-1 and ICOS. Nature 1999;402:827-32. DOI PubMed

126. Dong C, Juedes AE, Temann UA, et al. ICOS co-stimulatory receptor is essential for T-cell activation and function. Nature 2001;409:97-101. DOI PubMed

127. Rudd CE, Schneider H. Unifying concepts in CD28, ICOS and CTLA4 co-receptor signalling. Nat Rev Immunol 2003;3:544-56. DOI PubMed

128. Wei SC, Levine JH, Cogdill AP, et al. Distinct cellular mechanisms underlie anti-CTLA-4 and anti-PD-1 checkpoint blockade. Cell 2017;170:1120-33.e17. DOI PubMed PMC

129. Amatore F, Gorvel L, Olive D. Inducible co-stimulator (ICOS) as a potential therapeutic target for anti-cancer therapy. Expert Opin Ther Targets 2018;22:343-51. DOI PubMed

130. Fu T, He Q, Sharma P. The ICOS/ICOSL pathway is required for optimal antitumor responses mediated by anti-CTLA-4 therapy. Cancer Res 2011;71:5445-54. DOI PubMed

131. Fan X, Quezada SA, Sepulveda MA, Sharma P, Allison JP. Engagement of the ICOS pathway markedly enhances efficacy of CTLA4 blockade in cancer immunotherapy. J Exp Med 2014;211:715-25. DOI PubMed PMC

132. Clinical Trial. Phase 1/2 multicenter trial of ICOS agonist monoclonal antibody (mAb) JTX-2011 alone and in combination with nivolumab, ipilimumab, or pembrolizumab in adult subjects with advanced and/or refractory solid tumor malignancies. Available from: https://clinicaltrials.gov/ct2/show/NCT02904226 [Last accessed on 6 Aug 2021].

133. Yap TA, Burris HA, Kummar S, et al. ICONIC: biologic and clinical activity of first in class ICOS agonist antibody JTX-2011 +/nivolumab (nivo) in patients (pts) with advanced cancers. J Clin Oncol 2018;36:3000. DOI

134. Barroso-sousa R, Guo H, Barry WT, et al. A phase II study of nivolumab in combination with cabozantinib for metastatic triplenegative breast cancer (mTNBC). JCO 2018;36:TPS1119. DOI

135. Yakes FM, Chen J, Tan J, et al. Cabozantinib (XL184), a novel MET and VEGFR2 inhibitor, simultaneously suppresses metastasis, angiogenesis, and tumor growth. Mol Cancer Ther 2011;10:2298-308. DOI PubMed

136. Grüllich C. Cabozantinib: multi-kinase inhibitor of MET, AXL, RET, and VEGFR2. Recent Results Cancer Res 2018;211:67-75. DOI PubMed

137. Markowitz JN, Fancher KM. Cabozantinib: a multitargeted oral tyrosine kinase inhibitor. Pharmacotherapy 2018;38:357-69. DOI PubMed

138. Desai A, Small EJ. Treatment of advanced renal cell carcinoma patients with cabozantinib, an oral multityrosine kinase inhibitor of MET, AXL and VEGF receptors. Future Oncol 2019;15:2337-48. DOI PubMed

139. Fogli S, Porta C, Del Re M, et al. Optimizing treatment of renal cell carcinoma with VEGFR-TKIs: a comparison of clinical pharmacology and drug-drug interactions of anti-angiogenic drugs. Cancer Treat Rev 2020;84:101966. DOI PubMed

140. Liao W, Lin JX, Leonard WJ. IL-2 family cytokines: new insights into the complex roles of IL-2 as a broad regulator of T helper cell differentiation. Curr Opin Immunol 2011;23:598-604. DOI PubMed PMC

141. Boyman O, Sprent J. The role of interleukin-2 during homeostasis and activation of the immune system. Nat Rev Immunol 
2012;12:180-90. DOI PubMed

142. Atkins MB, Lotze MT, Dutcher JP, et al. High-dose recombinant interleukin 2 therapy for patients with metastatic melanoma: analysis of 270 patients treated between 1985 and 1993. J Clin Oncol 1999;17:2105-16. DOI PubMed

143. Rosenberg SA, Yang JC, Topalian SL, et al. Treatment of 283 consecutive patients with metastatic melanoma or renal cell cancer using high-dose bolus interleukin 2. JAMA 1994;271:907-13. PubMed

144. McDermott DF, Regan MM, Clark JI, et al. Randomized phase III trial of high-dose interleukin-2 versus subcutaneous interleukin-2 and interferon in patients with metastatic renal cell carcinoma. J Clin Oncol 2005;23:133-41. DOI PubMed

145. Payne R, Glenn L, Hoen H, et al. Durable responses and reversible toxicity of high-dose interleukin-2 treatment of melanoma and renal cancer in a community hospital biotherapy program. J Immunother Cancer 2014;2:13. DOI PubMed PMC

146. Charych D, Khalili S, Dixit V, et al. Modeling the receptor pharmacology, pharmacokinetics, and pharmacodynamics of NKTR-214, a kinetically-controlled interleukin-2 (IL2) receptor agonist for cancer immunotherapy. PLoS One 2017;12:e0179431. DOI PubMed PMC

147. NEKTAR. Bempegaldesleukin (NKTR-214). Available from: https://www.nektar.com/pipeline/rd-pipeline/nktr-214 [Last accessed on 6 Aug 2021].

148. Tolaney S, Baldini C, Spira A, et al. Clinical activity of BEMPEG plus NIVO observed in metastatic TNBC: preliminary results from the TNBC cohort of the Ph1/2 PIVOT-02 study. CRI-CIMT-EATI-AACR, 5th International Cancer Immunotherapy Conference. Paris: Abstracts Book; 2019. p. 2.

149. Mosser DM, Zhang X. Interleukin-10: new perspectives on an old cytokine. Immunol Rev 2008;226:205-18. DOI PubMed PMC

150. Saraiva M, O'Garra A. The regulation of IL-10 production by immune cells. Nat Rev Immunol 2010;10:170-81. DOI PubMed

151. Bedke T, Muscate F, Soukou S, Gagliani N, Huber S. Title: IL-10-producing T cells and their dual functions. Semin Immunol 2019;44:101335. DOI PubMed

152. Zheng LM, Ojcius DM, Garaud F, et al. Interleukin-10 inhibits tumor metastasis through an NK cell-dependent mechanism. $J$ Exp Med 1996;184:579-84. DOI PubMed PMC

153. Groux H, Cottrez F, Rouleau M, Mauze S, Antonenko S, et al. A transgenic model to analyze the immunoregulatory role of IL-10 secreted by antigen-presenting cells. J Immunol 1999;162:1723-9. PubMed

154. Fujii S, Shimizu K, Shimizu T, Lotze MT. Interleukin-10 promotes the maintenance of antitumor CD8(+) T-cell effector function in situ. Blood 2001;98:2143-51. DOI PubMed

155. Emmerich J, Mumm JB, Chan IH, et al. IL-10 directly activates and expands tumor-resident CD8(+) T cells without de novo infiltration from secondary lymphoid organs. Cancer Res 2012;72:3570-81. DOI PubMed

156. Asadullah K, Sterry W, Stephanek K, et al. IL-10 is a key cytokine in psoriasis. Proof of principle by IL-10 therapy: a new therapeutic approach. J Clin Invest 1998;101:783-94. DOI PubMed PMC

157. Duncan SA, Dixit S, Sahu R, et al. Prolonged release and functionality of interleukin-10 encapsulated within PLA-PEG nanoparticles. Nanomaterials (Basel) 2019;9:1074. DOI PubMed PMC

158. Naing A, Papadopoulos KP, Autio KA, et al. Safety, Antitumor activity, and immune activation of pegylated recombinant human interleukin-10 (AM0010) in patients with advanced solid tumors. J Clin Oncol 2016;34:3562-9. DOI PubMed PMC

159. Naing A, Infante JR, Papadopoulos KP, et al. PEGylated IL-10 (Pegilodecakin) induces systemic immune activation, CD $8^{+}$T cell invigoration and polyclonal T cell expansion in cancer patients. Cancer Cell 2018;34:775-791.e3. DOI PubMed PMC

160. Naing A, Wong DJ, Infante JR, et al. Pegilodecakin combined with pembrolizumab or nivolumab for patients with advanced solid tumours (IVY): a multicentre, multicohort, open-label, phase 1b trial. Lancet Oncol 2019;20:1. DOI PubMed

161. Sharma P, Allison JP. The future of immune checkpoint therapy. Science 2015;348(6230):56-61. DOI PubMed

162. Lee HT, Lee SH, Heo YS. Molecular interactions of antibody drugs targeting PD-1, PD-L1, and CTLA-4 in immuno-oncology. Molecules 2019;24:1190. DOI PubMed PMC

163. Highlights of prescribing information. Available from : https://www.accessdata.fda.gov/drugsatfda_docs/label/2019/125514s0401bl.pdf [Last accessed on 6 Aug 2021].

164. European Medicines Agency. Keytruda. Available from: https://www.ema.europa.eu/en/medicines/human/EPAR/keytruda [Last accessed on 6 Aug 2021].

165. Schmid P, Salgado R, Park YH, et al. Pembrolizumab plus chemotherapy as neoadjuvant treatment of high-risk, early-stage triplenegative breast cancer: results from the phase $1 \mathrm{~b}$ open-label, multicohort KEYNOTE-173 study. Ann Oncol 2020;31:569-81. DOI PubMed

166. von Minckwitz G, Schneeweiss A, Loibl S, et al. Neoadjuvant carboplatin in patients with triple-negative and HER2-positive early breast cancer (GeparSixto; GBG 66): a randomised phase 2 trial. Lancet Oncol 2014;15:747-56. DOI PubMed

167. Sikov WM, Berry DA, Perou CM, et al. Impact of the addition of carboplatin and/or bevacizumab to neoadjuvant once-per-week paclitaxel followed by dose-dense doxorubicin and cyclophosphamide on pathologic complete response rates in stage II to III triplenegative breast cancer: CALGB 40603 (Alliance). J Clin Oncol 2015;33:13-21. DOI PubMed PMC

168. Cortazar P, Zhang L, Untch M, et al. Pathological complete response and long-term clinical benefit in breast cancer: the CTNeoBC pooled analysis. Lancet 2014;384:164-72. DOI PubMed

169. Nanda R, Liu MC, Yau C, et al. Effect of pembrolizumab plus neoadjuvant chemotherapy on pathologic complete response in women with early-stage breast cancer: an analysis of the ongoing phase 2 adaptively randomized I-SPY2 trial. JAMA Oncol 2020;6:676-84. DOI PubMed PMC

170. Schmid P, Cortes J, Pusztai L, et al; KEYNOTE-522 Investigators. Pembrolizumab for early triple-negative breast cancer. $N$ Engl $J$ Med 2020;382:810-21. DOI PubMed 
171. Clinical Trial. Neoadjuvant phase II study of pembrolizumab and carboplatin plus docetaxel in triple negative breast cancer. Available from: https://clinicaltrials.gov/ct2/show/NCT03639948 [Last accessed on 6 Aug 2021].

172. Adams S, Schmid P, Rugo HS, et al. Pembrolizumab monotherapy for previously treated metastatic triple-negative breast cancer: cohort A of the phase II KEYNOTE-086 study. Ann Oncol 2019;30:397-404. DOI PubMed

173. Adams S, Loi S, Toppmeyer D, et al. Pembrolizumab monotherapy for previously untreated, PD-L1-positive, metastatic triplenegative breast cancer: cohort B of the phase II KEYNOTE-086 study. Ann Oncol 2019;30:405-11. DOI PubMed

174. Cortés J, Lipatov O, Im S, et al. KEYNOTE-119: Phase III study of pembrolizumab (pembro) versus single-agent chemotherapy (chemo) for metastatic triple negative breast cancer (mTNBC). Ann Oncol 2019;30:v859-60. DOI

175. Apetoh L, Ghiringhelli F, Tesniere A, et al. Toll-like receptor 4-dependent contribution of the immune system to anticancer chemotherapy and radiotherapy. Nat Med 2007;13:1050-9. DOI PubMed

176. Surace L, Scheifinger NA, Gupta A, van den Broek M. Radiotherapy supports tumor-specific immunity by acute inflammation. Oncoimmunology 2016;5:e1060391. DOI PubMed PMC

177. Ho AY, Barker CA, Arnold BB, et al. A phase 2 clinical trial assessing the efficacy and safety of pembrolizumab and radiotherapy in patients with metastatic triple-negative breast cancer. Cancer 2020;126:850-60. DOI PubMed

178. Vanpouille-Box C, Alard A, Aryankalayil MJ, et al. DNA exonuclease Trex1 regulates radiotherapy-induced tumour immunogenicity. Nat Commun 2017;8:15618. DOI PubMed PMC

179. Weiss GJ, Waypa J, Blaydorn L, et al. A phase Ib study of pembrolizumab plus chemotherapy in patients with advanced cancer (PembroPlus). Br J Cancer 2017;117:33-40. DOI PubMed PMC

180. Kwa MJ, Iwano A, Esteva FJ, et al. Phase II trial of pembrolizumab in combination with nab-paclitaxel in patients with metastatic HER2-negative breast cancer. JCO 2017;35:TPS1124. DOI

181. Vincent BG, Moore DT, Moore SG, et al. LCCC 1525: Combination immunotherapy with cyclophosphamide plus pembrolizumab in patients with advanced triple negative breast cancer (TNBC). JCO 2017;35:TPS1125. DOI

182. Ge Y, Domschke C, Stoiber N, et al. Metronomic cyclophosphamide treatment in metastasized breast cancer patients: immunological effects and clinical outcome. Cancer Immunol Immunother 2012;61:353-62. DOI PubMed

183. Madondo MT, Quinn M, Plebanski M. Low dose cyclophosphamide: Mechanisms of T cell modulation. Cancer Treat Rev 2016;42:39. DOI PubMed

184. Togashi Y, Shitara K, Nishikawa H. Regulatory T cells in cancer immunosuppression - implications for anticancer therapy. Nat Rev Clin Oncol 2019;16:356-71. DOI PubMed

185. Hughes E, Scurr M, Campbell E, Jones E, Godkin A, Gallimore A. T-cell modulation by cyclophosphamide for tumour therapy. Immunology 2018;154:62-8. DOI PubMed PMC

186. Engel JB, Honig A, Kapp M, et al. Mechanisms of tumor immune escape in triple-negative breast cancers (TNBC) with and without mutated BRCA 1. Arch Gynecol Obstet 2014;289:141-7. DOI PubMed

187. Taylor NA, Vick SC, Iglesia MD, et al. Treg depletion potentiates checkpoint inhibition in claudin-low breast cancer. J Clin Invest 2017;127:3472-83. DOI PubMed PMC

188. Gandhi L, Rodríguez-Abreu D, Gadgeel S, et al; KEYNOTE-189 Investigators. Pembrolizumab plus chemotherapy in metastatic nonsmall-cell lung cancer. N Engl J Med 2018;378:2078-92. DOI PubMed

189. Paz-Ares L, Luft A, Vicente D, et al; KEYNOTE-407 Investigators. Pembrolizumab plus chemotherapy for squamous non-small-cell lung cancer. $N$ Engl J Med 2018;379:2040-51. DOI PubMed

190. Socinski MA, Jotte RM, Cappuzzo F, et al; IMpower150 Study Group. Atezolizumab for first-line treatment of metastatic nonsquamous NSCLC. N Engl J Med 2018;378:2288-301. DOI PubMed

191. West H, Mccleod M, Hussein M, et al. Atezolizumab in combination with carboplatin plus nab-paclitaxel chemotherapy compared with chemotherapy alone as first-line treatment for metastatic non-squamous non-small-cell lung cancer (IMpower130): a multicentre, randomised, open-label, phase 3 trial. Lancet Oncol 2019;20:924-37. DOI PubMed

192. Jotte R, Cappuzzo F, Vynnychenko I, et al. Atezolizumab in combination with carboplatin and nab-paclitaxel in advanced squamous NSCLC (IMpower131): results from a randomized phase III trial. J Thorac Oncol 2020;15:1351-60. DOI PubMed

193. Vidula N, Goga A, Hwang J, et al. A randomized phase II study of pembrolizumab, an anti-PD (programmed cell death) 1 antibody, in combination with carboplatin compared to carboplatin alone in breast cancer patients with chest wall disease, with immunologic and genomic correlative studies. J Clin Oncol 2018;36:TPS1113. DOI

194. Page DB, Chun B, Pucilowska J, et al. Pembrolizumab (pembro) with paclitaxel (taxol) or capecitabine (cape) as early treatment of metastatic triple-negative breast cancer (mTNBC). J Clin Oncol 2019;37:1015. DOI

195. Shah AN, Flaum L, Helenowski I, et al. Phase II study of pembrolizumab and capecitabine for triple negative and hormone receptorpositive, HER2-negative endocrine-refractory metastatic breast cancer. J Immunother Cancer 2020;8:e00173. DOI PubMed PMC

196. Fostira F, Papadimitriou M, Papadimitriou C. Current practices on genetic testing in ovarian cancer. Ann Transl Med 2020;8:1703. DOI PubMed PMC

197. U.S. Food \& Drug. Available from: www.fda.gov/Drugs/InformationOnDrugs/ApprovedDrugs/ucm592357 [Last accessed on 6 Aug 2021].

198. U.S. Food \& Drug. FDA approves talazoparib for gBRCAm HER2-negative locally advanced or metastatic breast cancer. Available from: https://www.fda.gov/drugs/drug-approvals-and-databases/fda-approves-talazoparib-gbrcam-her2-negative-locally-advanced-ormetastatic-breast-cancer [Last accessed on 6 Aug 2021].

199. Vinayak S, Tolaney SM, Schwartzberg L, et al. Open-label clinical trial of niraparib combined with pembrolizumab for treatment of advanced or metastatic triple-negative breast cancer. JAMA Oncol 2019;5:1132-40. DOI PubMed PMC 
200. Varnum BC, Young C, Elliott G, et al. Axl receptor tyrosine kinase stimulated by the vitamin K-dependent protein encoded by growth-arrest-specific gene 6. Nature 1995;373:623-6. DOI PubMed

201. Shieh YS, Lai CY, Kao YR, et al. Expression of axl in lung adenocarcinoma and correlation with tumor progression. Neoplasia 2005; 7:1058-64. DOI PubMed PMC

202. Gay CM, Balaji K, Byers LA. Giving AXL the axe: targeting AXL in human malignancy. Br J Cancer 2017;116:415-23. DOI PubMed PMC

203. Zhu C, Wei Y, Wei X. AXL receptor tyrosine kinase as a promising anti-cancer approach: functions, molecular mechanisms and clinical applications. Mol Cancer 2019;18:153. DOI PubMed PMC

204. Wiseman CL, Kharazi A. Phase I study with SV-BR-1 breast cancer cell line vaccine and GMCSF: clinical experience in 14 patients. TOBCANJ 2010;2:4-11. DOI

205. National Cancer Institute. AXL inhibitor BGB324. Available from: https://www.cancer.gov/publications/dictionaries/cancerdrug/def/bemcentinib [Last accessed on 6 Aug 2021].

206. Wnuk-Lipinska K, Davidsen K, Blø M, et al. BGB324, a selective small molecule inhibitor of receptor tyrosine kinase AXL, abrogates tumor intrinsic and microenvironmental immune suppression and enhances immune checkpoint inhibitor efficacy in lung and mammary adenocarcinoma models. Cancer Res 2017;77(13 Suppl):abstract nr 626. DOI

207. Yule M, Wnuk-Lipinska K, Davidsen K, et al. A phase II multi-center study of BGB324 in combination with pembrolizumab in patients with previously treated, locally advanced and unresectable or metastatic triple negative breast cancer (TNBC) or triple negative inflammatory breast cancer (TN-IBC). Cancer Res 2018;78(4 Suppl):abstract OT1-01.

208. Li B, Allendorf DJ, Hansen R, et al. Yeast beta-glucan amplifies phagocyte killing of iC3b-opsonized tumor cells via complement receptor 3-Syk-phosphatidylinositol 3-kinase pathway. J Immunol 2006;177:1661-9. DOI PubMed

209. Liu J, Gunn L, Hansen R, Yan J. Combined yeast-derived beta-glucan with anti-tumor monoclonal antibody for cancer immunotherapy. Exp Mol Pathol 2009;86:208-14. DOI PubMed PMC

210. Bose N, Chan AS, Guerrero F, et al. Binding of soluble yeast $\beta$-glucan to human neutrophils and monocytes is complementdependent. Front Immunol 2013;4:230. DOI PubMed PMC

211. O'day S, Borges VF, Chmielowski B, et al. An open label, multicenter phase II study combining imprime PGG (PGG) with pembrolizumab (P) in previously treated metastatic triple-negative breast cancer (mTNBC). JCO 2019;37:2550-2550. DOI

212. Abdou Y, Williams LE, Kalinski P, Opyrchal M. Chemokine modulation to enhance the effectiveness of pembrolizumab in patients with metastatic triple negative breast cancer. Cancer Res 2019;79(4 Suppl):abstract OT2-06. DOI

213. Theodoraki MN, Yerneni S, Sarkar SN, et al. Helicase-driven activation of NFkB-COX2 pathway mediates the immunosuppressive component of dsRNA-driven inflammation in the human tumor microenvironment. Cancer Res 2018;78:4292-302. DOI PubMed PMC

214. Mitchell WM. Efficacy of rintatolimod in the treatment of chronic fatigue syndrome/myalgic encephalomyelitis (CFS/ME). Expert Rev Clin Pharmacol 2016;9:755-70. DOI PubMed PMC

215. Taylor KM, Morgan HE, Johnson A, Hadley LJ, Nicholson RI. Structure-function analysis of LIV-1, the breast cancer-associated protein that belongs to a new subfamily of zinc transporters. Biochem J 2003;375:51-9. DOI PubMed PMC

216. Taylor KM, Hiscox S, Nicholson RI. Zinc transporter LIV-1: a link between cellular development and cancer progression. Trends Endocrinol Metab 2004;15:461-3. DOI PubMed

217. Sussman D, Smith LM, Anderson ME, et al. SGN-LIV1A: a novel antibody-drug conjugate targeting LIV-1 for the treatment of metastatic breast cancer. Mol Cancer Ther 2014;13:2991-3000. DOI PubMed

218. Cao AT, Higgins S, Stevens N, Gardai SJ, Sussman D. Additional mechanisms of action of ladiratuzumab vedotin contribute to increased immune cell activation within the tumor. Cancer Res 2018;78(13 Suppl):abstract nr 2742. DOI

219. Nagayama A, Vidula N, Ellisen L, Bardia A. Novel antibody-drug conjugates for triple negative breast cancer. Ther Adv Med Oncol 2020;12:1758835920915980. DOI PubMed PMC

220. Han HS, Alemany CA, Brown-glaberman UA, et al. SGNLVA-002: Single-arm, open label phase Ib/II study of ladiratuzumab vedotin $(\mathrm{LV})$ in combination with pembrolizumab for first-line treatment of patients with unresectable locally advanced or metastatic triple-negative breast cancer. JCO 2019;37:TPS1110. DOI PubMed

221. Lacher MD, Bauer G, Fury B, et al. SV-BR-1-GM, a Clinically effective GM-CSF-secreting breast cancer cell line, expresses an immune signature and directly activates CD4 ${ }^{+}$T Lymphocytes. Front Immunol 2018;9:776. DOI PubMed PMC

222. National Cancer Institute. Allogeneic GM-CSF-secreting breast cancer vaccine SV-BR-1-GM. Available from: https://www.cancer.gov/publications/dictionaries/cancer-drug/def/allogeneic-gm-csf-secreting-breast-cancer-vaccine-sv-br-1-gm [Last accessed on 6 Aug 2021].

223. Williams W, Dakhil SR, Holmes JP, Bhattacharya S, Calfa C, et al. Efficacy and safety of a modified whole tumor cell targeted immunotherapy in patients with advanced breast cancer alone and in combination with immune checkpoint inhibitors. Cancer Res 2020;80:(4 Supplement):abstract P3-09-08. DOI

224. National Cancer Institute. Spartalizumab. Available from: https://www.cancer.gov/publications/dictionaries/cancerdrug/def/spartalizumab [Last accessed on 6 Aug 2021].

225. Naing A, Gainor JF, Gelderblom H, et al. A first-in-human phase 1 dose escalation study of spartalizumab (PDR001), an anti-PD-1 antibody, in patients with advanced solid tumors. J Immunother Cancer 2020;8:e00530. DOI PubMed PMC

226. Minami H, Doi T, Toyoda M, et al. Phase I study of the antiprogrammed cell death-1 Ab spartalizumab (PDR001) in Japanese patients with advanced malignancies. Cancer Sci 2021;112:725-33. DOI PubMed PMC

227. Hong DS, Schoffski P, Calvo A, et al. Phase I/II study of LAG525 \pm spartalizumab (PDR001) in patients (pts) with advanced 
malignancies. JCO 2018;36:3012-3012. DOI

228. NCBI. Available from: https://www.ncbi.nlm.nih.gov/medgen/891402 [Last accessed on 6 Aug 2021].

229. Baumeister SH, Freeman GJ, Dranoff G, Sharpe AH. Coinhibitory Pathways in Immunotherapy for Cancer. Annu Rev Immunol 2016;34:539-73. DOI PubMed

230. Andrews LP, Marciscano AE, Drake CG, Vignali DA. LAG3 (CD223) as a cancer immunotherapy target. Immunol Rev 2017;276:8096. DOI PubMed PMC

231. Workman CJ, Vignali DA. The CD4-related molecule, LAG-3 (CD223), regulates the expansion of activated T cells. Eur J Immunol 2003;33:970-9. DOI PubMed

232. Workman CJ, Cauley LS, Kim IJ, Blackman MA, Woodland DL, Vignali DA. Lymphocyte activation gene-3 (CD223) regulates the size of the expanding T cell population following antigen activation in vivo. J Immunol 2004;172:5450-5. DOI PubMed

233. Calvo A, Joensuu H, Sebastian M, et al. Phase Ib/II study of lacnotuzumab (MCS110) combined with spartalizumab (PDR001) in patients (pts) with advanced tumors. JCO 2018;36:3014-3014. DOI

234. National Cancer Institute. Lacnotuzumab (Code C80044). Available from: https://ncit.nci.nih.gov/ncitbrowser/ConceptReport.jsp?dictionary=NCI\%20Thesaurus\&code=C80044 [Last accessed on 6 Aug 2021].

235. Kumar S, Ramesh A, Kulkarni A. Targeting macrophages: a novel avenue for cancer drug discovery. Expert Opin Drug Discov 2020;15:561-74. DOI PubMed

236. Pognan F, Couttet P, Demin I, et al. Colony-stimulating factor-1 antibody lacnotuzumab in a phase 1 healthy volunteer study and mechanistic investigation of safety outcomes. J Pharmacol Exp Ther 2019;369:428-42. DOI PubMed

237. Achkova D, Maher J. Role of the colony-stimulating factor (CSF)/CSF-1 receptor axis in cancer. Biochem Soc Trans 2016;44:333-41. DOI PubMed

238. Qiu SQ, Waaijer SJH, Zwager MC, de Vries EGE, van der Vegt B, Schröder CP. Tumor-associated macrophages in breast cancer: Innocent bystander or important player? Cancer Treat Rev 2018;70:178-89. DOI PubMed

239. United States securities and exchange commission. Available from: https://sec.report/Document/0001193125-19-003027 [Last accessed on 6 Aug 2021].

240. Barber GN. STING: infection, inflammation and cancer. Nat Rev Immunol 2015;15:760-70. DOI PubMed PMC

241. Corrales L, Glickman LH, McWhirter SM, et al. Direct activation of STING in the tumor microenvironment leads to potent and systemic tumor regression and immunity. Cell Rep 2015;11:1018-30. DOI PubMed PMC

242. Meric-bernstam F, Sandhu SK, Hamid O, et al. Phase Ib study of MIW815 (ADU-S100) in combination with spartalizumab (PDR001) in patients (pts) with advanced/metastatic solid tumors or lymphomas. J Clin Oncol 2019;37:2507. DOI

243. National Cancer Institute. avelumab. Available from: https://www.cancer.gov/publications/dictionaries/cancer-drug/def/avelumab [Last accessed on 6 Aug 2021].

244. Liu K, Tan S, Chai Y, et al. Structural basis of anti-PD-L1 monoclonal antibody avelumab for tumor therapy. Cell Res 2017;27:1513. DOI PubMed PMC

245. Picardo SL, Doi J, Hansen AR. Structure and optimization of checkpoint inhibitors. Cancers (Basel) 2019;12:38. DOI PubMed $\mathrm{PMC}$

246. Juliá EP, Amante A, Pampena MB, Mordoh J, Levy EM. Avelumab, an IgG1 anti-PD-L1 immune checkpoint inhibitor, triggers NK cell-mediated cytotoxicity and cytokine production against triple negative breast cancer cells. Front Immunol 2018;9:2140. DOI PubMed PMC

247. U.S. Food and Drug. FDA approves first treatment for rare form of skin cancer. Available from: https://www.fda.gov/newsevents/press-announcements/fda-approves-first-treatment-rare-form-skin-cancer [Last accessed on 6 Aug 2021].

248. U.S. Food and Drug. FDA grants accelerated approval to avelumab for urothelial carcinoma. Available from: https://www.fda.gov/drugs/resources-information-approved-drugs/fda-grants-accelerated-approval-avelumab-urothelial-carcinoma [Last accessed on 6 Aug 2021].

249. U.S. Food and Drug. FDA approves avelumab plus axitinib for renal cell carcinoma. Available from: https://www.fda.gov/drugs/resources-information-approved-drugs/fda-approves-avelumab-plus-axitinib-renal-cell-carcinoma [Last accessed on 6 Aug 2021].

250. U.S. Food and Drug. FDA approves avelumab for urothelial carcinoma maintenance treatment. Available from: https://www.fda.gov/drugs/drug-approvals-and-databases/fda-approves-avelumab-urothelial-carcinoma-maintenance-treatment [Last accessed on 6 Aug 2021].

251. Bavencio, INN-avelumab. Available from: https://www.ema.europa.eu/en/documents/product-information/bavencio-epar-productinformation_en.pdf [Last accessed on 6 Aug 2021].

252. Clinical Trial. A proof of concept window trial of the immunological effects of avelumab and aspirin in triple-negative breast cancer. Available from: https://clinicaltrials.gov/ct2/show/NCT04188119 [Last accessed on 6 Aug 2021].

253. Karavitis J, Hix LM, Shi YH, Schultz RF, Khazaie K, Zhang M. Regulation of COX2 expression in mouse mammary tumor cells controls bone metastasis and PGE2-induction of regulatory T cell migration. PLoS One 2012;7:e46342. DOI PubMed PMC

254. Wong JL, Obermajer N, Odunsi K, Edwards RP, Kalinski P. Synergistic COX2 Induction by IFN $\gamma$ and TNF $\alpha$ self-limits type-1 immunity in the human tumor microenvironment. Cancer Immunol Res 2016;4:303-11. DOI PubMed PMC

255. Miao J, Lu X, Hu Y, et al. Prostaglandin $\mathrm{E}_{2}$ and PD-1 mediated inhibition of antitumor CTL responses in the human tumor microenvironment. Oncotarget 2017;8:89802-10. DOI PubMed PMC

256. Conte PF, Dieci MV, Bisagni G, et al. Phase III randomized study of adjuvant treatment with the ANTI-PD-L1 antibody avelumab 
for high-risk triple negative breast cancer patients: the A-BRAVE trial. JCO 2020;38:TPS598-TPS598. DOI

257. Yap TA, Konstantinopoulos P, Telli ML, et al. JAVELIN PARP medley, a phase 1b/2 study of avelumab plus talazoparib: results from advanced breast cancer cohorts. Cancer Res 2020;80(4 Suppl):abstract nr P1-19. DOI

258. Mavratzas A, Seitz J, Smetanay K, Schneeweiss A, Jäger D, Fremd C. Atezolizumab for use in PD-L1-positive unresectable, locally advanced or metastatic triple-negative breast cancer. Future Oncol 2020;16:4439-53. DOI PubMed

259. Herbst RS, Soria JC, Kowanetz M, et al. Predictive correlates of response to the anti-PD-L1 antibody MPDL3280A in cancer patients. Nature 2014;515:563-7. DOI PubMed PMC

260. Matsumoto K, Fukuyama S, Eguchi-Tsuda M, et al. B7-DC induced by IL-13 works as a feedback regulator in the effector phase of allergic asthma. Biochem Biophys Res Commun 2008;365:170-5. DOI PubMed

261. Geyer CE, Loibl S, Rastogi P, et al. NSABP B-59/GBG 96-GeparDouze: a randomized double-blind phase III clinical trial of neoadjuvant chemotherapy (NAC) with atezolizumab or placebo in patients (pts) with triple-negative breast cancer (TNBC) followed by adjuvant atezolizumab or placebo. J Clin Oncol 2018;36:15_suppl. DOI

262. Loibl S, Jackisch C, Rastogi P, et al. GeparDouze/NSABP B-59: A randomized double-blind phase III clinical trial of neoadjuvant chemotherapy with atezolizumab or placebo in patients with triple negative breast cancer (TNBC) followed by adjuvant atezolizumab or placebo. Ann Oncol 2019;30:iii38. DOI

263. Gianni L, Huang C-S, Egle D, et al. GS3-04: pathologic complete response (pCR) to neoadjuvant treatment with or without atezolizumab in triple negative, early high-risk and locally advanced breast cancer. NeoTRIPaPDL1 michelangelo randomized study. Abstract presented at: 2019 San Antonio Breast Cancer Symposium; Dec 10-14, 2019; San Antonio, TX.

264. Mittendorf EA, Zhang H, Barrios CH, et al. Neoadjuvant atezolizumab in combination with sequential nab-paclitaxel and anthracycline-based chemotherapy versus placebo and chemotherapy in patients with early-stage triple-negative breast cancer (IMpassion031): a randomised, double-blind, phase 3 trial. Lancet 2020;396:1090-100. DOI PubMed

265. Clinical Trial. A randomized, double-blind, phase III clinical trial of neoadjuvant chemotherapy with atezolizumab or placebo in patients with triple-negative breast cancer followed by adjuvant continuation of atezolizumab or placebo. Available from: https:/clinicaltrials.gov/ct2/show/NCT03281954 [Last accessed on 6 Aug 2021].

266. Mcarthur HL, Ignatiadis M, Guillaume S, et al. ALEXANDRA/IMpassion030: A phase III study of standard adjuvant chemotherapy with or without atezolizumab in early-stage triple-negative breast cancer. JCO 2019;37:TPS598. DOI PubMed

267. Clinical Trial. A phase I, open-label, dose-escalation study of the safety and pharmacokinetics of atezolizumab (MPDL3280A) administered intravenously as a single agent to patients with locally advanced or metastatic solid tumors or hematologic malignancies. Available from: https://clinicaltrials.gov/ct2/show/NCT01375842 [Last accessed on 6 Aug 2021].

268. Adams S, Diamond JR, Hamilton E, et al. Atezolizumab plus nab-paclitaxel in the treatment of metastatic triple-negative breast cancer with 2-year survival follow-up: a phase 1b clinical trial. JAMA Oncol 2019;5:334-42. DOI PubMed PMC

269. Schmid P, Adams S, Rugo HS, et al; IMpassion130 Trial Investigators. Atezolizumab and nab-paclitaxel in advanced triple-negative breast cancer. N Engl J Med 2018;379:2108-21. DOI PubMed

270. Schmid P, Rugo HS, Adams S, et al. Atezolizumab plus nab-paclitaxel as first-line treatment for unresectable, locally advanced or metastatic triple-negative breast cancer (IMpassion130): updated efficacy results from a randomised, double-blind, placebocontrolled, phase 3 trial. Lancet Oncol 2020;21:44-59. DOI PubMed

271. Iwata H, Inoue K, Kaneko K, et al. Subgroup analysis of Japanese patients in a Phase 3 study of atezolizumab in advanced triplenegative breast cancer (IMpassion130). Jpn J Clin Oncol 2019;49:1083-91. DOI PubMed PMC

272. Adams S, Diéras V, Barrios CH, et al. Patient-reported outcomes from the phase III IMpassion130 trial of atezolizumab plus nabpaclitaxel in metastatic triple-negative breast cancer. Ann Oncol 2020;31:582-9. DOI PubMed

273. Weng X, Huang X, Li H, et al. First-line treatment with atezolizumab plus nab-paclitaxel for advanced triple-negative breast cancer: a cost-effectiveness analysis. Am J Clin Oncol 2020;43:340-8. DOI PubMed

274. Ruiz-borrego M, Martin Jimenez M, Ruiz A, et al. Phase III evaluating the addition of fulvestrant (F) to anastrozol (A) as adjuvant therapy in postmenopausal women with hormone receptor positive HER2 negative (HR+/HER2-) early breast cancer (EBC): results from the GEICAM/2006-10 study. Ann Oncol 2017;28:v43. DOI

275. Businesswire. Genentech provides update on phase III study of tecentriq in combination with paclitaxel for people with metastatic triple-negative breast cancer. Available from: https://www.businesswire.com/news/home/20200806005915/en/Genentech-ProvidesUpdate-on-Phase-III-Study-of-Tecentriq-in-Combination-With-Paclitaxel-for-People-With-Metastatic-Triple-Negative-Breast-Cancer [Last accessed on 6 Aug 2021].

276. Dent R, Andre F, Goncalves A, et al. IMpassion132: a double-blind randomized phase 3 trial evaluating chemotherapy (CT) \pm atezolizumab (atezo) for early progressing locally advanced/metastatic triple-negative breast cancer (mTNBC). J Clin Oncol 2018;36:TPS1115. DOI

277. Ibrahim R, Stewart R, Shalabi A. PD-L1 blockade for cancer treatment: MEDI4736. Semin Oncol 2015;42:474-83. DOI PubMed

278. Stewart R, Morrow M, Hammond SA, et al. Identification and characterization of MEDI4736, an antagonistic anti-PD-L1 monoclonal antibody. Cancer Immunol Res 2015;3:1052-62. DOI PubMed

279. Syed YY. Durvalumab: first global approval. Drugs 2017;77:1369-76. DOI PubMed PMC

280. IMFINZI, INN-durvalumab. Available from: https://www.ema.europa.eu/en/documents/product-information/imfinzi-epar-productinformation_en.pdf [Last accessed on 6 Aug 2021].

281. U.S. Food \& Drug. FDA approves durvalumab for extensive-stage small cell lung cancer. Available from: https://www.fda.gov/drugs/resources-information-approved-drugs/fda-approves-durvalumab-extensive-stage-small-cell-lung-cancer [Last accessed on 6 Aug 2021]. 
282. Pusztai L, Reisenbichler E, Bai Y, et al. Durvalumab (MEDI4736) concurrent with nab-paclitaxel and dose dense doxorubicin cyclophosphamide (ddAC) as neoadjuvant therapy for triple negative breast cancer (TNBC). Cancer Res 2020;80(4 Suppl):abstract nr PD1-01. DOI

283. Loibl S, Untch M, Burchardi N, et al. A randomised phase II study investigating durvalumab in addition to an anthracycline taxanebased neoadjuvant therapy in early triple-negative breast cancer: clinical results and biomarker analysis of GeparNuevo study. Ann Oncol 2019;30:1279-88. DOI PubMed

284. Clinical Trial. A randomized phase II study evaluating pathologic response rates following pre-operative non-anthracycline chemotherapy, durvalumab (MEDI4736) +/- RAdiation therapy (RT) in triple negative breast cancer (TNBC): the PANDoRA Study. Available from: https://clinicaltrials.gov/ct2/show/NCT03872505 [Last accessed on 6 Aug 2021].

285. Clinical Trial. PHOENIX DDR/Anti-PD-L1 trial: a pre-surgical window of opportunity and post-surgical adjuvant biomarker study of DNA damage response inhibition and/or anti-PD-L1 immunotherapy in patients with neoadjuvant chemotherapy resistant residual triple negative breast cancer. Available from: https://clinicaltrials.gov/ct2/show/NCT03740893 [Last accessed on 6 Aug 2021].

286. National Cancer Institute. Ceralasertib. Available from: https://www.cancer.gov/publications/dictionaries/cancerdrug/def/ceralasertib?redirect=true [Last accessed on 6 Aug 2021].

287. Clinical Trial. A phase IB/II study of durvalumab (MEDI4736) combined with dose-dense EC in a neoadjuvant setting for patients with locally advanced luminal B HER2(-) or triple negative breast cancers. Available from: https://clinicaltrials.gov/ct2/show/NCT03356860 [Last accessed on 6 Aug 2021].

288. Clinical Trial. PERSONALIZED MEDICINE GROUP / UCBG UC-0105/1304: SAFIR02 breast - evaluation of the efficacy of high throughput genome analysis as a therapeutic decision tool for patients with metastatic breast cancer. Available from: https://clinicaltrials.gov/ct2/show/NCT02299999 [Last accessed on 6 Aug 2021].

289. Bachelot T, Filleron T, Bieche I, et al. Durvalumab compared to maintenance chemotherapy in metastatic breast cancer: the randomized phase II SAFIR02-BREAST IMMUNO trial. Nat Med 2021;27:250-5. DOI PubMed

290. Durvalumab and paclitaxel combination for treatment of metastatic triple negative breast cancer is safe with very promising efficacy. Available from: https://www.annalsofoncology.org/article/S0923-7534(19)59484-4/pdf [Last accessed on 6 Aug 2021].

291. Zimmer AS, Nichols E, Cimino-Mathews A, et al. A phase I study of the PD-L1 inhibitor, durvalumab, in combination with a PARP inhibitor, olaparib, and a VEGFR1-3 inhibitor, cediranib, in recurrent women's cancers with biomarker analyses. J Immunother Cancer 2019;7:197. DOI PubMed PMC

292. National Cancer Institute. Cediranib maleate. Available from: https://www.cancer.gov/publications/dictionaries/cancerdrug/def/cediranib-maleate [Last accessed on 6 Aug 2021].

293. Bindra RS, Schaffer PJ, Meng A, et al. Down-regulation of Rad51 and decreased homologous recombination in hypoxic cancer cells. Mol Cell Biol 2004;24:8504-18. DOI PubMed PMC

294. Kandalaft LE, Motz GT, Busch J, Coukos G. Angiogenesis and the tumor vasculature as antitumor immune modulators: the role of vascular endothelial growth factor and endothelin. Cancer Immunol Immunother 2011;344:129-48. DOI PubMed

295. Domchek SM, Postel-vinay S, Im S, et al. Olaparib and durvalumab in patients with germline BRCA-mutated metastatic breast cancer (MEDIOLA): an open-label, multicentre, phase 1/2, basket study. Lancet Oncol 2020;21:1155-64. DOI PubMed 